\title{
Chemical segregation in hot cores with disk candidates
}

\section{An investigation with ALMA}

\author{
V. Allen ${ }^{1,2}$, F. F. S. van der Tak ${ }^{1,2}$, Á. Sánchez-Monge ${ }^{3}$, R. Cesaroni ${ }^{4}$, and M. T. Beltrán ${ }^{4}$ \\ 1 Kapteyn Astronomical Institute, University of Groningen, 9712 Groningen, The Netherlands \\ e-mail: allen@astro.rug.nl; vdtak@sron.nl \\ 2 SRON, 9747 Groningen, The Netherlands \\ 3 I. Physikalisches Institut, 50937 Köln, Germany \\ ${ }^{4}$ INAF, Osservatorio Astrofisico di Arcetri, 50125 Firenze, Italy
}

Received 15 June 2016 / Accepted 17 May 2017

\begin{abstract}
Context. In the study of high-mass star formation, hot cores are empirically defined stages where chemically rich emission is detected toward a massive YSO. It is unknown whether the physical origin of this emission is a disk, inner envelope, or outflow cavity wall and whether the hot core stage is common to all massive stars.

Aims. We investigate the chemical makeup of several hot molecular cores to determine physical and chemical structure. We use high spectral and spatial resolution submillimeter observations to determine how this stage fits into the formation sequence of a high-mass star.

Methods. The submillimeter interferometer ALMA (Atacama Large Millimeter Array) was used to observe the G35.20-0.74N and G35.03+0.35 hot cores at $350 \mathrm{GHz}$ in Cycle 0. We analyzed spectra and maps from four continuum peaks (A, B1, B2 and B3) in G35.20-0.74N, separated by 1000-2000 AU, and one continuum peak in G35.03+0.35. We made all possible line identifications across $8 \mathrm{GHz}$ of spectral windows of molecular emission lines down to a $3 \sigma$ line flux of $0.5 \mathrm{~K}$ and determined column densities and temperatures for as many as 35 species assuming local thermodynamic equilibrium (LTE).

Results. In comparing the spectra of the four continuum peaks, we find each has a distinct chemical composition expressed in over 400 different transitions. In G35.20, B1 and B2 contain oxygen- and sulfur-bearing organic and inorganic species but few nitrogenbearing species whereas $\mathrm{A}$ and $\mathrm{B} 3$ are strong sources of $\mathrm{O}-, \mathrm{S}-$, and $\mathrm{N}$-bearing organic and inorganic species (especially those with the $\mathrm{CN}$ bond). Column densities of vibrationally excited states are observed to be equal to or greater than the ground state for a number of species. Deuterated methyl cyanide is clearly detected in A and B3 with D/H ratios of 8 and 13\%, respectively, but is much weaker at B1 and undetected at B2. No deuterated species are detected in G35.03, but similar molecular abundances to G35.20 were found in other species. We also find co-spatial emission of isocyanic acid ( $\mathrm{HNCO})$ and formamide $\left(\mathrm{NH}_{2} \mathrm{CHO}\right)$ in both sources indicating a strong chemical link between the two species.

Conclusions. The chemical segregation between N-bearing organic species and others in G35.20 suggests the presence of multiple protostars surrounded by a disk or torus.
\end{abstract}

Key words. astrochemistry - stars: formation - stars: massive - ISM: individual objects: G35.20-0.74N - submillimeter: stars ISM: individual objects: G35.03+0.35

\section{Introduction}

Studying the formation of high-mass stars $\left(>8 M_{\odot}\right)$ is important because they drive the chemical evolution of their host galaxies by injecting energy, through UV radiation, strong stellar winds, and supernovae, and heavy elements into their surroundings (Zinnecker \& Yorke 2007). In the study of high-mass star formation, several models have been proposed to explain the earliest processes involved. In particular, the work of McKee \& Tan (2003) describes a process similar to that of low-mass stars including a turbulent accretion disk and bipolar outflows (see also Tan et al. 2014), the model by Bonnell \& Smith (2011) proposes that matter is gathered competitively from low-turbulence surroundings between many low-mass protostars funneling more material to the most massive core, and the model by Keto (2007) uses gravitationally trapped hypercompact HII regions to help a massive protostar to acquire more mass. All of these models predict the existence of disks as a mechanism to allow matter to accrete onto the protostar despite high radiation pressure (Krumholz et al. 2009). However, until recently only a few candidate disks around B-type protostars were known. Several disks have been detected through the study of complex organic molecules (COMs), molecular species bearing carbon and at least six atoms, allowing for the detection of more disks (Cesaroni et al. 2006; Kraus et al. 2010; Beltrán \& de Wit 2016).

While the earliest stages of high-mass star formation have not yet been clearly determined, it is well known that a chemically rich stage exists, known as a hot molecular core (HMC; see Tan et al. 2014 for a review of high-mass star formation). In this stage COMs are released from the icy surfaces of dust grains or formed in the hot circumstellar gas (Herbst \& van Dishoeck 2009). These hot cores are dense $\left(n_{\mathrm{H}}>10^{7} \mathrm{~cm}^{-3}\right)$, warm (100$500 \mathrm{~K})$, and compact $(<0.05 \mathrm{pc})$ and are expected to last up to $10^{5} \mathrm{yr}$. The signpost of the hot core stage is a rich molecular emission spectrum including many COMs like methanol $\left(\mathrm{CH}_{3} \mathrm{OH}\right)$ and methyl cyanide $\left(\mathrm{CH}_{3} \mathrm{CN}\right)$. These species may be 
formed on dust grain surfaces in a cooler place (or time) and released from grain surfaces as the forming star heats the grains. Alternatively, they may form in the hot gas surrounding these massive young objects as the higher temperature allows for endothermic reactions to take place more readily. In reality, it is likely that both formation paths are necessary to achieve the molecular abundances seen around hot cores. High spatial and spectral resolution observations can help us to disentangle the different COMs and their spatial distribution during this phase. Disks candidates have been discovered in a few HMC sources, suggesting a link between disks and HMC chemistry. Studying the chemistry of such regions can help us to understand the process of high-mass star formation as chemical differences across small physical scales provide clues to the different evolutionary stages involved.

With the advent of the Atacama Large Millimeter Array (ALMA), it is now possible to make highly sensitive, high spectral, and spatial resolution observations of less abundant molecular species. The search continues for the precursors of life, such as the simplest amino acid, glycine $\left(\mathrm{H}_{2} \mathrm{NCH}_{2} \mathrm{COOH}\right)$, but complex organic species with up to 12 atoms have already been detected $^{1}$. These include important precursors to amino acids, such as aminoacetonitrile $\left(\mathrm{H}_{2} \mathrm{NCH}_{2} \mathrm{CN}\right)$, detected by Belloche et al. (2008); the simplest monosaccharide sugar glycolaldehyde $\left(\mathrm{CH}_{2} \mathrm{OHCHO}\right)$, first observed in a hot molecular core outside the Galactic center by Beltrán et al. (2009); and formamide $\left(\mathrm{NH}_{2} \mathrm{CHO}\right)$ extensively studied by López-Sepulcre et al. (2015). With ALMA we have the ability to detect hot cores and study their properties in detail to determine how the spatial distribution of COMs influences the formation of massive stars. Despite advances in technology, astronomers have yet to determine whether the emission from the hot core arises from the inner envelope (spherical geometry) or from a circumstellar disk (flat geometry). It is also possible that these hot cores could be outflow cavity walls as has been recently modeled for low-mass stars by Drozdovskaya et al. (2015).

In this paper we study the chemical composition and spatial distribution of species in two high-mass star-forming regions, G35.20-0.74N and G35.03+0.35 (hereafter G35.20 and G35.03 respectively), which have been shown to be strong diskbearing candidates. We present a line survey of the hot core in G35.03 and in four continuum peaks in the G35.20 hot core containing $\sim 18$ different molecular species (plus 12 vibrationally excited states and 22 isotopologues) of up to 10 atoms and $>400$ emission lines per source. We also present our analysis of the chemical segregation within core B of G35.20 depicting a small-scale $(<1000 \mathrm{AU})$ separation of nitrogen chemistry and temperature difference. A chemical separation on the scale of a few 1000s of AU within a star-forming region has been seen before in Orion KL (Caselli et al. 1993), W3(OH) and $\mathrm{W} 3\left(\mathrm{H}_{2} \mathrm{O}\right)$ (Wyrowski et al. 1999b), and AFGL2591 (Jiménez-Serra et al. 2012).

The distance to both sources has been estimated from parallax measurements to be $2.2 \mathrm{kpc}$ for G35.20 (Zhang et al. 2009) and $2.32 \mathrm{kpc}$ for G35.03 (Wu et al. 2014). G35.20 has a bolometric luminosity of $3.0 \times 10^{4} L_{\odot}$ (Sánchez-Monge et al. 2014) and has been previously studied in Sánchez-Monge et al. (2013) and Sánchez-Monge et al. (2014) in which they report the detection of a large $(r \sim 2500 \mathrm{AU})$ Keplerian disk around core B and a tentative Keplerian disk in core A. The bolometric luminosity of G35.03 is $1.2 \times 10^{4} L_{\odot}$ and was reported to have a Keplerian

\footnotetext{
1 https://www.astro.uni-koeln.de/cdms/molecules
}

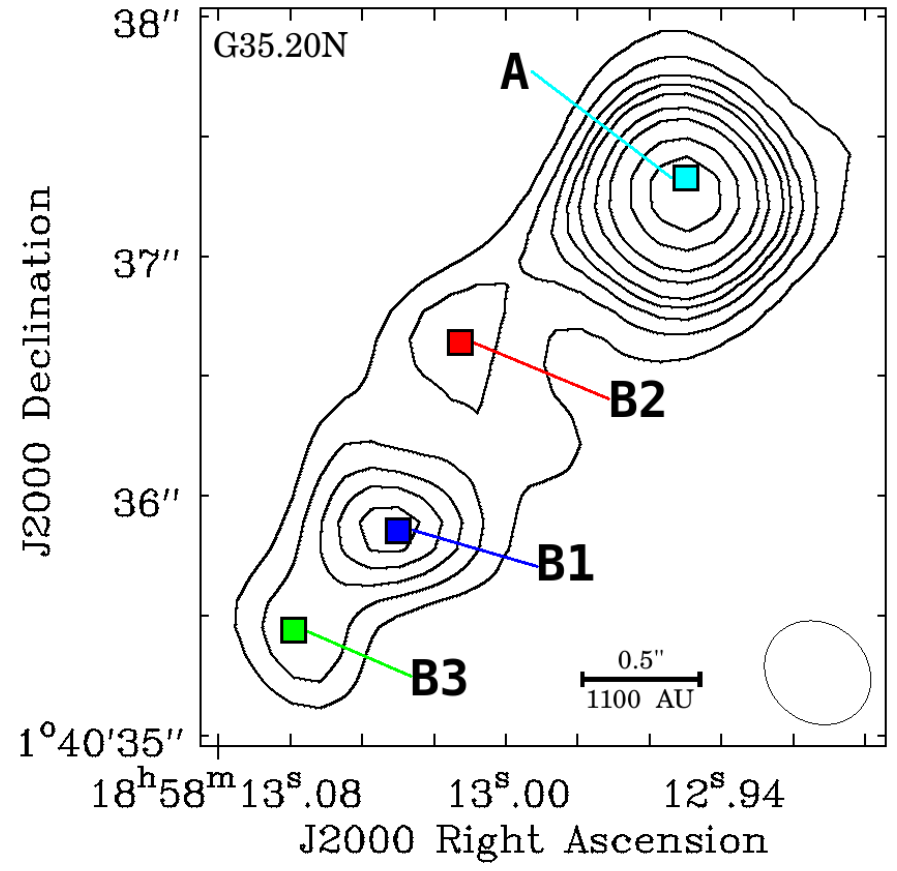

Fig. 1. Image of the $870 \mu \mathrm{m}$ continuum emission from Cycle 0 ALMA observations of G35.20. Contour levels are $0.03,0.042,0.055,0.067$, $0.08,0.10,0.13,0.18$, and $0.23 \mathrm{Jy} /$ beam $(\sigma=1.8 \mathrm{mJy} /$ beam $)$. The pixelsized colored squares indicate each of the spectral extraction points.

disk ( $r \sim 1400-2000 \mathrm{AU})$ around the hot core A in Beltrán et al. (2014).

\section{Observations and method}

\subsection{Observations}

G35.20 and G35.03 were observed with ALMA in Cycle 0 between May and June 2012 (2011.0.00275.S). The sources were observed in Band $7(350 \mathrm{GHz})$ with the 16 antennas of the array in the extended configuration (baselines in the range 36$400 \mathrm{~m}$ ) providing sensitivity to structures $0.4^{\prime \prime}-2^{\prime \prime}$. The digital correlator was configured in four spectral windows (with dual polarization) of $1875 \mathrm{MHz}$ and 3840 channels each, providing a resolution of $\sim 0.4 \mathrm{~km} \mathrm{~s}^{-1}$. The four spectral windows covered the frequency ranges [336 849.57-338723.83] $\mathrm{MHz}$, [334 965.73-336 839.99] MHz, [348 843.78-350 718.05] MHz, and [346 891.29-348 765.56] MHz. The rms noise of the continuum maps are $1.8 \mathrm{mJy} /$ beam for G35.20 and $3 \mathrm{mJy} / \mathrm{beam}$ for G35.03. For full details, see Sánchez-Monge et al. (2014) and Beltrán et al. (2014).

\subsection{Line identification process}

Spectra were extracted from the central pixel of the continuum peak in core $A$ and the three continuum peaks in core B (B1, B2, B3) in G35.20 and the continuum peak in core A in G35.03 using CASA ${ }^{2}$ (see Figs. 1 and 2 for spectra extraction positions and continuum levels and Table 1 for the J2000 coordinates and a summary of statistics). The other peaks (B$F$ in G35.03 and C-G in G35.20) were not analyzed because they do not show hot core chemistry, i.e., little or no emission from COMs. The three continuum peaks in G35.20 B

\footnotetext{
2 Common Astronomy Software Applications is available from http:
} //casa.nrao.edu/ 


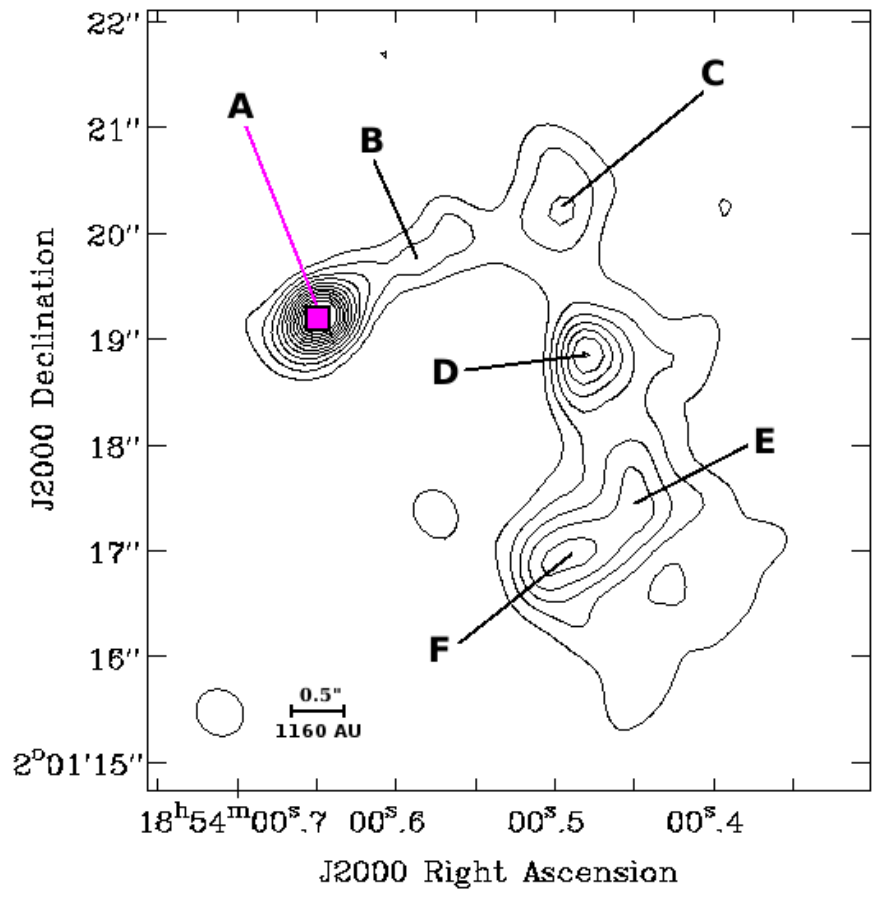

Fig. 2. Image of the $870 \mu \mathrm{m}$ continuum emission from Cycle 0 ALMA observations of G35.03. Contour levels are 8.6, 16.8, 24.9, 33, 41.2, $49.3,57.4,65.5,73.6,81.8$, and $89.9 \mathrm{mJy} / \mathrm{beam}(\sigma=3.0 \mathrm{mJy} / \mathrm{beam})$. The pixel-sized colored square indicates the spectral extraction point. The cores identified in Beltrán et al. (2014) are labeled A-F.

were chosen to investigate the chemical structure across the disk shown in Sánchez-Monge et al. (2014; who analyzed B as a single core); however, the disk in G35.03 A only has a single continuum point associated with the hot core, so analysis for this source was from this peak. G35.20 A was analyzed as the strongest continuum source in the region with hot core chemistry and was also analyzed at the single continuum peak. Line parameters (listed in Appendix B) were determined using Gaussian profile fits to spectral lines from each continuum peak via Cassis ${ }^{3}$, primarily using the Cologne Database for Molecular Spectroscopy (CDMS; Müller et al. 2005) database and Jet Propulsion Laboratory (JPL; Pickett et al. 1998) database for deuterated methanol $\left(\mathrm{CH}_{2} \mathrm{DOH}\right)$, ethanol $\left(\mathrm{C}_{2} \mathrm{H}_{5} \mathrm{OH}\right), \mathrm{NH}_{2} \mathrm{CHO}$, acetaldehyde $\left(\mathrm{CH}_{3} \mathrm{CHO}\right)$, and $\mathrm{CH}_{3} \mathrm{OH}(v=2)$ transitions.

The process of identifying all species present in these spectra consisted of several parts. Bright lines $\left(T_{\mathrm{B}}>\right.$ $5 \mathrm{~K}$ ) from known species were identified first (i.e., those from Sánchez-Monge et al. (2014): $\mathrm{CH}_{3} \mathrm{OH}$, methyl formate $\left(\mathrm{CH}_{3} \mathrm{OCHO}\right), \mathrm{CH}_{3} \mathrm{CN}$, simple molecules) numbering about 100 lines per source. The remaining bright lines $(>5 \mathrm{~K})$ were identified by choosing the most likely molecular candidate, namely the transition with the higher Einstein coefficient that is limited to a minimum of about $10^{-7} \mathrm{~s}^{-1}$, or with a upper level energy $\left(E_{\text {up }}\right)$ within the expected range, generally less than $500 \mathrm{~K}$, composed of $\mathrm{C}, \mathrm{H}, \mathrm{O}$ and/or $\mathrm{N}$ and within $2 \mathrm{~km} \mathrm{~s}^{-1}(\sim 2 \mathrm{MHz})$ of the rest frequency of the transition. This brings the total to about 200 per source. Finally, for any remaining unidentified lines $>3 \sigma$ $(\sim 0.5 \mathrm{~K})$ a potential species was selected, then the entire spectrum was checked for nondetections of expected transitions of this species. The total number of identified lines was over 400 for each source, including partially blended and blended transitions

\footnotetext{
3 CASSIS has been developed by IRAP-UPS/CNRS (http:// cassis.irap.omp.eu).
}

for which it was evident or implied by the line shape that another transition was present. It is noted in Appendix B if the line identity is uncertain in case of strong blending or multiple probable candidates.

The remaining total of unidentified and unclear identity (where there is more than one potential species) lines is about 80 for the peaks in B and G35.03 with an additional 30 in G35.20 A. These unknown transitions could be either species whose transitions for this frequency regime have not yet been measured/calculated or species whose likely identity was not clear. The peak intensities of the unknown lines were all less than $5 \mathrm{~K}$. Line parameters were measured by fitting a Gaussian profile to the emission line with the Cassis line spectrum tool. In some cases, partially blended lines were fit together with one or more extra Gaussians for a more accurate measurement, although in those cases the errors were larger. The full line survey can be found in Appendices A and B, but an example is given in Table 2, where the parameters obtained for thioformaldehyde $\left(\mathrm{H}_{2} \mathrm{CS}\right)$ are listed. The line identities are first presented ordered by frequency, and then, to emphasize the chemistry of these objects, the tables of measured line parameters are sorted by molecular species.

To validate the line identifications, fits were made simultaneously to all identified species via the XCLASS software Möller et al. $(2017)^{4}$. This program models the data by solving the radiative transfer equation for an isothermal object in one dimension, taking into account source size and dust attenuation. The residuals between the fitted lines and observed spectra are between 5 and 25\%, validating the XCLASS fits and our line identifications. The observed spectra and the XCLASS fits can be found in Appendix E and further information about the XCLASS analysis is detailed in Sect. 3.4.

\subsection{Image analysis}

To confirm our identifications of several complex organic species, maps were made of unblended transitions. Similar spatial distributions and velocity profiles of transitions with similar upper energy levels are consistent with these being the same species. Figure 3 shows integrated intensity (moment zero) maps of $\mathrm{CH}_{3} \mathrm{OCHO} v=0$ and $v=1$ transitions, $\mathrm{H}_{2} \mathrm{CS},\left(\mathrm{CH}_{2} \mathrm{OH}\right)_{2}$, $\mathrm{CH}_{3} \mathrm{CHO} v=0$, and $v=2$ transitions in G35.20 and Fig. 4 shows the same transitions in G35.03. During this process, we discovered a difference in spatial extent between N-bearing species and O-bearing species in G35.20 core B. The N-bearing species peak at the location of continuum peak B3 and are generally not found at the other side of the disk near continuum peak B2. We comment on this difference in detail in Sect. 4.2. Channel maps were made in CASA for 20 different species for interesting isolated lines with a range of upper energy levels (see Table 3) to determine the spatial distribution of various species. Zeroth (integrated intensity), first (velocity), and second (dispersion) moment maps were also made for these species. A selection of integrated intensity maps can be found in Figs. 3 and 4.

\section{Results and analysis}

\subsection{Line detections}

A total of 431 different transitions were identified in 52 different catalog entries (18 "regular" $v=0$ main isotopes species plus

\footnotetext{
4 The software can be downloaded from here: https://xclass. astro.uni-koeln.de/
} 
Table 1. Source continuum characteristics.

\begin{tabular}{cccccccc}
\hline \hline Continuum peak & Right ascension & Declination & Size $\left(^{(\prime)}\right)^{a}$ & $S_{v}(\mathrm{Jy})^{b}$ & $T_{\text {kin }}(\mathrm{K})^{c}$ & $N\left(\mathrm{H}_{2}\right)\left(\mathrm{cm}^{-2}\right)^{d}$ & Mass $\left(M_{\odot}\right)^{e}$ \\
\hline G35.20 A & $18: 58: 12.948$ & $+01: 40: 37.419$ & 0.58 & 0.65 & 285 & $2.4 \times 10^{25}$ & 13.0 \\
G35.20 B1 & $18: 58: 13.030$ & $+01: 40: 35.886$ & 0.61 & 0.19 & 160 & $6.4 \times 10^{24}$ & 3.8 \\
G35.20 B2 & $18: 58: 13.013$ & $+01: 40: 36.649$ & 0.65 & 0.12 & 120 & $3.3 \times 10^{24}$ & 2.2 \\
G35.20 B3 & $18: 58: 13.057$ & $+01: 40: 35.442$ & 0.58 & 0.08 & 300 & $2.5 \times 10^{24}$ & 1.4 \\
G35.03 A & $18: 54: 00.645$ & $+02: 01: 19.235$ & 0.49 & 0.21 & 275 & $1.1 \times 10^{25}$ & 4.4 \\
\hline
\end{tabular}

Notes. ${ }^{(a)}$ Deconvolved average diameter of the $50 \%$ contour of the $870 \mu \mathrm{m}$ continuum. ${ }^{(b)}$ Integrated flux density within the $10 \sigma$ contour of the $870 \mu \mathrm{m}$ continuum. ${ }^{(c)}$ Average kinetic temperature based on $\mathrm{CH}_{3} \mathrm{CN}$ line ratios as calculated using RADEX. For details, see Sect. 3.3. ${ }^{(d)}$ Calculated from source size, continuum flux density, and kinetic temperature (Sect. 3.3). ${ }^{(e)}$ Sources mass calculated as in Sánchez-Monge et al. (2014) using the average kinetic temperatures.

Table 2. Line detections and measurements for $\mathrm{H}_{2} \mathrm{CS}$.

\begin{tabular}{|c|c|c|c|c|c|c|c|c|c|c|c|}
\hline \multirow[b]{2}{*}{ Transition } & \multirow[b]{2}{*}{$\begin{array}{c}\text { Frequency } \\
(\mathrm{MHz})\end{array}$} & \multicolumn{2}{|c|}{$\mathrm{G} 35.20 \mathrm{~A}$} & \multicolumn{2}{|c|}{ G35.20 B1 } & \multicolumn{2}{|c|}{ G35.20 B2 } & \multicolumn{2}{|c|}{ G35.20 B3 } & \multicolumn{2}{|c|}{ G35.03 A } \\
\hline & & $\begin{array}{c}F W H M \\
\left(\mathrm{~km} \mathrm{~s}^{-1}\right)\end{array}$ & $\begin{array}{c}T_{\text {peak }} \\
(\mathrm{K})\end{array}$ & $\begin{array}{l}F W H M \\
\left(\mathrm{~km} \mathrm{~s}^{-1}\right)\end{array}$ & $\begin{array}{c}T_{\text {peak }} \\
(\mathrm{K})\end{array}$ & $\begin{array}{l}F W H M \\
\left(\mathrm{~km} \mathrm{~s}^{-1}\right)\end{array}$ & $\begin{array}{c}T_{\text {peak }} \\
(\mathrm{K})\end{array}$ & $\begin{array}{l}F W H M \\
\left(\mathrm{~km} \mathrm{~s}^{-1}\right)\end{array}$ & $\begin{array}{c}T_{\text {peak }} \\
(\mathrm{K})\end{array}$ & $\begin{array}{l}F W H M \\
\left(\mathrm{~km} \mathrm{~s}^{-1}\right)\end{array}$ & $\begin{array}{c}T_{\text {peak }} \\
(\mathrm{K})\end{array}$ \\
\hline \multicolumn{12}{|c|}{$\mathrm{H}_{2} \mathrm{CS} v=0$} \\
\hline $10_{1,10}-9_{1,9}$ & 338083 & $5.9 \pm 0.1$ & $51.7 \pm 0.9$ & $2.7 \pm 0.1$ & $27.3 \pm 1.0$ & $2.4 \pm 0.1$ & $28 \pm 1$ & $2.54 \pm 0.06$ & $44.3 \pm 0.9$ & $6.6 \pm 0.1$ & $21.0 \pm 0.3$ \\
\hline $10_{1,9}-9_{1,8}$ & 348532 & $5.8 \pm 0.1$ & $59.2 \pm 1.3$ & $2.6 \pm 0.1$ & $31 \pm 1$ & $2.3 \pm 0.1$ & $31 \pm 1$ & $2.58 \pm 0.04$ & $52.1 \pm 0.7$ & $6.33 \pm 0.09$ & $21.3 \pm 0.3$ \\
\hline \multicolumn{12}{|c|}{$\mathrm{H}_{2} \mathrm{C}^{33} \mathrm{~S}$} \\
\hline $10_{1,10}-9_{1,9}$ & 335160 & $7.5 \pm 0.2$ & $3.91 \pm 0.09$ & $1.6 \pm 0.5$ & $0.4 \pm 0.1$ & $1.5 \pm 0.6$ & $0.4 \pm 0.2$ & $2.5 \pm 0.2$ & $1.47 \pm 0.08$ & & \\
\hline \multicolumn{12}{|c|}{$\mathrm{H}_{2} \mathrm{C}^{34} \mathrm{~S}$} \\
\hline $10_{0,10}-9_{0,9}$ & 337125 & \multirow{2}{*}{\multicolumn{2}{|c|}{$\begin{array}{c}\text { blended } \\
\text { blended with } \mathrm{CH}_{3} \mathrm{OH} v=1\end{array}$}} & $1.2 \pm 0.7$ & $0.7 \pm 0.4$ & $1.5 \pm 0.2$ & $1.0 \pm 0.1$ & $1.9 \pm 0.1$ & $2.5 \pm 0.1$ & \multirow{3}{*}{\multicolumn{2}{|c|}{$\begin{array}{c}<3 \sigma \\
\text { blended with } \mathrm{CH}_{3} \mathrm{OH} v=1 \\
\text { blended with } \mathrm{CH}_{3} \mathrm{OH} v=1\end{array}$}} \\
\hline $10_{4,6}-9,5$ & 337460 & & & in abs & eature & $1.5 \pm 0.4$ & $0.55 \pm 0.09$ & blended with & $\mathrm{H}_{3} \mathrm{OH} v=1$ & & \\
\hline $10_{2,9}-9_{2,8}$ & 337475 & $6.3 \pm 0.3$ & $16.0 \pm 0.3$ & $1.66 \pm 0.08$ & $3.8 \pm 0.2$ & $1.7 \pm 0.1$ & $3.8 \pm 0.2$ & $3.1 \pm 0.2$ & $4.9 \pm 0.2$ & & \\
\hline $10_{3,8}-9,7$ & 337555 & \multicolumn{2}{|c|}{ blended } & $2.0 \pm 0.2$ & $0.78 \pm 0.05$ & $1.7 \pm 0.5$ & $0.6 \pm 0.2$ & $2.03 \pm 0.04$ & $2.35 \pm 0.03$ & \multicolumn{2}{|c|}{$<3 \sigma$} \\
\hline $10_{3,7}-9_{3,6}$ & 337559 & \multicolumn{2}{|c|}{ blended } & $2.16 \pm 0.09$ & $1.55 \pm 0.04$ & $1.3 \pm 0.1$ & $0.54 \pm 0.04$ & $2.37 \pm 0.06$ & $2.26 \pm 0.03$ & \multicolumn{2}{|c|}{$<3 \sigma$} \\
\hline $10_{2,8}-9_{2,7}$ & 337933 & \multicolumn{2}{|c|}{ blended } & $1.2 \pm 0.5$ & $0.8 \pm 0.2$ & $1.8 \pm 0.5$ & $0.7 \pm 0.1$ & $2.3 \pm 0.1$ & $2.4 \pm 0.1$ & \multicolumn{2}{|c|}{$<3 \sigma$} \\
\hline
\end{tabular}
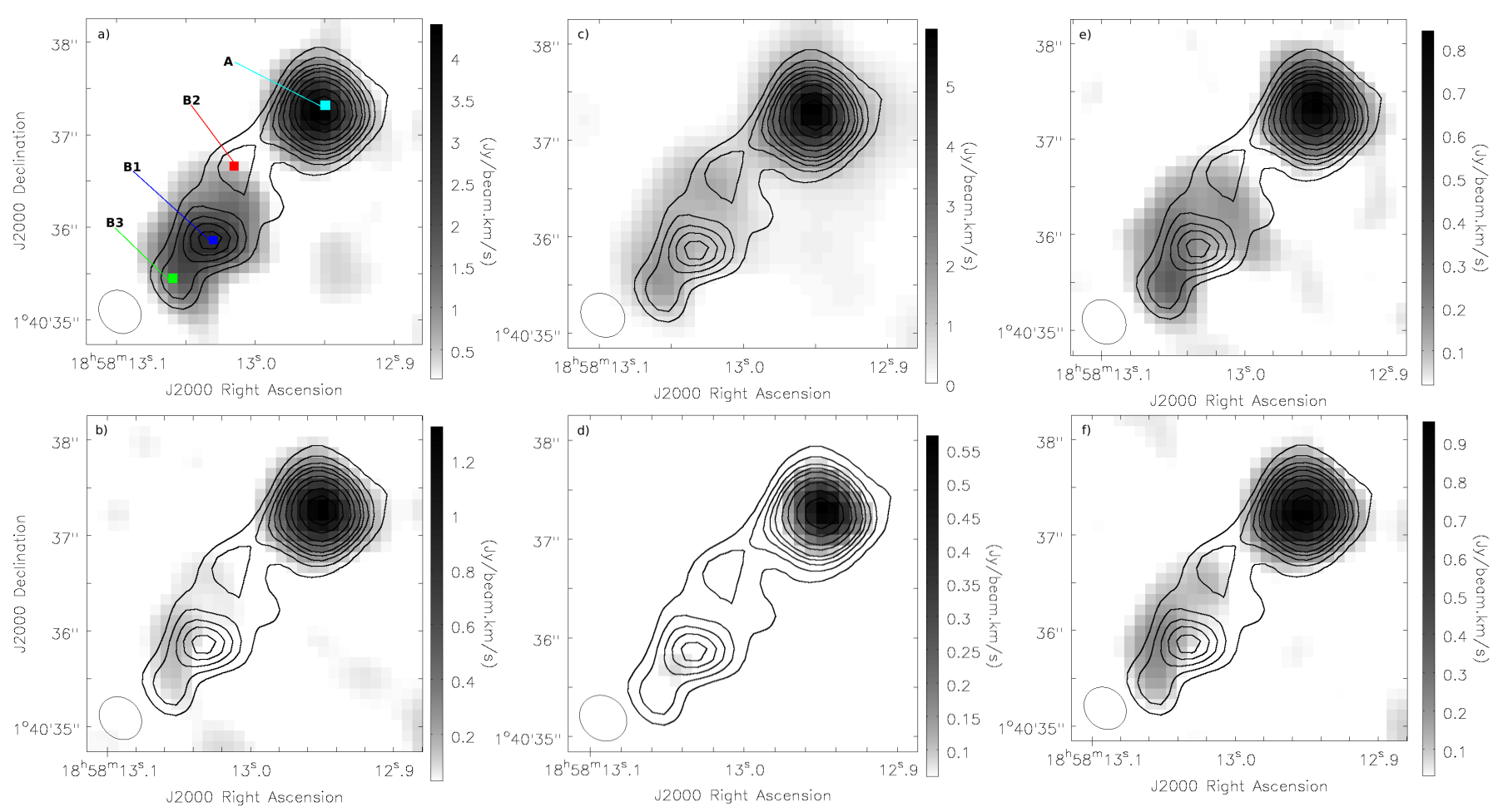

Fig. 3. Integrated intensity maps of six species across G35.20, where the contours are the $870 \mu \mathrm{m}$ continuum with the same levels as Fig. 1 . Panel a) shows the $\mathrm{CH}_{3} \mathrm{OCHO} v=0$ emission at $336.086 \mathrm{GHz}$ integrated from 18.5 to $38 \mathrm{~km} \mathrm{~s}^{-1}$. Panel b) shows the $\mathrm{CH}_{3} \mathrm{OCHO} v=1 \mathrm{emission}$ at $348.084 \mathrm{GHz}$ integrated from 26 to $38.5 \mathrm{~km} \mathrm{~s}^{-1}$. Panel c) shows the $\mathrm{H}_{2} \mathrm{CS}$ emission at $338.083 \mathrm{GHz}$ integrated from 24.5 to $38.5 \mathrm{~km} \mathrm{~s}^{-1}$. Panel d) shows ethylene glycol $\left(\left(\mathrm{CH}_{2} \mathrm{OH}\right)_{2}\right)$ emission at $335.030 \mathrm{GHz}$ integrated from $25-36.5 \mathrm{~km} \mathrm{~s}^{-1}$. Panel e) shows $\mathrm{CH}_{3} \mathrm{CHO} v=0$ emission at $335.318 \mathrm{GHz}$ integrated from 22.5 to $37 \mathrm{~km} \mathrm{~s}^{-1}$. Panel f) shows $\mathrm{CH}_{3} \mathrm{CHO} v=2$ emission at $349.752 \mathrm{GHz}$ integrated from 24 to $29 \mathrm{~km} \mathrm{~s}{ }^{-1}$. It can clearly be seen between panels a) and $\mathbf{b}$ ) and between $\mathbf{e}$ ) and $\mathbf{f}$ ) that vibrationally excited states have a much smaller emitting region. It is also clear in panel d) that $\left(\mathrm{CH}_{2} \mathrm{OH}\right)_{2}$ is only seen in core $\mathrm{A}$. 

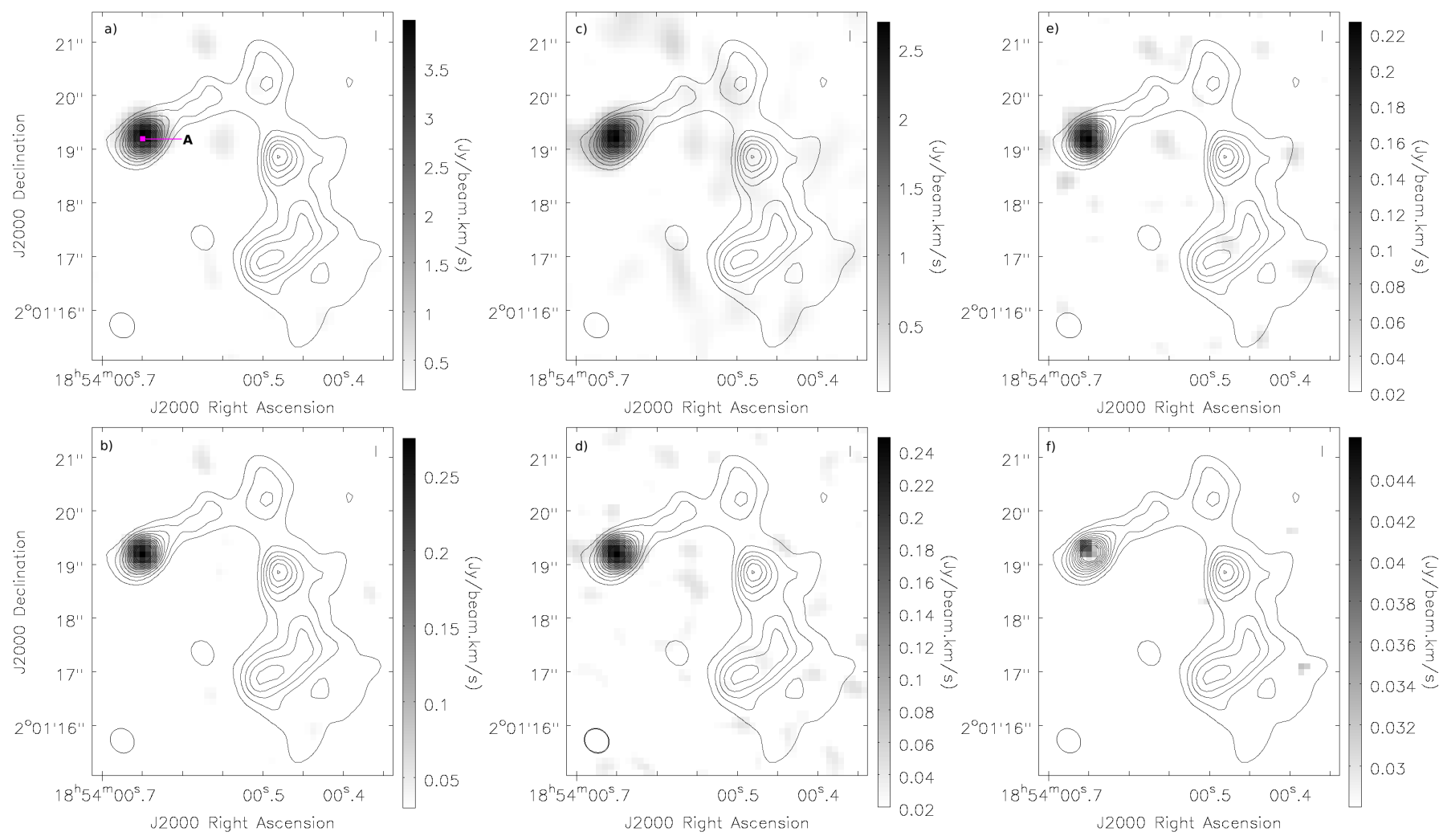

Fig. 4. Integrated intensity maps of six species across G35.03, for which the contours are the $870 \mu \mathrm{m}$ continuum with the same levels as Fig. 2. Panel a) shows the $\mathrm{CH}_{3} \mathrm{OCHO} v=0$ emission at $336.086 \mathrm{GHz}$ integrated from 37 to $57 \mathrm{~km} \mathrm{~s}^{-1}$. Panel b) shows the $\mathrm{CH}_{3} \mathrm{OCHO} v=1 \mathrm{emission}$ at $348.084 \mathrm{GHz}$ integrated from 42 to $50 \mathrm{~km} \mathrm{~s}^{-1}$. Panel c) shows the $\mathrm{H}_{2} \mathrm{CS}$ emission at $338.083 \mathrm{GHz}$ integrated from 37 to $52 \mathrm{~km} \mathrm{~s}^{-1}$. Panel d) shows $\left(\mathrm{CH}_{2} \mathrm{OH}\right)_{2}$ emission at $335.030 \mathrm{GHz}$ integrated from 38.5 to $48.5 \mathrm{~km} \mathrm{~s}^{-1}$. Panel e) shows $\mathrm{CH}_{3} \mathrm{CHO} v=0$ emission at $335.318 \mathrm{GHz}$ integrated from 39.5 to $48.5 \mathrm{~km} \mathrm{~s}^{-1}$. Panel f) shows $\mathrm{CH}_{3} \mathrm{CHO} v=2$ emission at $349.752 \mathrm{GHz}$ integrated from 42 to $47 \mathrm{~km} \mathrm{~s}^{-1}$. It is clear between panels a) and b) and between e) and f) that vibrationally excited states have a much smaller emitting region. It is also clear in panel $\mathbf{d})$ that $\left(\mathrm{CH}_{2} \mathrm{OH}\right)_{2}$ is observed in this source.

Table 3. Table of source line characteristics.

\begin{tabular}{ccccc}
\hline \hline Continuum peak & Species (total) & $\begin{array}{c}E_{\mathrm{up}} \\
(\mathrm{K})\end{array}$ & $\begin{array}{c}\langle F W H M\rangle \\
\left(\mathrm{km} \mathrm{s}^{-1}\right)\end{array}$ & $\begin{array}{c}\left\langle v_{\mathrm{LSR}}\right\rangle \\
\left(\mathrm{km} \mathrm{s}^{-1}\right)\end{array}$ \\
\hline G35.20 A & $23(52)$ & $17-1143$ & 5.2 & 32.2 \\
G35.20 B1 & $21(42)$ & $17-1074$ & 2.1 & 29.2 \\
G35.20 B2 & $21(41)$ & $17-973$ & 1.9 & 32.3 \\
G35.20 B3 & $22(50)$ & $17-1143$ & 2.4 & 28.5 \\
G35.03 A & $22(46)$ & $17-1143$ & 4.7 & 45.3 \\
\hline
\end{tabular}

Notes. Column 1 lists the name of the peak. Column 2 shows the number of molecular species with one or more transition detected. The total in parentheses indicates the number of XCLASS catalog entries including isotopologues and vibrationally excited transitions separately. Column 3 gives the range of upper level energies observed. Column 4 is the average line width for each peak. Column 5 is the average velocity of the lines at each peak. Averages are calculated from all Gaussian line measurements as listed in Appendix B.

34 vibrationally excited states and isotopologues). Table 3 shows the number of species detected per source and Table 4 shows the number of unblended and partially blended transitions detected per species in each source. In addition, a few species were identified from a single transition and are listed in Table 6.

The peak with the most transitions is the weakest continuum source, B3. The strongest continuum source, G35.20 A, suffers greatly from blending and therefore has fewer unblended transitions, but is also chemically diverse (containing 23 identified species versus 22 in B3). G35.03 A, the second strongest continuum source, contains the third most molecular species, mainly because deuterated species are not present. Regarding line flux, B3 generally has the brightest emission of core B except in a few cases where B1 has slightly brighter lines. Overall B2 has the weakest emission, but still has a diverse range of species. The lines in G35.03 A are less bright than G35.20 A and are generally brighter than B3. The line fluxes from continuum peak G35.20 A are higher than any of the peaks in B except in a few cases in which B3 has higher line fluxes.

\subsection{Line profiles}

Most lines are fit by single Gaussians, but some profiles are more complex. Table 3 shows a summary of line properties at each peak. The average measured line width for G35.20 A was $5.2 \mathrm{~km} \mathrm{~s}^{-1}$ with an average $v_{\mathrm{LSR}}$ of $32.2 \mathrm{~km} \mathrm{~s}^{-1}$. In G35.20 A, $23 \%$ of identified unblended lines are double peaked and nearly all of the rest are broad (FWHM in A is $5-8 \mathrm{~km} \mathrm{~s}^{-1}$ compared to $1-3 \mathrm{~km} \mathrm{~s}^{-1}$ at the B peaks; see below) suggesting that rotation of an unresolved structure is present (see Fig. 5). As the double peaked transitions tend to have higher upper energies (typically $\sim 300 \mathrm{~K}$ ), we propose that these originate in a warmer region closer to the central source, therefore indicating Keplerian-type rotation. This effect is especially prominent in the $\mathrm{CH}_{3} \mathrm{OCHO}$, $\mathrm{C}_{2} \mathrm{H}_{5} \mathrm{OH}$, and $\mathrm{CH}_{2} \mathrm{DOH}$ lines. Fits were made to each of the two components for $\mathrm{CH}_{3} \mathrm{OCHO}$ using Cassis and the peaks were 


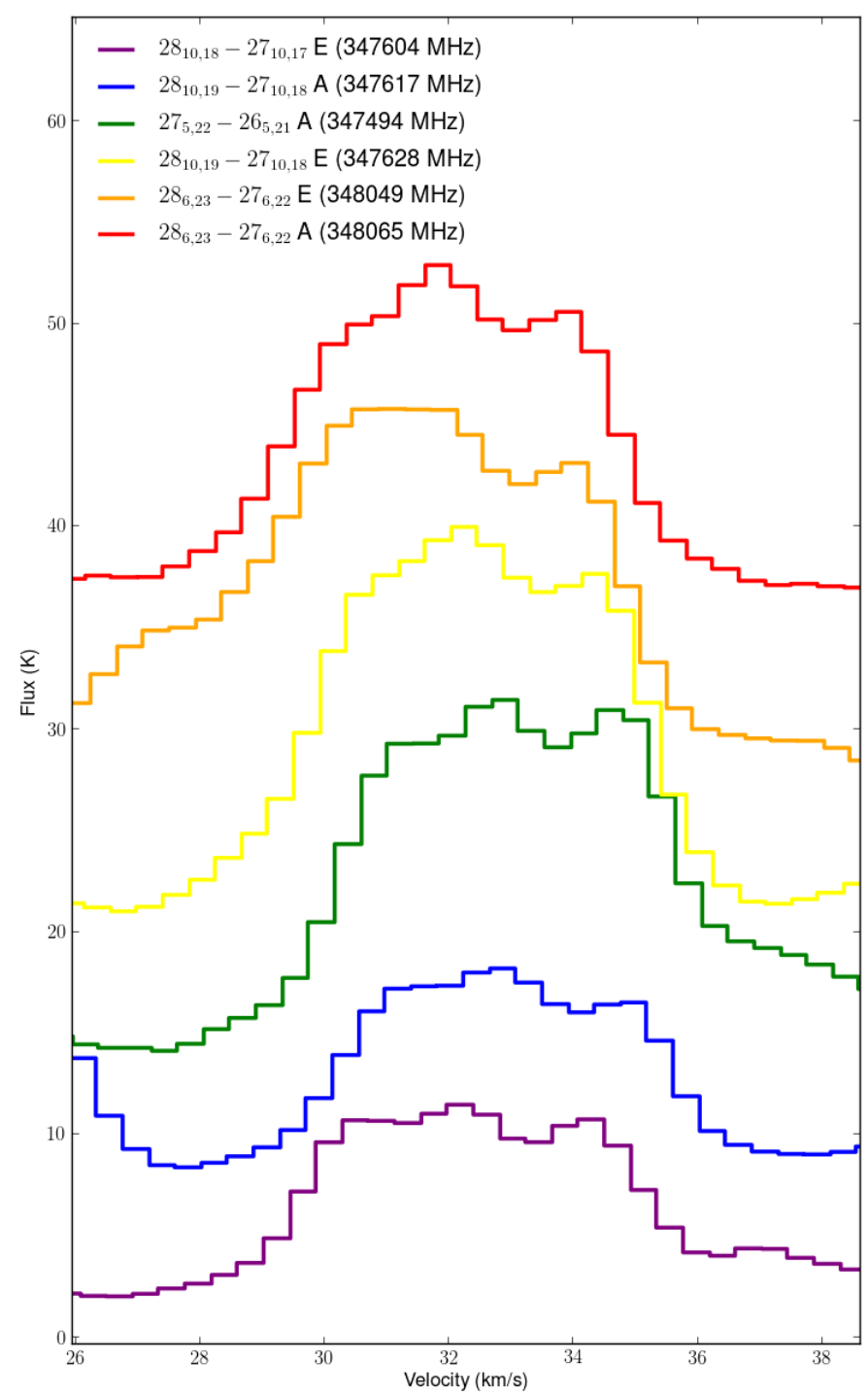

Fig. 5. Profiles of $\mathrm{CH}_{3} \mathrm{OCHO}$ transitions toward source G35.20 A showing double peaked emission lines. Features at the edge of the frame are separate lines. If the source is more compact than the beam, this could indicate rotation.

found to be separated by about $2.5 \mathrm{~km} \mathrm{~s}^{-1}$. Double peaked lines are indicated in the line property tables in Appendix B. Line blending is prominent for G35.20 A, possibly because the object is more compact and therefore less resolved than core $\mathrm{B}$. This could also be a consequence of G35.20 A being more chemically rich or having intrinsically broader line widths. There are a number of emission lines that are weakly detected in A and undetected at any other continuum peak. This is possibly because $\mathrm{A}$ is the brightest source in both line and continuum emission, so these species may also be present at the continuum peaks in B, but are lost in the noise. The emission lines from G35.20 A were fit with a single Gaussian for consistency, even where double peaked lines appeared, as the goal was chemical not kinematic analysis.

The average line widths for the emission lines from continuum peaks B1, B2, and B3 were 2.1, 1.9, and $2.4 \mathrm{~km} \mathrm{~s}^{-1}$, respectively. The $v_{\mathrm{LSR}}$ of each of the continuum peaks in core $\mathrm{B}$ corresponds well with the velocity gradient of the disk observed in Sánchez-Monge et al. (2014). At B3 in the southeast of the core, the average measured $v_{\mathrm{LSR}}$ is $28.5 \mathrm{~km} \mathrm{~s}^{-1}$, at $\mathrm{B} 1$, the brightest

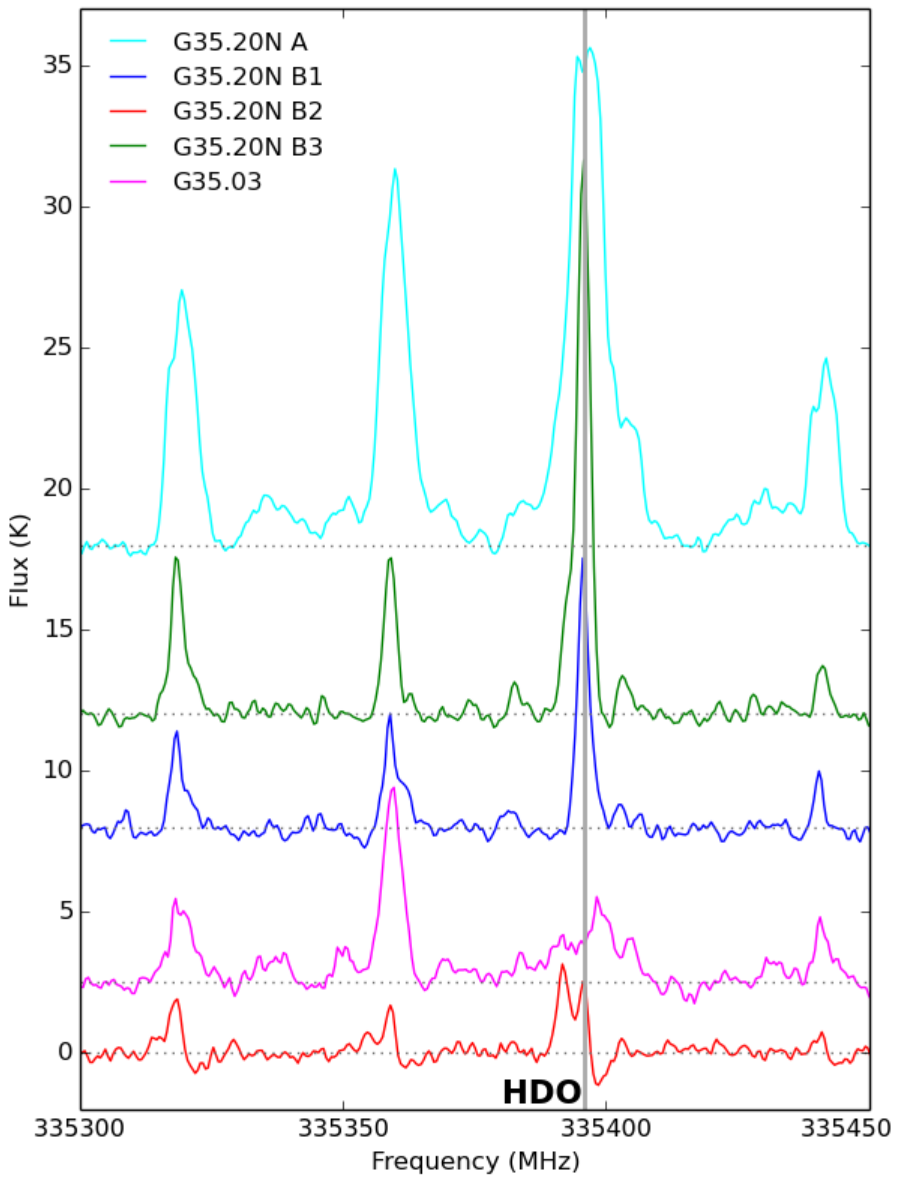

Fig. 6. Sample spectrum for the frequency range $335.3-335.45 \mathrm{GHz}$ in the rest frame of each peak to indicate the diversity of these sources. G35.03 and G35.20 A do not appear to have any absorption features (in this range), but it is notable that the lines for these two sources are broader. The deuterated water (HDO) emission line at 335.396 is especially strong in B3, double peaked in G35.20 A, possibly has two velocity components in $\mathrm{B} 2$, and is either very weak or offset by several $\mathrm{km} \mathrm{s}^{-1}$ in G35.03.

in continuum in the center of the core, the average $v_{\mathrm{LSR}}$ is $29.2 \mathrm{~km} \mathrm{~s}^{-1}$, and at B2 in the northernmost part of core B the average $v_{\mathrm{LSR}}$ is $32.3 \mathrm{~km} \mathrm{~s}^{-1}$. For the continuum peaks B1, B2, and B3, only the emission component was measured and taken into account for LTE modeling.

The spectra of sources B1, B2, and B3 show apparent absorption features, which originate in gaps in the observations due to emission larger than about $2^{\prime \prime}$ being resolved out. In the spectra from B1, apparent redshifted absorption features are seen in every bright line except $\mathrm{SO}_{2}$ and $\mathrm{SO}$. In $\mathrm{CH}_{3} \mathrm{CN}$, the absorption is less pronounced, but the emission lines are asymmetrically blue. In the spectra of B2, the apparent absorption features are blueshifted and are obvious in all lines and are especially deep $(\sim 2.5 \mathrm{~K})$ for $\mathrm{CH}_{3} \mathrm{CN}$. In B3, the apparent absorption features can be seen weakly in all species but are strong $(\sim 5 \mathrm{~K})$ for $\mathrm{CH}_{3} \mathrm{OH}$ $v=0$ transitions.

G35.03 A generally has weaker lines than the brightest sources in G35.20 (A and B3) and broader lines than those in $\mathrm{B} 1, \mathrm{~B} 2$, and B3 with an average FWHM of $4.7 \mathrm{~km} \mathrm{~s}^{-1}$. The measured average $v_{\mathrm{LSR}}$ of the emission lines from this continuum peak was $45.3 \mathrm{~km} \mathrm{~s}^{-1}$. There are no strong absorption features or double peaked emission lines. Figure 6 shows the different properties of each source in example spectra. 


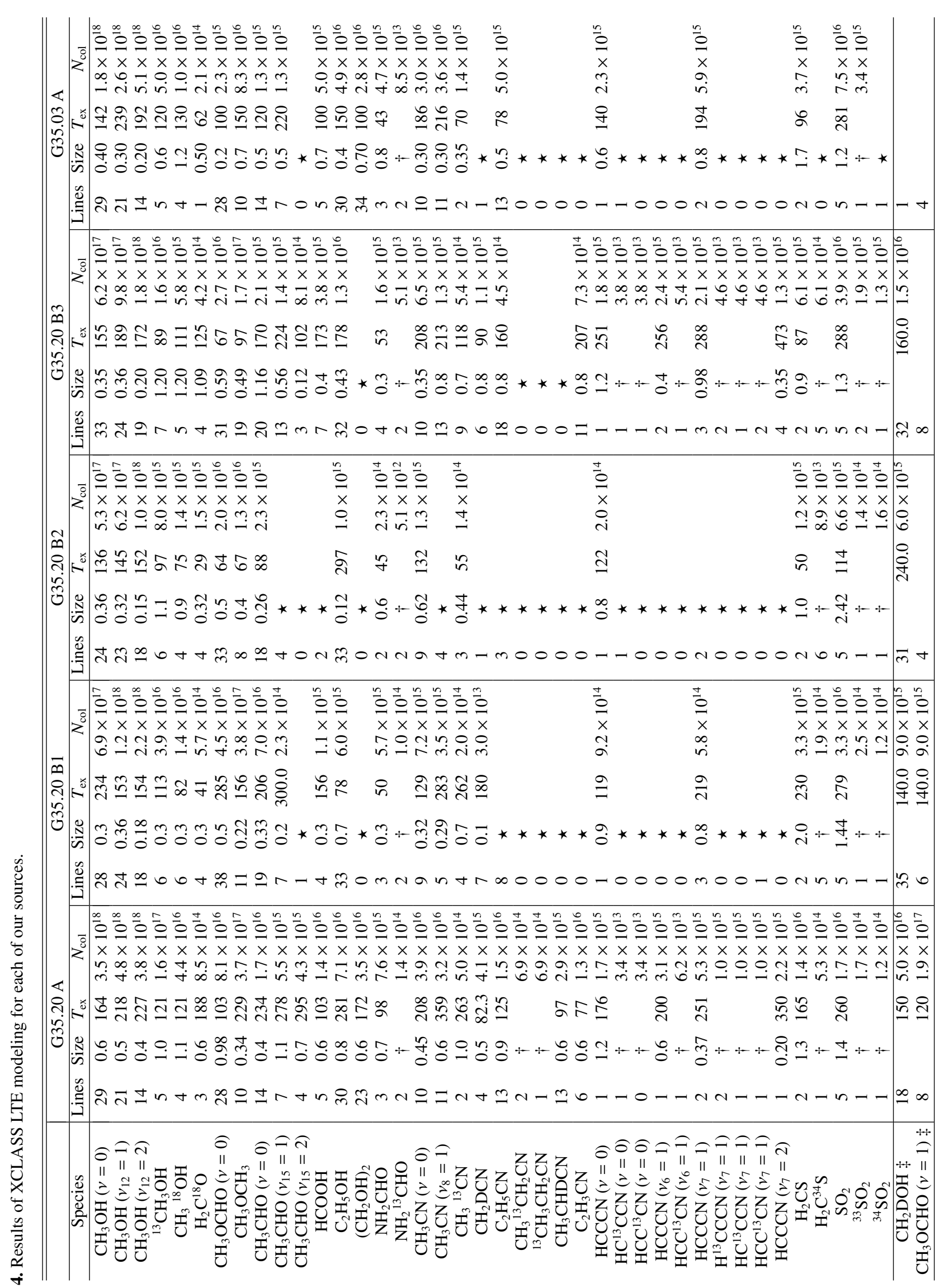




\subsection{Kinetic gas temperatures}

To estimate the kinetic temperature $\left(T_{\text {kin }}\right)$ for each region without assuming local thermodynamic equilibrium (LTE), we use RADEX (van der Tak et al. 2007), which is a radiative transfer code that assumes an isothermal and homogeneous medium, treats optical depth with a local escape probability, and uses collisional rate coefficients from the LAMDA database (Schöier et al. 2005; Green 1986). We use this software to calculate line intensity ratios across a range of kinetic temperatures and densities and determine whether it is reasonable to assume LTE.

We used the $\mathrm{CH}_{3} \mathrm{CN}$ line ratios for these sources as this species is a known tracer (Wang et al. 2013) of kinetic temperature as a near-symmetric top molecule where transitions with different energy levels have similar critical densities. We consider as input parameters the ratios of the peaks of unblended $\mathrm{CH}_{3} \mathrm{CN}$ lines. The transitions used were $19_{8}-18_{8}, 19_{6}-18_{6}, 19_{5}-$ $18_{5}, 19_{4}-18_{4}, 19_{3}-18_{3}$, and $19_{2}-18_{2}$ with a column density of $5 \times 10^{15} \mathrm{~cm}^{-2}$. The line ratios were modeled for kinetic temperatures between 100 and $500 \mathrm{~K}$ and for $\mathrm{H}_{2}$ densities between $10^{6}$ and $10^{9} \mathrm{~cm}^{-3}$. Errors were calculated from the measured error on the Gaussian fit of each spectral line.

We find that B2 is the coolest region with an average $T_{\text {kin }}$ of $120 \mathrm{~K}$ and a range from $90-170 \mathrm{~K}$. Next hottest is B1 with an average $T_{\text {kin }}$ of $160 \mathrm{~K}$ and a range from $120-220 \mathrm{~K}$. G35.20 A is significantly hotter than these with an average $T_{\text {kin }}$ of $285 \mathrm{~K}$ and a range from $150-450 \mathrm{~K}$. B3 is consistently the hottest, ranging from $175-490 \mathrm{~K}$ with an average $T_{\text {kin }}$ of $300 \mathrm{~K}$. The kinetic temperatures in G35.03 are also very high, ranging from 100-450 K with an average $T_{\text {kin }}$ of $275 \mathrm{~K}$.

The varying temperatures for different transition ratios may indicate a temperature gradient within the sampled gas, which requires advanced methods such as RATRAN (Hogerheijde \& van der Tak 2000) or LIME (Brinch \& Hogerheijde 2010) to model. The $K=6 / K=4$ ratio consistently traces the lowest temperature. The $K=8 / K=3$ ratio traces the highest temperature for A, B3, and G35.03, while the highest temperatures for $\mathrm{B} 1$ and $\mathrm{B} 2$ are traced by the $K=6 / K=3$ and $K=6 / K=5$ ratios, respectively.

These average kinetic temperatures were used in calculating the mass of the core and $\mathrm{H}_{2}$ column density based on the $870 \mu \mathrm{m}$ continuum flux as in Sánchez-Monge et al. (2014). Using a dust opacity of $1.75 \mathrm{~cm}^{2} \mathrm{~g}^{-1}$ and a gas-to-dust ratio of 100 , core A has a mass of $13.0 M_{\odot}, \mathrm{B} 1$ has a mass of $3.8 M_{\odot}$, B2 has a mass of $2.2 M_{\odot}$, B3 has a mass of $1.4 M_{\odot}$, and G35.03 has a mass of $4.4 M_{\odot}$. G35.20 A generally has a lower kinetic temperature than B3, but higher energy transitions are observed and it is also much more massive with a continuum flux density that is 10 times higher.

\subsection{Molecular column densities}

To estimate the column densities of each detected species, we used the XCLASS software. For any given set of parameters (source size, temperature, column density, velocity, and line width) XCLASS determines the opacity for each spectral channel for each species, and these opacities are added to produce a spectrum of the opacity changing with frequency. In a last step, the opacity is converted into brightness temperature units to be directly compared with the observed spectrum. The fitting process compares the synthetic spectrum to the observed spectrum, and minimizes the $\chi^{2}$ by changing the five parameters indicated above. As input parameters, we limited the line width and $v_{\mathrm{LSR}}$

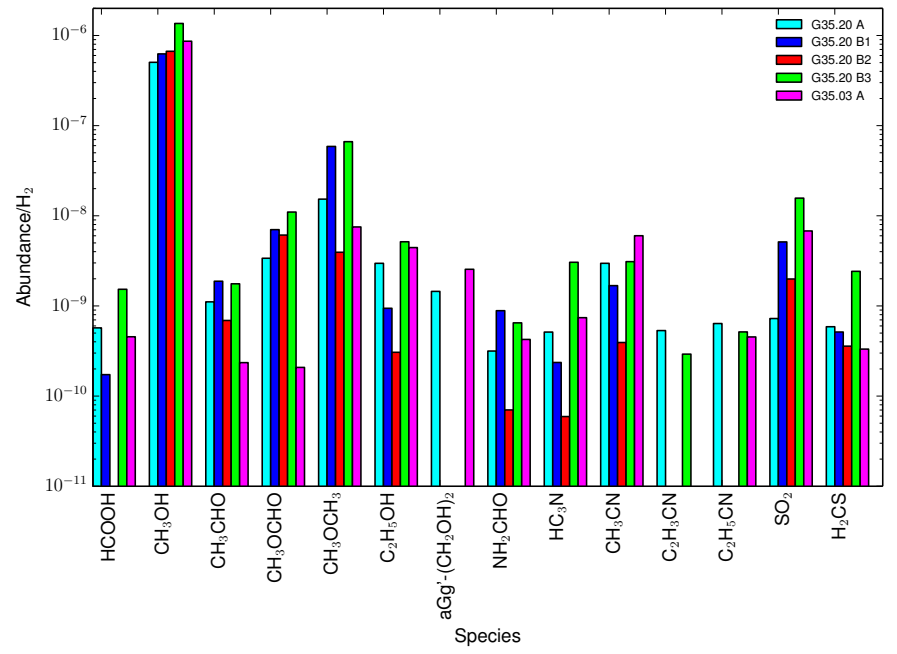

Fig. 7. Abundances vs. $\mathrm{H}_{2}$ as determined using the XCLASS software package for each of the sources modeled. All main isotope species modeled from more than one transition are shown. The column densities for vibrationally excited states were added to the $v=0$ state for $\mathrm{CH}_{3} \mathrm{OH}, \mathrm{CH}_{3} \mathrm{CHO}, \mathrm{CH}_{3} \mathrm{CN}$, and cyanoacetylene $\left(\mathrm{HC}_{3} \mathrm{~N}\right)$ to determine abundances. The $\mathrm{CN}$-bearing species in both plots clearly indicate the missing emission in $\mathrm{B} 1$ and $\mathrm{B} 2$ for vinyl cyanide $\left(\mathrm{C}_{2} \mathrm{H}_{3} \mathrm{CN}\right)$ and ethyl cyanide $\left(\mathrm{C}_{2} \mathrm{H}_{5} \mathrm{CN}\right)$ and reduced abundances in $\mathrm{B} 2$ for $\mathrm{CH}_{3} \mathrm{CN}$ and $\mathrm{HC}_{3} \mathrm{~N}$. We stress that as these species do not always trace the same gas, these abundances are lower limits.

to $\pm 1 \mathrm{~km} \mathrm{~s}^{-1}$ from the measured values so the transitions could easily be identified by the fitting algorithm. Source size, excitation temperature $\left(T_{\mathrm{ex}}\right)$, and column density $\left(N_{\mathrm{col}}\right)$ were allowed to vary widely to begin with and then were better constrained around the lowest $\chi^{2}$ fits per parameter per species. For species that were observed to be located only in the regions of the hot cores (mostly complex organic molecules), the source size was varied from $0.1-1.5^{\prime \prime}$ to be comparable with the observed emission extent and the $T_{\mathrm{ex}}$ was allowed to vary from $50-500 \mathrm{~K}$. The column density was allowed to vary from $10^{13}-10^{19} \mathrm{~cm}^{-2}$. For species that were observed to emit over a more extended region $\left(\mathrm{H}_{2} \mathrm{CS}\right.$ and $\left.\mathrm{SO}_{2}\right)$, the source size input range was varied between $1.0-3.5^{\prime \prime}$, the $T_{\mathrm{ex}}$ input range was $20-200 \mathrm{~K}$, and the column density input range was $10^{12}-10^{16} \mathrm{~cm}^{-2}$.

For a few species $\left(\mathrm{SiO}, \mathrm{H}^{13} \mathrm{CO}^{+}, \mathrm{C}^{17} \mathrm{O}, \mathrm{H}^{13} \mathrm{CN}\right.$, and $\left.\mathrm{C}^{34} \mathrm{~S}\right)$ only one transition was observed, so we kept the source size fixed at the measured extent of the emission at $3 \sigma$ and the excitation temperature fixed at $50 \mathrm{~K}$ and $100 \mathrm{~K}$ to determine the column densities at these two possible temperatures. The results for the single line transitions are given in Table 6.

Figure 7 presents a summary of the abundances observed per core as modeled via XCLASS. The excitation temperatures ranged from about 100-300 K generally with a few species outside this range. The $\mathrm{H}_{2}$ column densities used were based on the $870 \mu \mathrm{m}$ continuum emission (values shown in Table 1) as determined in Sect. 4.1 of Sánchez-Monge et al. (2014). These mass and column density estimates are lower limits as Sánchez-Monge et al. (2014) determined that in our observations we recover $30 \%$ of the flux compared to SCUBA $850 \mu \mathrm{m}$ observations. The modeled values for column density and excitation temperature were checked against rotational diagrams from Cassis and found to be in agreement. The column densities determined using Cassis are lower than those from XCLASS, but this is an effect of a less robust optical depth analysis and assuming the source size fills the beam. 
Uncertainties on excitation temperatures tend to be 10-20\%, but for some species the fit results are upper or lower limits. For entries that are not upper or lower limits, the range of errors is $1-160 \mathrm{~K}$ with an average temperature error of $40 \mathrm{~K}$ (or 37\%). Source size uncertainties are generally $0.1-0.3^{\prime \prime}$ with an average error of $0.2^{\prime \prime}$, but range from 0.01-1.0". Error ranges for column densities were typically less than 1 order of magnitude (with an average error of 0.7 orders of magnitude) with a range between 0.2 and 2.8 orders of magnitude. For species where only one transition is modeled uncertainties for the column densities of these species are up to two orders of magnitude. Table 4 shows the full list of detected species and isotopologues with the number of transitions detected in each core and indicates whether the listed species or isotopologue was modeled in XCLASS. The resulting synthetic spectra are shown together with the observed spectra in Appendix E and can be seen to be very good fits of the data. The results of the XCLASS analysis are summarized in Appendix D.

In the following subsections, we outline any special considerations used in modeling specific molecules. Section 3.4.1 outlines the treatment of most complex organic molecules and their isotopologues and excited states. Section 3.4.2 details the special treatment of the observed $\mathrm{HC}_{3} \mathrm{~N}$ emission. Section 3.4.3 explains the fitting methods for $\mathrm{SO}_{2}$ and $\mathrm{H}_{2} \mathrm{CS}$. Section 3.4.4 shows how simple molecules with only one transition are modeled. Section 3.4.5 summarizes how the few species not included in the XCLASS database are handled.

\subsubsection{Complex organic molecules}

We modeled 10 different species containing 6 or more atoms: methanol $\left(\mathrm{CH}_{3} \mathrm{OH}\right)$, ethanol $\left(\mathrm{C}_{2} \mathrm{H}_{5} \mathrm{OH}\right)$, methyl formate $\left(\mathrm{CH}_{3} \mathrm{OCHO}\right)$, acetaldehyde $\left(\mathrm{CH}_{3} \mathrm{CHO}\right)$, dimethyl ether $\left(\mathrm{CH}_{3} \mathrm{OCH}_{3}\right)$, formamide $\left(\mathrm{NH}_{2} \mathrm{CHO}\right)$, ethylene glycol $\left(\left(\mathrm{CH}_{2} \mathrm{OH}\right)_{2}\right)$, methyl cyanide $\left(\mathrm{CH}_{3} \mathrm{CN}\right)$, vinyl cyanide $\left(\mathrm{C}_{2} \mathrm{H}_{3} \mathrm{CN}\right)$, and ethyl cyanide $\left(\mathrm{C}_{2} \mathrm{H}_{5} \mathrm{CN}\right)$.

Several species with ${ }^{13} \mathrm{C}$ isotopologues were detected, along with many cases of deuteration. The ${ }^{18} \mathrm{O}$ isotopologue for methanol and formaldehyde were detected in all cores, but in no other species. This is due, in part, to limited laboratory data where the properties of these transitions have not yet been measured or calculated.

High energy transitions in our sources are observed to emit from a much smaller area than lower energy transitions (see Figs. 3 and 4) and many are not observed in B1 or B2. Because these vibrationally excited states emit from a smaller region, we assume that this emission originates from a denser and possibly hotter region and therefore, the continuum derived $\mathrm{H}_{2}$ column density is a lower limit. For this reason the column densities for these species cannot be easily converted to abundances, and cannot be precisely compared to their $v=0$ states. Nevertheless, noting their derived excitation temperatures and densities is useful in comparing the properties of the different regions of gas.

\subsubsection{Cyanoacetylene $\left(\mathrm{HC}_{3} \mathrm{~N}\right)$ and vibrational temperature}

Between 2 and 10 different states were detected in each source for this species, but with only a few transitions, so the isotopologues were coupled to the main isotopologue for each vibrational state and fixed at a ${ }^{12} \mathrm{C} /{ }^{13} \mathrm{C}$ isotope ratio of 50 . The $v=0$ state was modeled for all regions and the isotopologue $\mathrm{HC}^{13} \mathrm{CCN} v=0$ was coupled with $\mathrm{HC}_{3} \mathrm{~N} v=0$ to improve the uncertainty (from fitting one transition to fitting two). The fit for

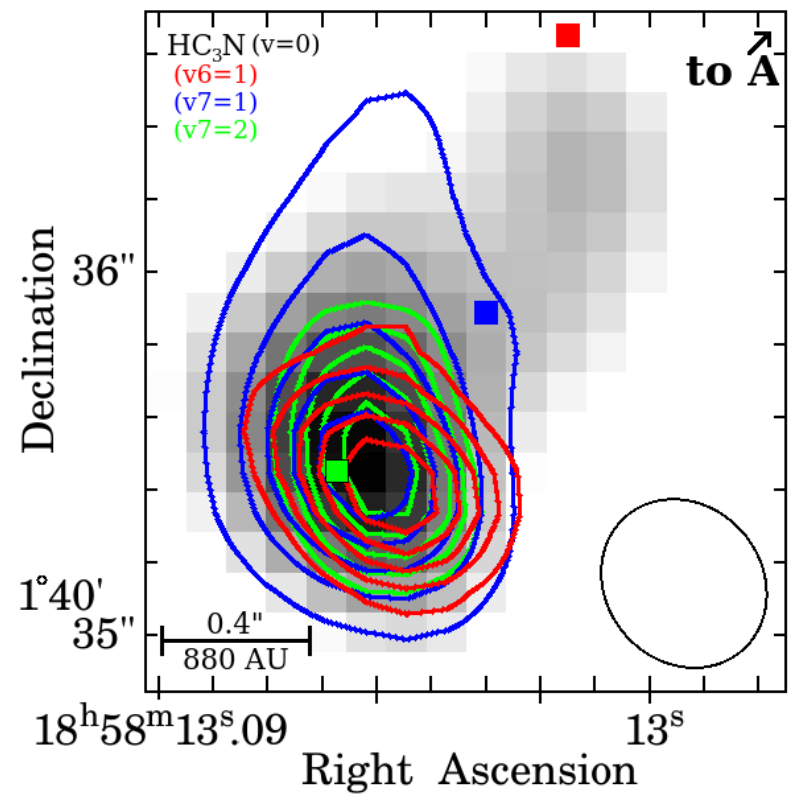

Fig. 8. Integrated intensity of $\mathrm{HC}_{3} \mathrm{~N} J=37-36$ emission is shown: $(v=0)$ (grayscale), $v_{7}=1$ (blue contours), $v_{6}=1$ (red contours), and $v_{7}=2$ (green contours). The green contours are 0.05, 0.069, 0.088, 0.106 , and $0.125 \mathrm{Jy} / \mathrm{beam} \mathrm{km} \mathrm{s}^{-1}$. Blue contours are $0.2,0.422,0.644$, 0.866 , and $1.088 \mathrm{Jy} / \mathrm{beam}_{\mathrm{km} \mathrm{s}}{ }^{-1}$. Red contours are $0.043,0.067,0.092$, 0.117 , and $0.141 \mathrm{Jy} / \mathrm{beam} \mathrm{km} \mathrm{s}^{-1}$. Sources B1, B2, and B3 are indicated with colored boxes as in Fig. 1 .

$\mathrm{HCC}^{13} \mathrm{CN} v=0$ was also coupled with $\mathrm{HC}_{3} \mathrm{~N} v=0$ for $\mathrm{B} 3$, as this is the only location where this species was detected.

Each of the vibrational states $\left(v_{6}=1, v_{7}=1, v_{7}=2\right)$ were modeled separately due to their differing spatial extent (Fig. 8) and the source size was observed to be more compact with higher excitation. No vibrationally excited states were modeled for B2, as they were not detected in the observations and only the $v_{7}=1$ state was modeled for $\mathrm{B} 1$ and $\mathrm{G} 35.03 . \mathrm{HC}_{3} \mathrm{~N} v_{6}=1$ was modeled for $\mathrm{A}$ and $\mathrm{B} 3$ and was coupled with $\mathrm{HCC}^{13} \mathrm{CN} v_{6}=1$ with the ${ }^{12} \mathrm{C} /{ }^{13} \mathrm{C}$ isotope ratio fixed at $50 . \mathrm{HC}_{3} \mathrm{~N} v_{7}=1$ was also modeled coupled with the three different ${ }^{13} \mathrm{C}$ isotopologues of $\mathrm{HC}_{3} \mathrm{~N} v_{7}=1$ for $\mathrm{A}$ and $\mathrm{B} 3$ with the isotope ratio fixed at 50 . $\mathrm{HC}_{3} \mathrm{~N} v_{7}=2$ was only modeled for $\mathrm{A}$ and $\mathrm{B} 3$ where the emission becomes very compact.

We determined vibrational temperatures from all of the observed $\mathrm{HC}_{3} \mathrm{~N}$ lines for each peak and found them to be in agreement with our RADEX and XCLASS results (see Table 5 and Fig. 9). The temperatures ranged from 120-210 K, which indicates that our assumption of LTE is reasonable, even where species are vibrationally excited. The vibrational temperature for peak B3 is smaller than the kinetic temperature, but is consistent within errors (see Table 5).

The ratio of intensities of $\mathrm{HC}_{3} \mathrm{~N} v_{7}$ and $v_{0}$ transitions indicates the proportion of vibrationally excited to ground-state molecules in the region (Wyrowski et al. 1999a). For G35.20 B1 and B2 this ratio is $\sim 0.15$ and for A and B3 it is $\sim 0.3$. Our sources are all similar to the other hot cores studied in Wyrowski et al. (1999a), where G35.20 A is similar to SgrB2N, $\mathrm{B} 1$ and $\mathrm{B} 2$ similar to Orion $\mathrm{KL}$ and $\mathrm{W} 3\left(\mathrm{H}_{2} \mathrm{O}\right)$, and $\mathrm{B} 3$ similar to G29.96-0.02. Vibrational temperature analysis for G35.03 A could not be completed as the only unblended $\mathrm{HC}_{3} \mathrm{~N}$ lines detected were from the vibrational state $v_{7}=1$. 
Table 5. Temperatures (vibrational, kinetic, and excitation) and column densities determined using different methods.

\begin{tabular}{cccccc}
\hline \hline Source & $\begin{array}{c}T_{\text {vib }} \\
(\mathrm{K})\end{array}$ & $\begin{array}{c}N_{\text {col }}(\mathrm{vib}) \\
\left(\mathrm{cm}^{-2}\right)\end{array}$ & $\begin{array}{c}T_{\text {kin }} \\
(\mathrm{K})\end{array}$ & $\begin{array}{c}T_{\text {ex }} \\
(\mathrm{K})\end{array}$ & $\begin{array}{c}N_{\text {col }}(\text { XCLASS }) \\
\left(\mathrm{cm}^{-2}\right)\end{array}$ \\
\hline G35.20 A & $210 \pm 80$ & $4_{-3}^{+11} \times 10^{15}$ & $285_{-135}^{+165}$ & 280 & $1.2 \times 10^{16}$ \\
G35.20 B1 & $160 \pm 20$ & $6.2_{-6.0}^{+340} \times 10^{14}$ & $160_{-40}^{+60}$ & 210 & $1.6 \times 10^{15}$ \\
G35.20 B2 & $120 \pm 60$ & $5_{-4}^{+27} \times 10^{14}$ & $120_{-30}^{+50}$ & 130 & $2 \times 10^{14}$ \\
G35.20 B3 & $160 \pm 20$ & $2.4_{-0.9}^{+1.4} \times 10^{15}$ & $300_{-125}^{+190}$ & 310 & $8.4 \times 10^{15}$ \\
G35.03 A & n/a & n/a & $275 \pm 175$ & 170 & $8.1 \times 10^{15}$ \\
\hline
\end{tabular}

Notes. Columns 2 and 3 list vibrational temperatures for $\mathrm{HC}_{3} \mathrm{~N}$ with corresponding column densities. Fluxes for ${ }^{13} \mathrm{C}$ isotopologues were multiplied by 50 to be comparable to Galactic isotope ratios. Columns 4 and 5 correspond to the kinetic temperatures (from RADEX) and the average excitation temperatures (from all XCLASS modeled $\mathrm{HC}_{3} \mathrm{~N}$ vibrational states) and Col. 6 is the total column density from the XCLASS fits.

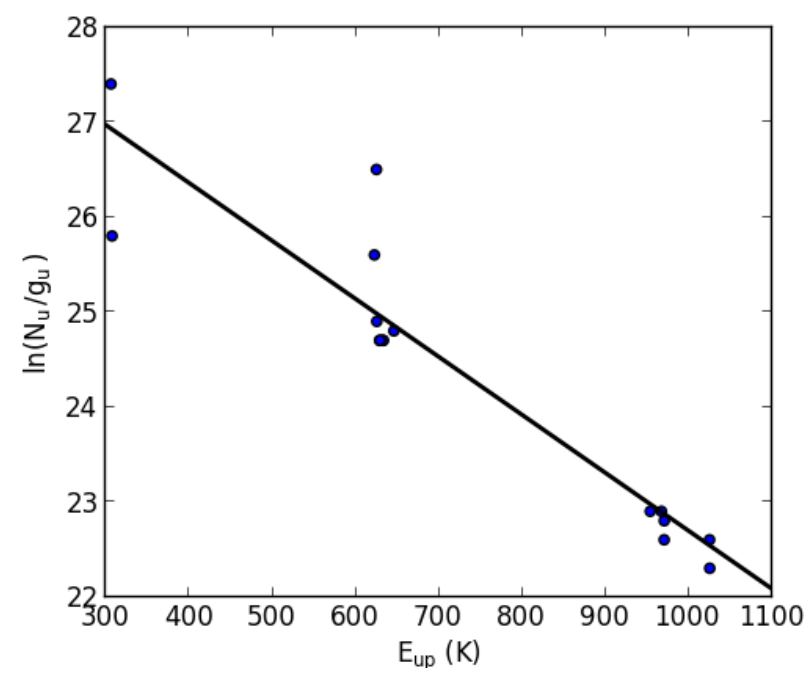

Fig. 9. Vibrational diagram for all of the $\mathrm{HC}_{3} \mathrm{~N}$ transitions from G35.20 B3 including ground and vibrationally excited states with $J=$ $37-36$ and $J=38-37$. Fluxes for ${ }^{13} \mathrm{C}$ isotopologues were multiplied by 50 to be comparable to Galactic isotope ratios. The vibrational temperature calculated for peak B3 is $160 \pm 20 \mathrm{~K}$

\subsubsection{Sulfur bearing molecules}

Sulfur bearing molecules $\mathrm{SO}_{2}$ and $\mathrm{H}_{2} \mathrm{CS}$ were modeled with their detected isotopologues coupled to the main isotopologue varying the isotope ratio. Sulfur isotope ratios in the ISM have been shown to be $15-35$ for ${ }^{32} S /{ }^{34} S$ and $4-9$ for ${ }^{34} S /{ }^{33} S$ (Chin et al. 1996). Solar isotope ratios are 22.6 for ${ }^{32} \mathrm{~S} /{ }^{34} \mathrm{~S}$ and 5.5 for ${ }^{34} \mathrm{~S} /{ }^{33} \mathrm{~S}$ (Anders \& Grevesse 1989). Our best-fit isotope ratio for ${ }^{32} \mathrm{SO}_{2} /{ }^{33} \mathrm{SO}_{2}$ was between 16 and 100 . The ratio of ${ }^{32} \mathrm{SO}_{2} /{ }^{33} \mathrm{SO}_{2}$ in space has been reported for Orion KL in Esplugues et al. (2013), with varying ratios for different parts of the region ranging from 5.8-125 reporting a ratio of 25 in the Orion hot core. The best-fit isotope ratio for our observations of ${ }^{32} \mathrm{SO}_{2} /{ }^{34} \mathrm{SO}_{2}$ was around 33. The main isotopologue fit of $\mathrm{H}_{2} \mathrm{CS}$ was made based on three transitions and was modeled with $\mathrm{H}_{2} \mathrm{C}^{34} \mathrm{~S}$ coupled (only the abundance ratio was varied). The best-fit isotopic ratio for $\mathrm{H}_{2} \mathrm{C}^{32} \mathrm{~S} / \mathrm{H}_{2} \mathrm{C}^{34} \mathrm{~S}$ was 11 , where the ratio reported for SgrB2 by Belloche et al. (2013) was 22 .

\subsubsection{Simple molecules}

For the following simple species (those with less than six atoms), only a single transition was observed, so to estimate their column densities, the source size and excitation temperatures were fixed. The temperatures were modeled at $50 \mathrm{~K}$ and $100 \mathrm{~K}$ for all but $\mathrm{C}^{17} \mathrm{O}$, which was modeled at $20 \mathrm{~K}$ and the source size was fixed at the measured extent of the $3 \sigma$ emission. Several species were previously demonstrated to have quite extended emission $\left(\mathrm{H}^{13} \mathrm{CO}^{+}, \mathrm{C}^{17} \mathrm{O}, \mathrm{SiO}\right)$ in Sánchez-Monge et al. (2014), Beltrán et al. (2014). A summary of the results for these species is given in Table 6.

- Formyl cation $\left(\mathrm{H}^{13} \mathrm{CO}^{+} 4-3\right)$ - only the emission component of this species was modeled. Extended emission shown in Sánchez-Monge et al. (2014), Beltrán et al. (2014).

- Carbon monoxide $\left(\mathrm{C}^{17} \mathrm{O} 3-2\right)$ - at the location of our pixel sources there was a lot of uncertainty in identifying of this line owing to severe line blending at this frequency. For G35.20 A this could not be modeled owing to line confusion. Extended emission indicates that this species is seen in the surrounding cloud, so a larger source size and a lower temperature were used.

- Heavy (Deuterated) water (HDO $3_{3,1}-4_{2,2}$ ) - this transition, along with all other deuterated species, was not clearly detected in G35.03, so HDO $3_{3,1}-4_{2,2}$ was not modeled there. For the other peaks, the emission was fairly extended and the best-fit source sizes were between 0.6" (at B2) and 1.5" (at B3).

\subsubsection{Species analyzed with Cassis}

Some species could not be modeled with XCLASS as they were not yet included in its database. These species were measured and analyzed with Cassis.

- Deuterated methanol $\left(\mathrm{CH}_{2} \mathrm{DOH}\right)$ - rotational diagrams were created using Cassis for all peaks in G35.20. The rotational temperatures ranged from $140-240 \mathrm{~K}$ and column densities were $0.6-5.0 \times 10^{16} \mathrm{~cm}^{-2}$. The $\mathrm{CH}_{3} \mathrm{OH} v=0$ rotational diagrams were made using Cassis to compare to these values to determine deuteration fraction.

- Vibrationally excited methyl formate $\left(\mathrm{CH}_{3} \mathrm{OCHO} v=1\right)$ rotational diagrams were made from all $\mathrm{CH}_{3} \mathrm{OCHO}$ transitions and the high energy $v=1$ transitions continued the trend of the rotational diagrams well. Therefore the reported rotational temperatures and column densities are those of all transitions for that peak.

- Doubly deuterated formaldehyde $\left(\mathrm{D}_{2} \mathrm{CO}\right)$ - this species was not modeled because only a single partially blended transition was detected.

\section{Discussion}

\subsection{Overall chemical composition}

Despite originating from different clouds, G35.03 and G35.20 have similar (within an order of magnitude) abundances of all modeled species except deuterated isotopologues (see Sect. 4.4). We find peak B3 shows the highest abundances within G35.20 B versus $\mathrm{H}_{2}$ of all species except for $\mathrm{NH}_{2} \mathrm{CHO}$ and $\mathrm{CH}_{3} \mathrm{CHO}$, for which peak $\mathrm{B} 1$ has the highest abundance and $\mathrm{H}_{2} \mathrm{CO}$, for which peak B2 has the highest abundance.

It is possible that comparing the column densities of various complex organic molecules to that of $\mathrm{H}_{2}$ is a less effective 
Table 6. Column densities $\left(\mathrm{cm}^{-2}\right)$ determined via XCLASS for species with single transition detections.

\begin{tabular}{|c|c|c|c|c|c|c|c|c|c|c|c|c|c|c|c|}
\hline \multirow[b]{2}{*}{ Species } & \multicolumn{3}{|c|}{$\mathrm{G} 35.20 \mathrm{~A}$} & \multicolumn{3}{|c|}{ G35.20 B1 } & \multicolumn{3}{|c|}{$\mathrm{G} 35.20 \mathrm{~B} 2$} & \multicolumn{3}{|c|}{$\mathrm{G} 35.20 \mathrm{~B} 3$} & \multicolumn{3}{|c|}{$\mathrm{G} 35.03 \mathrm{~A}$} \\
\hline & Size & $50 \mathrm{~K}$ & $100 \mathrm{~K}$ & Size & $50 \mathrm{~K}$ & $100 \mathrm{~K}$ & Size & $50 \mathrm{~K}$ & $100 \mathrm{~K}$ & Size & $50 \mathrm{~K}$ & $100 \mathrm{~K}$ & Size & $50 \mathrm{~K}$ & $100 \mathrm{~K}$ \\
\hline $\mathrm{HN}^{13} \mathrm{C}$ & 1.5 & $31 \times 10$ & $4.1 \times 10^{13}$ & 0.8 & $1.7 \times 10^{13}$ & $1.6 \times 10^{13}$ & & $1.6 \times 10^{13}$ & $1.6 \times 10^{13}$ & 1.5 & $1.1 \times 10^{14}$ & $1.2 \times 10^{14}$ & & & \\
\hline SO & 1.5 & $3.6 \times 10^{13}$ & & 1.4 & & & 1.2 & $3.7 \times 10^{16}$ & $1.7 \times 1$ & 1.2 & & & 1.3 & $4 \times 10^{17}$ & \\
\hline $\mathrm{H}^{13} \mathrm{CO}+$ & 1.5 & $1.6 \times 10^{13}$ & $5.3 \times 10^{12}$ & 0.8 & $8.3 \times 10^{12}$ & $8.2 \times 10^{12}$ & 1.0 & $3.1 \times 10^{13}$ & $3.1 \times 10^{13}$ & 1.5 & $6.5 \times 10^{12}$ & $2.8 \times 10^{13}$ & 1.5 & $1.7 \times 10^{13}$ & $2.1 \times 10^{13}$ \\
\hline $\mathrm{SiO}$ & 1.4 & $7.1 \times 10^{13}$ & $7.2 \times 10^{13}$ & 1.1 & $9.0 \times 10^{13}$ & $8.7 \times 10^{13}$ & 1.1 & $6.2 \times 10^{12}$ & $6.2 \times 10^{12}$ & 0.8 & $1.2 \times 10^{11}$ & $2.8 \times 10^{11}$ & 1.1 & $5.7 \times 10^{13}$ & $1.1 \times 10^{14}$ \\
\hline$C^{34} S$ & 1.7 & $2.8 \times 10^{15}$ & $1.2 \times 10^{15}$ & 1.2 & $3.4 \times 10^{14}$ & $2.9 \times 10^{14}$ & 1.0 & $4.6 \times 10^{14}$ & $3.5 \times 10^{14}$ & 1.1 & $5.3 \times 10^{14}$ & $6.8 \times 10^{14}$ & 1.5 & $8.1 \times 10^{14}$ & $7.1 \times 10^{14}$ \\
\hline $\mathrm{HNCO}$ & 1.3 & $2.3 \times 10^{16}$ & $7.5 \times 10^{16}$ & 1.0 & $1.2 \times 10^{16}$ & $6.9 \times 10^{15}$ & 1.0 & $2.2 \times 10^{15}$ & $9.4 \times 10^{14}$ & 1.1 & $2.3 \times 10^{16}$ & $8.4 \times 10^{15}$ & 1.1 & $1.8 \times 10^{16}$ & $7.7 \times 10^{15}$ \\
\hline $\mathrm{HDCO}$ & 1.5 & $1.6 \times 10^{15}$ & $2.6 \times 10^{13}$ & 1.2 & $4.5 \times 10^{14}$ & $1.0 \times 10^{15}$ & 1.0 & $1.7 \times 10^{14}$ & $2.6 \times 10^{14}$ & 1.5 & $1.6 \times 10^{15}$ & $1.5 \times 10^{15}$ & & N/A & \\
\hline HDO & 1.3 & $1.8 \times 10^{18}$ & $4.8 \times 10^{17}$ & 0.9 & $5.6 \times 10^{17}$ & $3.3 \times 10^{16}$ & 0.7 & $1.8 \times 10^{17}$ & $7.8 \times 10^{15}$ & 1.0 & $9.2 \times 10^{17}$ & $7.6 \times 10^{16}$ & & N/A & \\
\hline
\end{tabular}

Notes. Each peak was modeled with the excitation temperatures fixed at $50 \mathrm{~K}$ and $100 \mathrm{~K}$. The source sizes are the measured diameter of the $3 \sigma$ emission in arcseconds (").

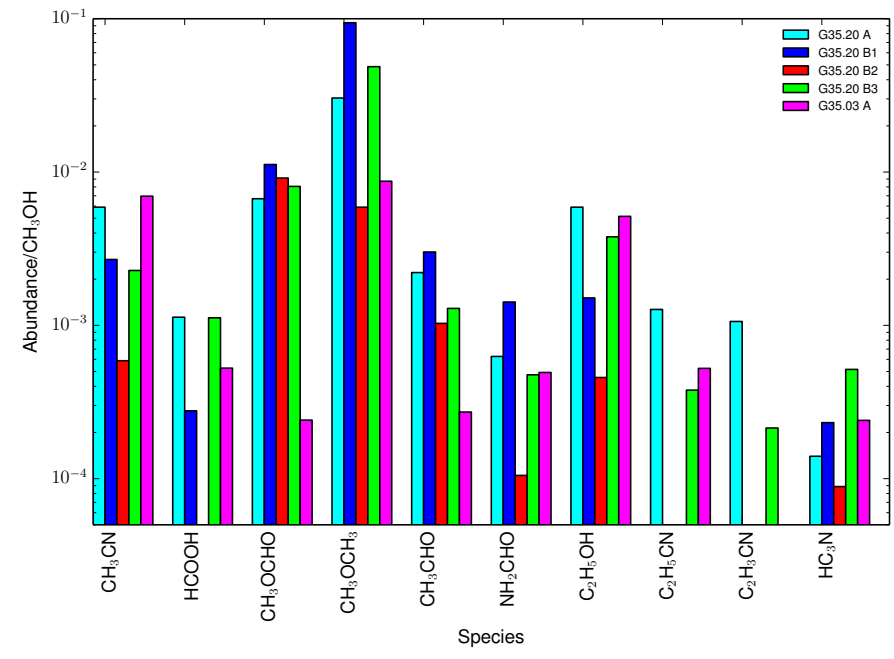

Fig. 10. Molecular abundances vs. $\mathrm{CH}_{3} \mathrm{OH}$ as determined using the XCLASS software package for each of the sources modeled. The column densities for vibrationally excited states were added to the $v=$ 0 state for $\mathrm{CH}_{3} \mathrm{OH}, \mathrm{CH}_{3} \mathrm{CHO}, \mathrm{CH}_{3} \mathrm{CN}$, and $\mathrm{HC}_{3} \mathrm{~N}$ to determine abundances.

method of comparing abundances between these sources. The value for $\mathrm{H}_{2}$ column density derived from the continuum (and therefore the dust) does not necessarily reflect the density of the warm dense gas where COMs are formed. Given the uncertainty of the $\mathrm{H}_{2}$ column densities, we also estimated the abundances of some molecules relative to $\mathrm{CH}_{3} \mathrm{OH}$, whose emission is less resolved than the continuum emission. Figure 10 shows the relative abundance for several species. This figure confirms the main result of Fig. 7 namely that abundances in B3 are higher than the other continuum peaks in G35.20 B except in $\mathrm{NH}_{2} \mathrm{CHO}$ and $\mathrm{CH}_{3} \mathrm{CHO}$. We thus conclude that $\mathrm{B} 3$ appears to be the most chemically rich of the three sources in G35.20 B. The ratio versus methanol for our sources are less than any of the different types of objects reviewed in Herbst \& van Dishoeck (2009). Comparing the ratio of $\mathrm{CH}_{3} \mathrm{CN}$ to $\mathrm{CH}_{3} \mathrm{OH}$ in our sources to those in Öberg et al. (2013), we see that to reach a similar ratio in NGC 7538 IRS9, the gas would be over 7000 AU from the center.

In Öberg et al. (2014), it is suggested that the ratio of abundances of $\mathrm{CH}_{3} \mathrm{CHO}+\mathrm{CH}_{3} \mathrm{OCHO}(\mathrm{X}-\mathrm{CHO})$ and $\mathrm{CH}_{3} \mathrm{OCH}_{3}+$ $\mathrm{C}_{2} \mathrm{H}_{5} \mathrm{OH}\left(\mathrm{X}-\mathrm{CH}_{3}\right)$ is related to the temperature and type of source. Laboratory experiments have shown that higher abundance of $\mathrm{CHO}$-bearing molecules indicates the importance of cold ice COM chemistry. If $\mathrm{X}-\mathrm{CHO} / \mathrm{X}-\mathrm{CH}_{3}$ is near 1 , then the source is a cooler, lower mass source and a ratio much less than 1 corresponds to a hotter and more massive source. In line with their observation, we also see a higher ratio of $\mathrm{X}-\mathrm{CHO} / \mathrm{X}-\mathrm{CH}_{3}$ at the coolest peak, G35.20 B2, where the ratio is 1.6, and low ratios at the hottest peaks, G35.20 A, B1, B3, and G35.03 A (0.25, $0.15,0.18$, and 0.04, respectively). From Fig. 1 in Öberg et al. (2014), peak G35.20 B2 could be a massive hot core, but it could also be low mass, whereas peaks G35.20 A, B1, B3, and G35.03 A definitely fall into the massive hot core regime, where warm ice chemistry becomes more important.

Our XCLASS model fits show higher or nearly equal column densities for several vibrationally excited states versus their ground states. The XCLASS analysis is satisfactory as long as the energy of the lines span a relatively small range, but a single temperature model is inadequate to fit lines with very different excitation energy. Because of the presence of temperature gradients in these sources, the ground state lines and vibrationally excited lines can be fitted with significantly different temperatures since they trace gas originating from smaller areas with equal or higher column densities.

\subsection{Chemical segregation in G35.20}

Sánchez-Monge et al. (2013) show evidence for a Keplerian disk in core B of G35.20. When analyzing the chemical structure of this core at continuum peaks B1, B2, and B3, we see a striking chemical difference within this disk, which argues against a simple axisymmetric disk scenario. Our data show clear evidence for chemical segregation of the G35.20 core on a scale of 100 s of AU. Nitrogen-bearing species, especially those containing the cyanide $(\mathrm{CN})$ group $\left(\mathrm{HC}_{3} \mathrm{~N}, \mathrm{C}_{2} \mathrm{H}_{5} \mathrm{CN}\right.$, etc.), are only observed in $\mathrm{A}$ and the southern part of B (peak B3) except for $\mathrm{CH}_{3} \mathrm{CN} v=0$, which appears in all four locations, although the abundance compared to $\mathrm{CH}_{3} \mathrm{OH}$ at $\mathrm{B} 3$ is four times that at $\mathrm{B} 2 ; \mathrm{HN}^{13} \mathrm{C}$, where the abundance versus $\mathrm{CH}_{3} \mathrm{OH}$ at $\mathrm{B} 3$ is six times more than at $\mathrm{B} 2$; and $\mathrm{HC}_{3} \mathrm{~N} v=0$, where the abundance compared to $\mathrm{CH}_{3} \mathrm{OH}$ at B3 is 7.5 times that at B2 (see Fig. 10). The linear scale for this separation of chemistry is less than $1000 \mathrm{AU}$, which is the smallest observed chemical separation in a star-forming region to date. Figures 8 and 11 show that cyanides $\left(\mathrm{HC}_{3} \mathrm{~N}, \mathrm{C}_{2} \mathrm{H}_{5} \mathrm{CN}\right.$, etc. $)$ are only observed toward $\mathrm{A}$ and the southern part of $\mathrm{B}$ with higher abundances at peak B3 and low abundances or missing emission toward B1 and B2.

There are three plausible scenarios to explain this chemical differentiation. First, core B could be a disk in the process of fragmenting on scales that are not well resolved in this dataset, where each of the fragments are developing their own chemistry. Second, there could also be two or three distinct sources within 

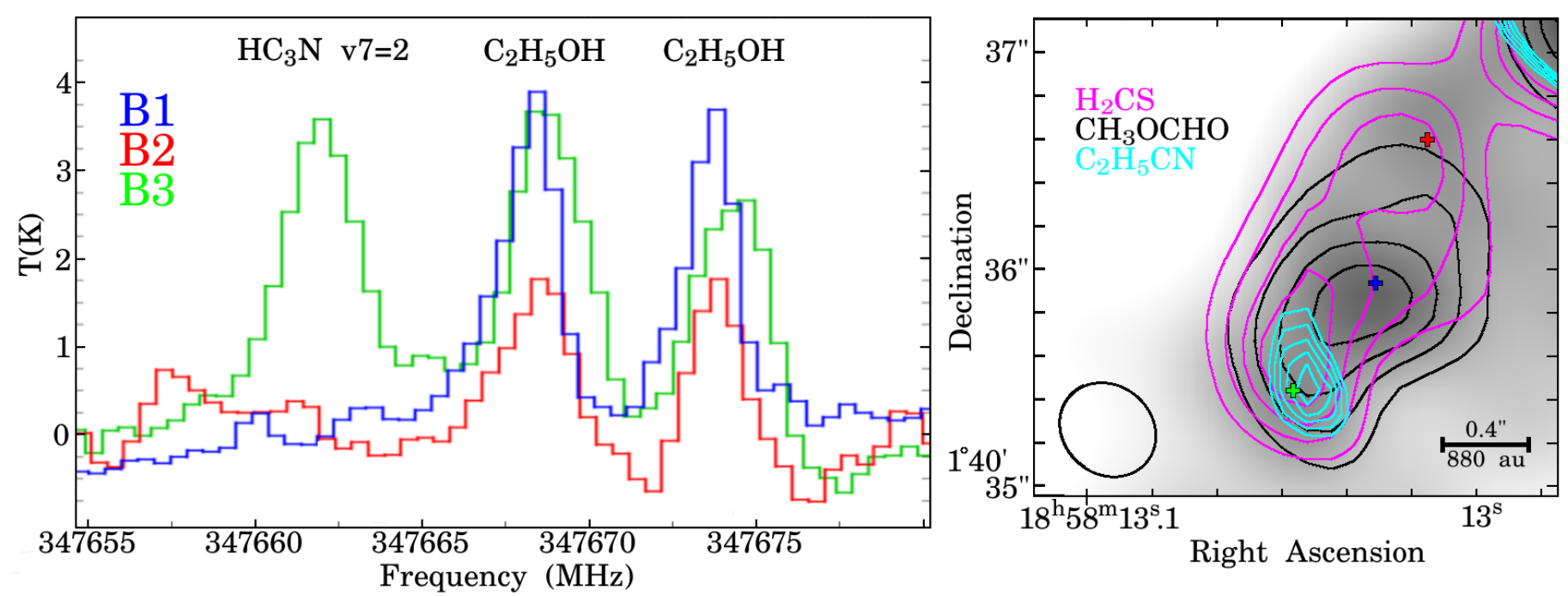

Fig. 11. G35.20 core B shows clear evidence for small-scale chemical segregation. On the left are spectra extracted from each continuum peak in core $\mathrm{B}$ (corresponding to the red, blue, and green crosses in the map to the right). It can clearly be seen in the spectra that the N-bearing species $\left(\mathrm{HC}_{3} \mathrm{~N}\right)$ is only strong in $\mathrm{B} 3$, where the O-bearing species $\left(\mathrm{C}_{2} \mathrm{H}_{5} \mathrm{OH}\right)$ is strong in all 3 regions. On the right, the integrated intensity contours of $\mathrm{H}_{2} \mathrm{CS} 10_{1,9}-9_{1,8}\left(0.55,0.94,1.34\right.$, and $1.73 \mathrm{Jy} /$ beam km s$\left.{ }^{-1}\right), \mathrm{CH}_{3} \mathrm{OCHO} 27_{9,18}-26_{9,17}\left(0.70,1.28,1.85\right.$, and $\left.2.43 \mathrm{Jy} / \mathrm{beam} \mathrm{km} \mathrm{s}^{-1}\right)$, and $\mathrm{C}_{2} \mathrm{H}_{5} \mathrm{CN}$ $40_{1,39}-39_{1,38}\left(0.085,0.100,0.115,0.130\right.$, and $\left.0.145 \mathrm{Jy} / \mathrm{beam} \mathrm{km} \mathrm{s}^{-1}\right)$ are shown overlaid on the continuum (grayscale) for core B of G35.20. While the $\mathrm{O}$ - and S-bearing organics are distributed across core $\mathrm{B}$, the $\mathrm{N}$-bearing species is only found toward the southwestern part.

core $\mathrm{B}$, each uniquely influencing the chemistry of their surroundings, which could be due to evolutionary age and/or physical conditions. If the higher kinetic temperature of this region is driving the nitrogen enrichment, Crockett et al. (2015) showed that cyanides can also be made more easily in the hot gas phase than other COMs. If the age is a factor, then an age difference between sources would affect the chemistry of the surroundings. With enhanced abundances of almost all species, it is possible that B3 contains the hottest source in a multicore system sharing a circumcluster disk with sources at B1 and B2.

Third, G35.20B could be a disrupted disk, where it is possible that there are chemical changes within the rotation period of the disk, which is 9700-11 $100 \mathrm{yr}$ (based on the observed radial velocity $3.5-4 \mathrm{~km} \mathrm{~s}^{-1}$ and minimum linear diameter of $2500 \mathrm{AU}$ and assuming an edge-on circular orbit). This is quite a short period of time chemically, although warm-up chemical models like those seen in Crockett et al. (2015) show a sharp increase in abundance from $10^{-10}$ to $10^{-8}$ over about $5000 \mathrm{yr}$ for $\mathrm{CH}_{3} \mathrm{CN}$. Although $\mathrm{N}$-bearing species are limited to the east side of the disk, $\mathrm{N}$ - and O-bearing species formamide $\left(\mathrm{NH}_{2} \mathrm{CHO}\right)$ and isocyanic acid (HNCO) have a more extended range but show significantly reduced emission at B2 as seen in Fig. 12. These chemical relationships will be further investigated in a following paper using chemical models.

\subsection{HNCO and formamide co-spatial emission}

It has previously been proposed (Bisschop et al. 2007; Mendoza et al. (2014; López-Sepulcre et al. 2015) based on single dish observations that formamide $\left(\mathrm{NH}_{2} \mathrm{CHO}\right)$ forms through the hydrogenation of $\mathrm{HNCO}$ because there appears to be a constant abundance ratio across a large range of source luminosities and masses. Figure 12 shows that these two species have almost the same spatial extent in G35.20 B and their emission peaks are only $0.15^{\prime \prime}$ (or $\sim 300 \mathrm{AU}$ ) apart in G35.20 B. The separation is less than $0.11^{\prime \prime}$ (240 AU) in G35.20 A. The velocity intervals spanned by the line peak velocities in each pixel differ by only $0.5-1 \mathrm{~km} \mathrm{~s}^{-1}$. Our modeled abundance values show
$\mathrm{N}(\mathrm{HNCO}) / \mathrm{N}\left(\mathrm{NH}_{2} \mathrm{CHO}\right)$ is between 2 and 8 for $\mathrm{HNCO}$ at $50 \mathrm{~K}$ and between 1 and 10 for HNCO modeled at $100 \mathrm{~K}$.

In G35.03, the HNCO and formamide emissions have a separation of less than $0.11^{\prime \prime}(255 \mathrm{AU})$, with the velocity peak differences between 0.5 and $1.0 \mathrm{~km} \mathrm{~s}^{-1}$. The striking physical connection between these two species makes a strong case for the formation of formamide predominantly through the hydrogenation of HNCO. Coutens et al. (2016) has also recently observed co-spatial emission in HNCO and formamide in the low-mass protobinary system IRAS 16293.

\subsection{Deuteration}

We detect seven deuterated species in G35.20, four of which we detect with only one or two observed transitions. We determined the deuterium fractionation of the other three, i.e., $\mathrm{CH}_{2} \mathrm{DCN}, \mathrm{CH}_{2} \mathrm{DOH}$, and $\mathrm{CH}_{3} \mathrm{CHDCN}$, using rotation diagrams in Cassis for consistency because $\mathrm{CH}_{2} \mathrm{DOH}$ was not in the XCLASS database. From these rotation diagrams, we calculated the $\mathrm{D} / \mathrm{H}$ values based on the best-fit column densities obtained using the opacity function in Cassis. Relatively little has previously been written about the $\mathrm{D} / \mathrm{H}$ ratio in methyl cyanide $\left(\mathrm{CH}_{3} \mathrm{CN}\right)$. In its place of first discovery, Orion KL, the $\mathrm{D} / \mathrm{H}$ ratio is $0.4-0.9 \%$ (Gerin et al. 1992). In a recent paper by Belloche et al. (2016), $\mathrm{CH}_{2} \mathrm{DCN}$ was detected in Sgr B2 with a $\mathrm{D} / \mathrm{H}$ of $0.4 \%$. A $\mathrm{D} / \mathrm{H}$ for methyl cyanide of $1.3 \%$ was also reported in Taquet et al. (2014) in low-mass protostar IRAS 16293-2422. Our values for G35.20 are significantly higher and the varying deuterium fractionation across core $\mathrm{B}$ is quite pronounced for this species. The $\mathrm{D} / \mathrm{H}$ range in methyl cyanide for each continuum peak is $1-11 \%$ at $\mathrm{A}, 0.3-6 \%$ at $\mathrm{B} 1$, and $7-21 \%$ at B3. Only one unblended transition of $\mathrm{CH}_{2} \mathrm{DCN}$ was detected at continuum peak $\mathrm{B} 2$, so the $\mathrm{D} / \mathrm{H}$ could not be determined. The $\mathrm{D} / \mathrm{H}$ percentages for methyl cyanide determined using the XCLASS fits were $10 \%$ at A, $0.4 \%$ at B1, and $15 \%$ at B3, which fall within the ranges determined using Cassis. We are therefore justified in using Cassis to determine $\mathrm{D} / \mathrm{H}$ for methanol. 


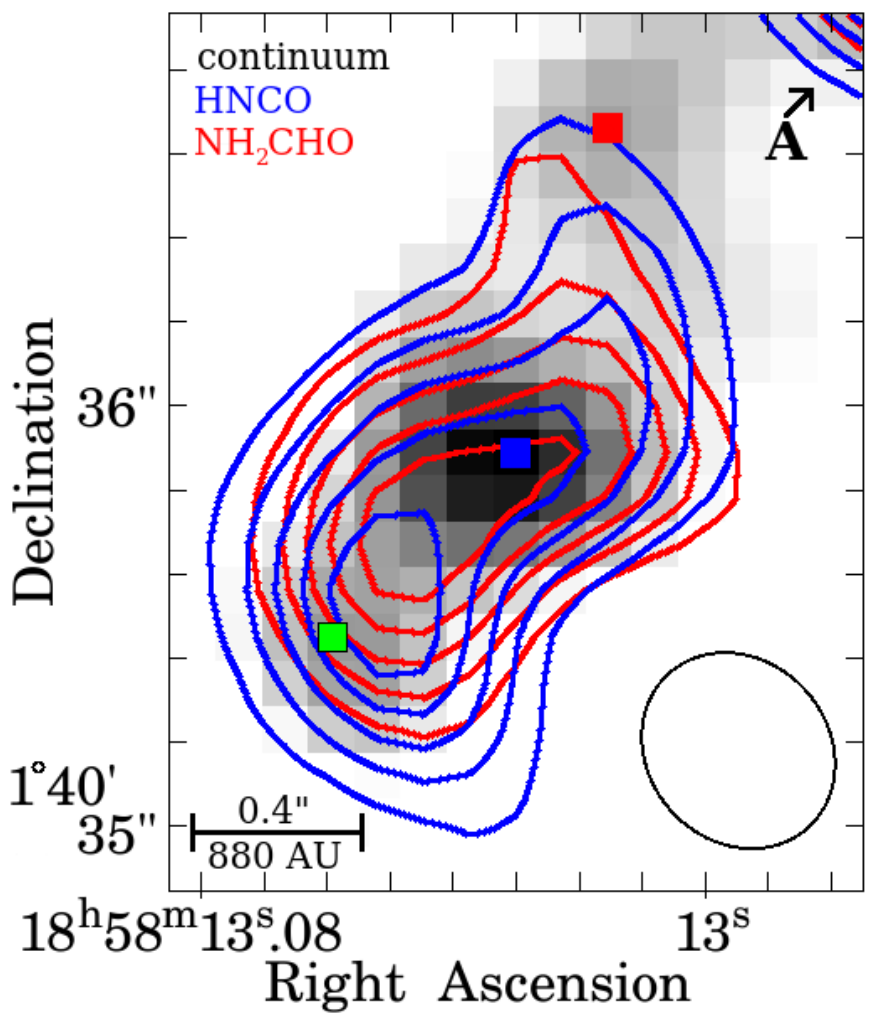

Fig. 12. Formamide $16_{2,15}-15_{2,14}$ (red contours) and HNCO $16_{1,16^{-}}$ $15_{1,15}$ (blue contours) emissions are shown overlaid on the dust continuum (grayscale) for core $\mathrm{B}$. These $\mathrm{N}$ - and O-bearing species are present in $\mathrm{B} 3$ and $\mathrm{B} 1$, but $\mathrm{B} 2$ is just outside the outermost contour (indicating $1 \sigma$ ). The red contours are $0.20,0.33,0.47,0.61$, and $0.74 \mathrm{Jy} / \mathrm{beam} \mathrm{km} \mathrm{s}^{-1}$ and the blue contours are $0.40,0.75,1.10,1.45$, and $1.80 \mathrm{Jy} / \mathrm{beam} \mathrm{km} \mathrm{s}^{-1}$. B1, B2, and B3 are denoted with colored boxes as in Fig. 1.

Table 7. Deuterium fractionation percentages (\%) at continuum peaks in G35.20 as calculated using Cassis.

\begin{tabular}{cccc}
\hline \hline \multirow{2}{*}{ Source } & CH2DCN & $\frac{\mathrm{CH} 2 \mathrm{DOH}}{\mathrm{CH} 3 \mathrm{CN}}$ & $\mathrm{CH} 3 \mathrm{CH}$ CHDCN \\
& $\mathrm{CH} 3 \mathrm{CH} 2 \mathrm{CN}$ \\
\hline $\mathrm{A}$ & $6 \pm 5$ & $4_{-2}^{+4}$ & $13_{-10}^{+13}$ \\
$\mathrm{~B} 1$ & $3_{-2.7}^{+3}$ & $4_{-2}^{+3}$ & $\times$ \\
$\mathrm{B} 2$ & $\times$ & $5_{-2}^{+3}$ & $\times$ \\
$\mathrm{B} 3$ & $12_{-5}^{+9}$ & $6_{-3}^{+4}$ & $\times$ \\
\hline
\end{tabular}

Notes. Deuterated ethyl cyanide is only detected at peak A and determining deuterium fractionation for methyl cyanide was not possible for B2.

Deuteration in methanol has been more widely studied. In low-mass star-forming regions the $\mathrm{CH}_{2} \mathrm{DOH} / \mathrm{CH}_{3} \mathrm{OH}$ abundance fraction has been observed to be about 37\% (Parise et al. 2002) in IRAS 16293, and in prestellar core L1544 it was close to $10 \%$ (Bizzocchi et al. 2014). For G35.20, the D/H ratio was 3-9\% at peaks B1 and B2, 4-12\% at B3, and $7-17 \%$ at A. These values are very similar across core B, although they are slightly enhanced at B3. It is possible that because the methanol emission is more extended, it is more homogeneous. The extra few percent at B3 could be linked to the high temperature and the possibility that this region has heated up recently allowing any deuterium enhancement on the grain surfaces to be released in the gas phase.

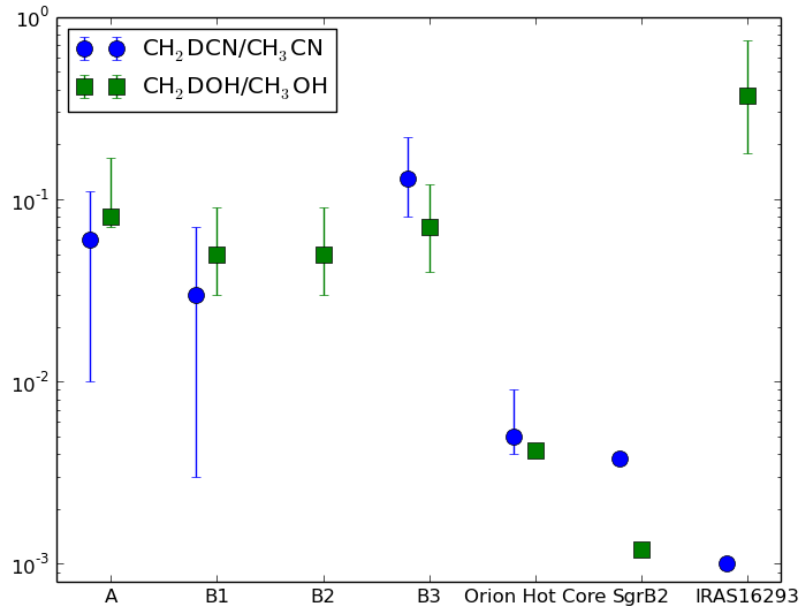

Fig. 13. D/H fractions for the four continuum peaks in $\mathrm{G} 35.20 \mathrm{com}-$ pared to the Orion hot core (HC), Sgr B2, and IRAS 16293-2422. The deuterium fractionation in G35.20 is higher than that of other high-mass star-forming regions in Orion and the Galactic center, but lower (for methanol) than in the low-mass star-forming region IRAS 16293. The methyl cyanide D/H value for IRAS 16293 is from an unpublished analysis reported in Taquet et al. (2014).

Deuterated ethyl cyanide was detected at A with five unblended transitions, eight partially blended transitions, and two identifiable blended transitions. The errors are larger for this species owing to the line blending, but the $\mathrm{D} / \mathrm{H}$ value for ethyl cyanide using Cassis was found to be between 3 and $26 \%$ with a best-fit value of $12 \%$ and the $\mathrm{D} / \mathrm{H}$ from the XCLASS fit is $19 \%$. A summary of these results is shown in Table 7 and Fig. 13.

In contrast, there is almost no sign of deuteration in G35.03. The presence of $\mathrm{CH}_{2} \mathrm{DOH}$ is shown through a single line with a brightness temperature of less than $1 \mathrm{~K}$, and HDO is not clearly present as it is either blended with other transitions or offset from $v_{\text {LSR }}$ by more than $3 \mathrm{~km} \mathrm{~s}^{-1}$. HDCO may be present, but is blended with other lines. Our RADEX analysis indicates that the kinetic temperature of the gas around peaks B3 and G35.03 is over $300 \mathrm{~K}$, so the deuterium fraction is unlikely to be tied to the kinetic temperature in these hot cores. From our results there is no clear trend with either mass or temperature and deuterium fraction.

A high fraction of deuterium can indicate that an object is very young $\left(<10^{5} \mathrm{yr}\right)$ as deuterated species are formed in cold environments where $\mathrm{CO}$ has been depleted onto dust grains (Millar et al. 1989). Once CO returns to the gas phase, deuterated species are destroyed, so a high deuterium fraction indicates that $\mathrm{CO}$ has only sublimated recently. We conclude that B3 is a much younger region than the hot core in G35.03, and in the case of multiple sources within the disk of core $\mathrm{B}$, sublimation of $\mathrm{CO}$ from ice grains has happened at different times or rates across the core.

\subsection{Comparison to other hot cores}

The hot core and compact ridge in Orion KL (separation $\sim 5000 \mathrm{AU}$ ) show a chemical difference between N-bearing and O-bearing species. In Caselli et al. (1993), the authors use a time-dependent model to explain the chemistry of both regions. In this model, shells at different distances were collapsing toward the nearby object IRc2, but when accretion stopped the regions heated up and the grain mantles sublimated showing different chemistry. The model does not perfectly replicate the Orion KL region, but is still a reasonable explanation. In G35.20, 
there is no clear nearby accreting (or formerly accreting) object that could have caused this same scenario.

The chemical differentiation between $\mathrm{W} 3(\mathrm{OH})$ and $\mathrm{W} 3\left(\mathrm{H}_{2} \mathrm{O}\right)$ (Wyrowski et al. 1999b) shows that the latter is a strong $\mathrm{N}$-bearing source with various complex organics, but the former only contains a handful of O-bearing species (both contain $\mathrm{CH}_{3} \mathrm{CN}$ ). In Qin et al. (2016), they conclude that this region is undergoing global collapse, but $\mathrm{W} 3(\mathrm{OH})$ contains an expanding $\mathrm{HII}$ region, whereas $\mathrm{W} 3\left(\mathrm{H}_{2} \mathrm{O}\right)$ contains a young stellar object that is accreting material but also has an outflow. This is similar to G35.20, but on a larger scale; the separation between these two sources is $\sim 7000$ AU.

Jiménez-Serra et al. (2012) observed that AFGL2591 has a hole in the methanol emission (diameter $~ 3000 \mathrm{AU}$ ), which is explained using concentric shells where methanol is mainly in a cooler outer shell and S- and N-bearing chemistry are driven by molecular UV photodissociation and high-temperature gasphase chemistry within the inner shell where the extinction is lower. This differs from G35.20 because the hot N-bearing regions are toward the outer edges of the emission with $\mathrm{O}$ - and S-bearing species found between.

Of the three regions where chemical differentiation has been observed, G35.20 core B is most similar to $\mathrm{W} 3(\mathrm{OH})$ and $\mathrm{W} 3\left(\mathrm{H}_{2} \mathrm{O}\right)$. Chemical differences would reasonably be seen if core $\mathrm{B}$ contains multiple objects at different evolutionary stages.

\section{Conclusions}

This work describes the chemical composition of G35.20-0.74N and $\mathrm{G} 35.03+0.35$, while providing a template for future chemical study of hot cores in this wavelength regime. Chemical segregation in high-mass star-forming regions is observed on a small scale $(<1000 \mathrm{AU})$ showing that the high spatial resolution capabilities of ALMA are needed to determine whether such segregation is common. Further observations are needed to determine whether core B in G35.20-0.74N contains a single or multiple sources. While the $\mathrm{CH}_{3} \mathrm{CN}$ emission points to Keplerian rotation (Sánchez-Monge et al. 2013), the continuum implies several protostars and the chemical variation across the proposed disk indicates a complicated source unlike simpler low-mass disks. Both of the regions studied showed co-spatial emission from $\mathrm{HNCO}$ and $\mathrm{NH}_{2} \mathrm{CHO}$ indicating a chemical link. Various deuterated species were detected at G35.20 peak B3 indicating a very young region. In contrast, G35.03 A shows no obvious deuteration.

Higher spatial resolution ALMA observations of this object are planned. This will allow us to better resolve the emission from core A and better determine the nature of the velocity gradient there. In addition it may allow us to better determine the origin of the chemical segregation in core B.

The XCLASS software package has a routine that carries out LTE analysis of each point in a map to demonstrate temperature and density differences pixel by pixel. Follow up work will be performed with this LTE analysis and non-LTE map analysis will be carried out with RADEX.

Time-dependent chemical modeling will help to determine if age is a significant factor in the presence of chemical segregation in star-forming regions. A physical chemical model can also help understand the nature of hot cores.

Acknowledgements. We would like to show our gratitude to the late Malcolm Walmsley, who acted as referee for this paper. His careful reading and numerous insightful comments have shaped this work into its complete form. This paper makes use of the following ALMA data: ADS/JAO.ALMA 2011.0.00275.S.
ALMA is a partnership of ESO (representing its member states), NSF (USA) and NINS (Japan), together with NRC (Canada) and NSC and ASIAA (Taiwan), in cooperation with the Republic of Chile. The Joint ALMA Observatory is operated by ESO, AUI/NRAO, and NAOJ. This paper made use of information from the Red MSX Source survey database at http://rms.leeds.ac. uk/cgi-bin/public/RMS_DATABASE.cgi, which was constructed with support from the Science and Technology Facilities Council of the UK. Á.S.-M. is supported by Deutsche Forschungsgemeinschaft through grant SFB 956 (subproject A6).

\section{References}

Anders, E., \& Grevesse, N. 1989, Geochim. Cosmochim. Acta, 53, 197 Belloche, A., Menten, K. M., Comito, C., et al. 2008, A\&A, 482, 179

Belloche, A., Müller, H. S. P., Menten, K. M., Schilke, P., \& Comito, C. 2013, A\&A, 559, A47

Belloche, A., Müller, H. S. P., Garrod, R. T., \& Menten, K. M. 2016, A\&A, 587, A91

Beltrán, M. T., \& de Wit, W. J. 2016, A\&ARv, 24, 6

Beltrán, M. T., Codella, C., Viti, S., Neri, R., \& Cesaroni, R. 2009, ApJ, 690, L93

Beltrán, M. T., Sánchez-Monge, Á., Cesaroni, R., et al. 2014, A\&A, 571, A52

Bisschop, S. E., Jørgensen, J. K., van Dishoeck, E. F., \& de Wachter, E. B. M. 2007, A\&A, 465, 913

Bizzocchi, L., Caselli, P., Spezzano, S., \& Leonardo, E. 2014, A\&A, 569, A27

Bonnell, I. A., \& Smith, R. J. 2011, Computational Star Formation, Proc. Int. Astron. Union, IAU Symp., 270, 57

Brinch, C., \& Hogerheijde, M. R. 2010, A\&A, 523, A25

Caselli, P., Hasegawa, T. I., \& Herbst, E. 1993, ApJ, 408, 548

Cesaroni, R., Galli, D., Lodato, G., Walmsley, M., \& Zhang, Q. 2006, Nature, 444,703

Chin, Y.-N., Henkel, C., Whiteoak, J. B., Langer, N., \& Churchwell, E. B. 1996, A\&A, 305, 960

Coutens, A., Jørgensen, J. K., van der Wiel, M. H. D., et al. 2016, A\&A, 590, L6

Crockett, N. R., Bergin, E. A., Neill, J. L., et al. 2015, ApJ, 806, 239

Drozdovskaya, M. N., Walsh, C., Visser, R., Harsono, D., \& van Dishoeck, E. F. 2015, MNRAS, 451, 3836

Esplugues, G. B., Tercero, B., Cernicharo, J., et al. 2013, A\&A, 556, A143

Gerin, M., Combes, F., Wlodarczak, G., et al. 1992, A\&A, 259, L35

Green, S. 1986, ApJ, 309, 331

Herbst, E., \& van Dishoeck, E. F. 2009, ARA\&A, 47, 427

Hogerheijde, M. R., \& van der Tak, F. F. S. 2000, A\&A, 362, 697

Jiménez-Serra, I., Zhang, Q., Viti, S., Martín-Pintado, J., \& de Wit, W.-J. 2012, ApJ, 753, 34

Keto, E. 2007, ApJ, 666, 976

Kraus, S., Hofmann, K.-H., Menten, K. M., et al. 2010, Nature, 466, 339

Krumholz, M. R., Klein, R. I., McKee, C. F., Offner, S. S. R., \& Cunningham, A. J. 2009, Science, 323, 754

López-Sepulcre, A., Jaber, A. A., Mendoza, E., et al. 2015, MNRAS, 449, 2438

McKee, C. F., \& Tan, J. C. 2003, ApJ, 585, 850

Mendoza, E., Lefloch, B., López-Sepulcre, A., et al. 2014, MNRAS, 445, 151

Millar, T. J., Bennett, A., \& Herbst, E. 1989, ApJ, 340, 906

Möller, T., Endres, C., \& Schilke, P. 2017, A\&A, 598, A7

Müller, H. S. P., Schlöder, F., Stutzki, J., \& Winnewisser, G. 2005, J. Mol. Struct., 742,215

Öberg, K. I., Boamah, M. D., Fayolle, E. C., et al. 2013, ApJ, 771, 95

Öberg, K. I., Fayolle, E. C., Reiter, J. B., \& Cyganowski, C. 2014, Faraday Discussions, 168, 81

Parise, B., Ceccarelli, C., Tielens, A. G. G. M., et al. 2002, A\&A, 393, L49

Pickett, H. M., Poynter, R. L., Cohen, E. A., et al. 1998, J. Quant. Spectr. Rad. Transf., 60, 883

Qin, S.-L., Schilke, P., Wu, J., et al. 2016, MNRAS, 456, 2681

Sánchez-Monge, Á., Cesaroni, R., Beltrán, M. T., et al. 2013, A\&A, 552, L10

Sánchez-Monge, Á., Beltrán, M. T., Cesaroni, R., et al. 2014, A\&A, 569, A11

Schöier, F. L., van der Tak, F. F. S., van Dishoeck, E. F., \& Black, J. H. 2005, A\&A, 432, 369

Tan, J. C., Beltrán, M. T., Caselli, P., et al. 2014, Protostars and Planets VI, 149 Taquet, V., Charnley, S. B., \& Sipilä, O. 2014, ApJ, 791, 1

van der Tak, F. F. S., Black, J. H., Schöier, F. L., Jansen, D. J., \& van Dishoeck, E. F. 2007 , A\&A, 468, 627

Wang, K.-S., Bourke, T. L., Hogerheijde, M. R., et al. 2013, A\&A, 558, A69

Wu, Y. W., Sato, M., Reid, M. J., et al. 2014, A\&A, 566, A17

Wyrowski, F., Schilke, P., \& Walmsley, C. M. 1999a, A\&A, 341, 882

Wyrowski, F., Schilke, P., Walmsley, C. M., \& Menten, K. M. 1999b, ApJ, 514, L43

Zhang, B., Zheng, X. W., Reid, M. J., et al. 2009, ApJ, 693, 419

Zinnecker, H., \& Yorke, H. W. 2007, ARA\&A, 45, 481 


\section{Appendix A: Properties of detected lines}

Table A.1. Detected lines organized by frequency with species, upper energy level (K), and Einstein coefficients $\left(\mathrm{s}^{-1}\right)$ indicated.

\begin{tabular}{|c|c|c|c|}
\hline Species & Frequency (MHz) & $E_{\text {up }}(\mathrm{K})$ & $A_{i j}\left(\mathrm{~s}^{-1}\right)$ \\
\hline $\mathrm{CH}_{3} \mathrm{OH} v=0$ & 334970 & 166.0 & $3.42 \mathrm{E}-8$ \\
\hline $\mathrm{CH}_{3} \mathrm{CHO} v=0$ & 334980 & 359.9 & $1.28 \mathrm{E}-3$ \\
\hline $\mathrm{CH}_{3} \mathrm{OCHO} v=1$ & 335016 & 443.5 & $5.33 \mathrm{E}-4$ \\
\hline $\mathrm{aGg}^{\prime}\left(\mathrm{CH}_{2} \mathrm{OH}\right)_{2}$ & 335030 & 279.4 & $9.34 \mathrm{E}-4$ \\
\hline $\mathrm{HC}^{13} \mathrm{CCN} v=0$ & 335092 & 305.6 & $3.01 \mathrm{E}-3$ \\
\hline HDCO & 335097 & 56.2 & $1.04 \mathrm{E}-3$ \\
\hline CCCS & 335109 & 474.6 & $2.98 \mathrm{E}-3$ \\
\hline $\mathrm{HCC}^{13} \mathrm{CN} v=0$ & 335124 & 305.6 & $3.01 \mathrm{E}-3$ \\
\hline $\mathrm{CH}_{3} \mathrm{OH} v=0$ & 335134 & 44.7 & $2.69 \mathrm{E}-5$ \\
\hline $\mathrm{CH}_{3} \mathrm{OCHO} v=0$ & 335145 & 94.9 & $1.39 \mathrm{E}-5$ \\
\hline $\mathrm{CH}_{3} \mathrm{OCHO} v=0$ & 335158 & 257.1 & $3.58 \mathrm{E}-4$ \\
\hline $\mathrm{H}_{2} \mathrm{C}^{33} \mathrm{~S}$ & 335160 & 101.7 & $5.53 \mathrm{E}-4$ \\
\hline $\mathrm{aGg}^{\prime}\left(\mathrm{CH}_{2} \mathrm{OH}\right)_{2}$ & 335180 & 316.7 & $8.51 \mathrm{E}-4$ \\
\hline $\mathrm{CH}_{3} \mathrm{OCHO} v=0$ & 335183 & 257.1 & $4.40 \mathrm{E}-5$ \\
\hline $\mathrm{t}-\mathrm{C}_{2} \mathrm{H}_{5} \mathrm{OH}$ & 335192 & 311.6 & $5.72 \mathrm{E}-5$ \\
\hline $\mathrm{CH}_{3} \mathrm{OCHO} v=0$ & 335208 & 281.6 & $3.89 \mathrm{E}-5$ \\
\hline $\mathrm{CH}_{3} \mathrm{OH} v=0$ & 335222 & 336.7 & $3.85 \mathrm{E}-8$ \\
\hline $\mathrm{CH}_{3} \mathrm{CHO} v=2$ & 335224 & 469.0 & $8.96 \mathrm{E}-4$ \\
\hline $\mathrm{CH}_{3} \mathrm{CHDCN}$ & 335229 & 332.8 & $3.00 \mathrm{E}-4$ \\
\hline $\mathrm{NH}_{2} \mathrm{CDO}$ & 335234 & 170.5 & $2.61 \mathrm{E}-3$ \\
\hline $\mathrm{CH}_{3} \mathrm{CHDCN}$ & 335237 & 332.8 & $3.20 \mathrm{E}-3$ \\
\hline $\mathrm{CH}_{3} \mathrm{CHDCN}$ & 335239 & 332.8 & $3.20 \mathrm{E}-3$ \\
\hline $\mathrm{CH}_{3} \mathrm{CHDCN}$ & 335246 & 332.8 & $3.00 \mathrm{E}-4$ \\
\hline $\mathrm{C}_{2} \mathrm{H}_{5} \mathrm{CN}$ & 335274 & 733.9 & $1.87 \mathrm{E}-4$ \\
\hline $\mathrm{CH}_{3} \mathrm{CHO} v=0$ & 335318 & 154.9 & $1.30 \mathrm{E}-3$ \\
\hline $\mathrm{aGg}^{\prime}\left(\mathrm{CH}_{2} \mathrm{OH}\right)_{2}$ & 335357 & 319.7 & $8.15 \mathrm{E}-4$ \\
\hline $\mathrm{CH}_{3} \mathrm{CHO} v=0$ & 335358 & 154.8 & $1.29 \mathrm{E}-3$ \\
\hline $\mathrm{CH}_{3} \mathrm{OH} v=0$ & 335363 & 112.7 & $8.78 \mathrm{E}-8$ \\
\hline $\mathrm{CH}_{3}^{13} \mathrm{CH}_{2} \mathrm{CN}$ & 335363 & 386.5 & $1.74 \mathrm{E}-4$ \\
\hline $\mathrm{CH}_{3}^{13} \mathrm{CH}_{2} \mathrm{CN}$ & 335369 & 325.9 & $3.13 \mathrm{E}-3$ \\
\hline $\mathrm{CH}_{3} \mathrm{CHO} v=1$ & 335382 & 361.5 & $1.31 \mathrm{E}-3$ \\
\hline $\mathrm{CH}_{3} \mathrm{OCHO} v=1$ & 335392 & 453.0 & $5.66 \mathrm{E}-3$ \\
\hline HDO & 335396 & 335.3 & $2.61 E-5$ \\
\hline $\mathrm{aGg}^{\prime}\left(\mathrm{CH}_{2} \mathrm{OH}\right)_{2}$ & 335397 & 316.7 & $8.53 \mathrm{E}-4$ \\
\hline $\mathrm{CH}_{3} \mathrm{OCHO} v=0$ & 335403 & 94.9 & $3.83 \mathrm{E}-5$ \\
\hline $\mathrm{NH}_{2}^{13} \mathrm{CHO}$ & 335403 & 149.1 & $2.74 \mathrm{E}-3$ \\
\hline $\mathrm{CH}_{3} \mathrm{CHDCN}$ & 335427 & 501.8 & $2.78 \mathrm{E}-3$ \\
\hline $\mathrm{CH}_{3} \mathrm{CHDCN}$ & 335430 & 476.0 & $2.84 \mathrm{E}-3$ \\
\hline $\mathrm{t}-\mathrm{C}_{2} \mathrm{H}_{5} \mathrm{OH}$ & 335441 & 293.6 & $2.17 \mathrm{E}-4$ \\
\hline $\mathrm{CH}_{3} \mathrm{OCHO} v=0$ & 335454 & 94.9 & $2.44 \mathrm{E}-5$ \\
\hline $\mathrm{CH}_{3} \mathrm{CHDCN}$ & 335511 & 330.0 & $3.18 \mathrm{E}-3$ \\
\hline $\mathrm{CH}_{3} \mathrm{CHDCN}$ & 335513 & 430.1 & $2.95 \mathrm{E}-3$ \\
\hline${ }^{13} \mathrm{CH} 3 \mathrm{OH}$ & 335560 & 192.7 & $4.04 \mathrm{E}-4$ \\
\hline $\mathrm{CH}_{3} \mathrm{OH} v=0$ & 335582 & 79.0 & $1.63 \mathrm{E}-4$ \\
\hline $\mathrm{t}-\mathrm{C}_{2} \mathrm{H}_{5} \mathrm{OH}$ & 335631 & 293.6 & $2.17 \mathrm{E}-4$ \\
\hline $\mathrm{aGg}^{\prime}\left(\mathrm{CH}_{2} \mathrm{OH}\right)_{2}$ & 335657 & 288.7 & $2.98 \mathrm{E}-4$ \\
\hline $\mathrm{CH}_{3} \mathrm{OH} v=0$ & 335702 & 1074.0 & $5.64 \mathrm{E}-5$ \\
\hline $\mathrm{aGg}^{\prime}\left(\mathrm{CH}_{2} \mathrm{OH}\right)_{2}$ & 335739 & 304.8 & $9.77 \mathrm{E}-4$ \\
\hline $\mathrm{H}^{13} \mathrm{CCCN} v_{7}=1$ & 335760 & 632.5 & $3.01 \mathrm{E}-3$ \\
\hline $\mathrm{CH}_{3}^{18} \mathrm{OH}$ & 335775 & 218.4 & $9.61 \mathrm{E}-4$ \\
\hline $\mathrm{CH}_{2}^{3} \mathrm{DOH}$ & 335796 & 381.1 & $3.98 \mathrm{E}-5$ \\
\hline $\mathrm{H}_{2} \mathrm{C}^{18} \mathrm{O}$ & 335815 & 60.2 & $1.05 \mathrm{E}-3$ \\
\hline
\end{tabular}

Notes. Most species are detected in all sources. Ethylene glycol $\left(\mathrm{aGg}^{\prime}\left(\mathrm{CH}_{2} \mathrm{OH}\right)_{2}\right)$ was only detected in $\mathrm{G} 35.20 \mathrm{~A}$ and $\mathrm{G} 35.03 \mathrm{~A}$ and deuterated ethyl cyanide $\left(\mathrm{CH}_{3} \mathrm{CHDCN}\right)$ was only detected in $\mathrm{G} 35.20 \mathrm{~A}$. For specific transitions see Appendix B.

Table A.1. continued.

\begin{tabular}{|c|c|c|c|}
\hline Species & Frequency $(\mathrm{MHz})$ & $E_{\text {up }}(\mathrm{K})$ & $A_{i j}\left(\mathrm{~s}^{-1}\right)$ \\
\hline $\mathrm{CH}_{3} \mathrm{OCHO} v=0$ & 335828 & 225.2 & $3.95 \mathrm{E}-5$ \\
\hline $\mathrm{CH}_{3} \mathrm{OCHO} v=0$ & 335839 & 225.2 & $6.97 \mathrm{E}-4$ \\
\hline $\mathrm{HC}^{13} \mathrm{CCN} v_{7}=1$ & 335883 & 622.2 & $3.01 \mathrm{E}-3$ \\
\hline $\mathrm{C}_{2} \mathrm{H}_{5} \mathrm{CN}$ & 335895 & 664.1 & $1.85 \mathrm{E}-4$ \\
\hline $\mathrm{CH}_{3} \mathrm{OCHO} v=0$ & 335900 & 277.8 & 2.69E-4 \\
\hline $\mathrm{aGg}^{\prime}\left(\mathrm{CH}_{2} \mathrm{OH}\right)_{2}$ & 335906 & 308.9 & 7.63E-4 \\
\hline $\mathrm{HCC} 13 \mathrm{CN}(v 6=1)$ & 335921 & 1009.6 & $3.02 \mathrm{E}-3$ \\
\hline $\mathrm{HCC}^{13} \mathrm{CN} v_{7}=1$ & 335930 & 624.7 & $3.01 \mathrm{E}-3$ \\
\hline $\mathrm{t}-\mathrm{C}_{2} \mathrm{H}_{5} \mathrm{OH}$ & 335950 & 87.9 & $1.61 \mathrm{E}-4$ \\
\hline $\mathrm{CH}_{3} \mathrm{OCHO} v=1$ & 335961 & 443.6 & $5.34 \mathrm{E}-4$ \\
\hline $\mathrm{CH}_{3} \mathrm{CHDCN}$ & 335989 & 478.7 & $1.75 \mathrm{E}-4$ \\
\hline $\mathrm{CH}_{2} \mathrm{DOH}$ & 335997 & 94.4 & $1.12 \mathrm{E}-4$ \\
\hline $\mathrm{aGg}^{\prime}\left(\mathrm{CH}_{2} \mathrm{OH}\right)_{2}$ & 336012 & 309.6 & 8.39E-4 \\
\hline $\mathrm{CH}_{3} \mathrm{CHO} v=2$ & 336025 & 535.3 & $1.31 \mathrm{E}-3$ \\
\hline $\mathrm{CH}_{3} \mathrm{OCHO} v=0$ & 336028 & 277.8 & $5.14 \mathrm{E}-4$ \\
\hline $\mathrm{g}-\mathrm{C}_{2} \mathrm{H}_{5} \mathrm{OH}$ & 336030 & 227.3 & $3.35 \mathrm{E}-4$ \\
\hline $\mathrm{CH}_{3} \mathrm{OCHO} v=0$ & 336032 & 277.8 & $5.39 \mathrm{E}-3$ \\
\hline $\mathrm{CH}_{3} \mathrm{OCHO} v=0$ & 336086 & 277.9 & $5.39 \mathrm{E}-3$ \\
\hline $\mathrm{SO}_{2}$ & 336089 & 276.0 & $2.67 \mathrm{E}-4$ \\
\hline $\mathrm{CH}_{3}^{18} \mathrm{OH}$ & 336100 & 35.1 & $1.83 \mathrm{E}-4$ \\
\hline $\mathrm{CH}_{3}^{3} \mathrm{OCHO} v=0$ & 336111 & 277.9 & $5.15 \mathrm{E}-4$ \\
\hline $\mathrm{NH}_{2} \mathrm{CHO} v=0$ & 336136 & 149.7 & $2.76 \mathrm{E}-3$ \\
\hline $\mathrm{t}-\mathrm{C}_{2} \mathrm{H}_{5} \mathrm{OH}$ & 336158 & 274.2 & $2.17 \mathrm{E}-4$ \\
\hline $\mathrm{NH}_{2} \mathrm{CHO} v=0$ & 336161 & 135.5 & $1.20 \mathrm{E}-4$ \\
\hline $\mathrm{CH}_{3} \mathrm{OCHO} v=0$ & 336219 & 277.9 & $2.70 \mathrm{E}-4$ \\
\hline $\mathrm{aGg}^{\prime}\left(\mathrm{CH}_{2} \mathrm{OH}\right)_{2}$ & 336223 & 304.7 & $7.84 \mathrm{E}-4$ \\
\hline $\mathrm{H}^{13} \mathrm{CCCN} v_{7}=1$ & 336227 & 632.9 & $3.02 \mathrm{E}-3$ \\
\hline $\mathrm{t}-\mathrm{C}_{2} \mathrm{H}_{5} \mathrm{OH}$ & 336270 & 274.2 & $2.17 \mathrm{E}-4$ \\
\hline $\mathrm{aGg}^{\prime}\left(\mathrm{CH}_{2} \mathrm{OH}\right)_{2}$ & 336323 & 288.4 & $9.23 \mathrm{E}-4$ \\
\hline $\mathrm{CH}_{2} \mathrm{DOH}$ & 336325 & 442.1 & $1.35 \mathrm{E}-4$ \\
\hline $\mathrm{aGg}^{\prime}\left(\mathrm{CH}_{2} \mathrm{OH}\right)_{2}$ & 336334 & 301.9 & $8.63 \mathrm{E}-4$ \\
\hline $\mathrm{CH}_{3} \mathrm{OCHO} v=0$ & 336351 & 249.4 & $5.49 \mathrm{E}-4$ \\
\hline $\mathrm{CH}_{3} \mathrm{OCHO} v=0$ & 336355 & 230.6 & $9.84 \mathrm{E}-3$ \\
\hline $\mathrm{CH}_{3} \mathrm{OCHO} v=0$ & 336368 & 249.4 & $5.49 \mathrm{E}-4$ \\
\hline $\mathrm{CH}_{3} \mathrm{OCHO} v=0$ & 336374 & 230.6 & $5.57 \mathrm{E}-4$ \\
\hline $\mathrm{HCC}^{13} \mathrm{CN} v_{7}=1$ & 336410 & 625.1 & $3.03 \mathrm{E}-3$ \\
\hline $\mathrm{CH}_{3} \mathrm{CHO} v=1$ & 336416 & 359.6 & $1.30 \mathrm{E}-3$ \\
\hline $\mathrm{CH}_{3} \mathrm{CHDCN}$ & 336425 & 361.4 & $3.13 \mathrm{E}-3$ \\
\hline $\mathrm{CH}_{3} \mathrm{OH} v=0$ & 336438 & 488.2 & $3.63 \mathrm{E}-5$ \\
\hline $\mathrm{CH}_{3} \mathrm{CHDCN}$ & 336453 & 361.4 & $3.13 \mathrm{E}-3$ \\
\hline $\mathrm{HC}_{3} \mathrm{~N}(v=0)$ & 336520 & 306.9 & $3.05 \mathrm{E}-3$ \\
\hline SO & 336553 & 142.9 & $6.25 \mathrm{E}-6$ \\
\hline $\mathrm{g}-\mathrm{C}_{2} \mathrm{H}_{5} \mathrm{OH}$ & 336572 & 232.3 & 3.37E-4 \\
\hline $\mathrm{CH}_{3} \mathrm{OH} v=2$ & 336606 & 747.4 & $1.63 \mathrm{E}-4$ \\
\hline $\mathrm{C}_{2} \mathrm{H}_{5} \mathrm{CN}$ & 336614 & 108.2 & $1.01 \mathrm{E}-4$ \\
\hline $\mathrm{t}-\mathrm{C}_{2} \mathrm{H}_{5} \mathrm{OH}$ & 336626 & 162.6 & $1.34 \mathrm{E}-4$ \\
\hline $\mathrm{SO}_{2}$ & 336670 & 245.1 & $5.84 \mathrm{E}-5$ \\
\hline $\mathrm{CH}_{3}^{18} \mathrm{OH}$ & 336743 & 100.9 & $1.50 \mathrm{E}-4$ \\
\hline $\mathrm{aGg}^{\prime}\left(\mathrm{CH}_{2} \mathrm{OH}\right)_{2}$ & 336756 & 316.7 & $9.45 \mathrm{E}-4$ \\
\hline $\mathrm{t}-\mathrm{C}_{2} \mathrm{H}_{5} \mathrm{OH}$ & 336767 & 255.7 & $2.16 \mathrm{E}-4$ \\
\hline $\mathrm{g}-\mathrm{C}_{2} \mathrm{H}_{5} \mathrm{OH}$ & 336795 & 228.0 & $3.42 \mathrm{E}-4$ \\
\hline $\mathrm{aGg}^{\prime}\left(\mathrm{CH}_{2} \mathrm{OH}\right)_{2}$ & 336828 & 266.3 & $8.95 \mathrm{E}-4$ \\
\hline $\mathrm{t}-\mathrm{C}_{2} \mathrm{H}_{5} \mathrm{OH}$ & 336832 & 255.7 & $2.16 \mathrm{E}-4$ \\
\hline $\mathrm{CH}_{3} \mathrm{OH} v=0$ & 336865 & 197.1 & $4.07 \mathrm{E}-4$ \\
\hline $\mathrm{CH}_{3} \mathrm{OCHO} v=0$ & 336889 & 235.5 & $5.53 \mathrm{E}-4$ \\
\hline $\mathrm{CH}_{3} \mathrm{OCHO} v=0$ & 336918 & 235.5 & $5.53 \mathrm{E}-4$ \\
\hline $\mathrm{aGg}^{\prime}\left(\mathrm{CH}_{2} \mathrm{OH}\right)_{2}$ & 336939 & 300.6 & $8.63 \mathrm{E}-4$ \\
\hline $\mathrm{CH}_{3} \mathrm{OH} v=2$ & 336970 & 1022.7 & $4.56 \mathrm{E}-5$ \\
\hline
\end{tabular}


Table A.1. continued.

\begin{tabular}{|c|c|c|c|}
\hline Species & Frequency $(\mathrm{MHz})$ & $E_{\text {up }}(\mathrm{K})$ & $A_{i j}\left(\mathrm{~s}^{-1}\right)$ \\
\hline$\overline{\mathrm{CH}}_{3} \mathrm{OH} v=2$ & 337022 & 971.8 & $1.36 \mathrm{E}-4$ \\
\hline $\mathrm{CH}_{3} \mathrm{OH} v=2$ & 337030 & 941.4 & $1.55 \mathrm{E}-4$ \\
\hline $\mathrm{C}_{2} \mathrm{H}_{3} \mathrm{CN}$ & 337040 & 309.7 & $3.19 \mathrm{E}-3$ \\
\hline $\mathrm{C}_{2} \mathrm{H}_{3} \mathrm{CN}$ & 337051 & 308.4 & $3.14 \mathrm{E}-3$ \\
\hline $\mathrm{C} 17 \mathrm{O}$ & 337060 & 32.0 & $2.32 \mathrm{E}-6$ \\
\hline $\mathrm{CH}_{3} \mathrm{OH} v=2$ & 337066 & 943.1 & $1.12 \mathrm{E}-4$ \\
\hline $\mathrm{HC}_{3} \mathrm{~N} v_{6}=1$ & 337070 & 1025.1 & $3.05 \mathrm{E}-3$ \\
\hline $\mathrm{CH}_{3} \mathrm{OH} v=2$ & 337079 & 901.5 & $8.38 \mathrm{E}-5$ \\
\hline $\mathrm{CH}_{3} \mathrm{CHO} v=2$ & 337082 & 526.1 & $1.26 \mathrm{E}-3$ \\
\hline $\mathrm{aGg}^{\prime}\left(\mathrm{CH}_{2} \mathrm{OH}\right)_{2}$ & 337082 & 309.1 & $5.46 \mathrm{E}-4$ \\
\hline $\mathrm{CH}_{3} \mathrm{OH} v=2$ & 337099 & 935.2 & $8.14 \mathrm{E}-5$ \\
\hline $\mathrm{CH}_{3} \mathrm{OH} v=2$ & 337114 & 855.8 & $1.65 \mathrm{E}-4$ \\
\hline $\mathrm{CH}_{3} \mathrm{OH} v=2$ & 337118 & 932.6 & $4.41 \mathrm{E}-5$ \\
\hline $\mathrm{H}_{2} \mathrm{C}^{34} \mathrm{~S}$ & 337125 & 89.1 & $5.77 \mathrm{E}-4$ \\
\hline $\mathrm{CH}_{3} \mathrm{OH} v=0$ & 337136 & 61.6 & $1.58 \mathrm{E}-5$ \\
\hline $\mathrm{CH}_{3} \mathrm{OH} v=2$ & 337159 & 755.0 & $4.54 \mathrm{E}-5$ \\
\hline $\mathrm{CH}_{3} \mathrm{OH} v=2$ & 337175 & 801.4 & $1.15 \mathrm{E}-4$ \\
\hline $\mathrm{CH}_{3} \mathrm{OH} v=2$ & 337186 & 791.1 & $1.68 \mathrm{E}-4$ \\
\hline $\mathrm{CH}_{3} \mathrm{OH} v=2$ & 337198 & 690.2 & $8.26 \mathrm{E}-5$ \\
\hline $\mathrm{CH}_{3} \mathrm{OH} v=2$ & 337252 & 722.8 & $1.39 \mathrm{E}-4$ \\
\hline $\mathrm{CH}_{3} \mathrm{OH} v=2$ & 337274 & 679.3 & $1.13 \mathrm{E}-4$ \\
\hline $\mathrm{CH}_{3} \mathrm{OH} v=2$ & 337279 & 701.8 & $1.54 \mathrm{E}-4$ \\
\hline $\mathrm{CH}_{3} \mathrm{OH} v=2$ & 337284 & 573.0 & $2.16 \mathrm{E}-4$ \\
\hline $\mathrm{CH}_{3} \mathrm{OH} v=1$ & 337297 & 390.0 & $1.65 \mathrm{E}-4$ \\
\hline $\mathrm{CH}_{3} \mathrm{OH} v=1$ & 337303 & 651.0 & $1.55 \mathrm{E}-4$ \\
\hline $\mathrm{CH}_{3} \mathrm{OH} v=2$ & 337312 & 588.9 & $1.65 \mathrm{E}-4$ \\
\hline $\mathrm{t}-\mathrm{C}_{2} \mathrm{H}_{5} \mathrm{OH}$ & 337323 & 238.0 & $2.15 \mathrm{E}-4$ \\
\hline $\mathrm{HC}_{3} \mathrm{~N} v_{6}=1$ & 337335 & 1025.3 & $3.06 \mathrm{E}-3$ \\
\hline $\mathrm{HC}_{3} \mathrm{~N} v_{7}=1$ & 337344 & 629.0 & $3.05 \mathrm{E}-3$ \\
\hline $\mathrm{C}_{2} \mathrm{H}_{5} \mathrm{CN}$ & 337347 & 322.4 & $3.23 \mathrm{E}-3$ \\
\hline $\mathrm{CH}_{2} \mathrm{DOH}$ & 337349 & 96.3 & $1.46 \mathrm{E}-4$ \\
\hline $\mathrm{C}^{34} \mathrm{~S}$ & 337400 & 64.8 & $8.04 \mathrm{E}-4$ \\
\hline $\mathrm{CH}_{3} \mathrm{OCH}_{3}$ & 337421 & 220.1 & $1.76 \mathrm{E}-4$ \\
\hline $\mathrm{t}-\mathrm{HCOOH}$ & 337429 & 386.6 & $2.80 \mathrm{E}-4$ \\
\hline $\mathrm{t}-\mathrm{HCOOH}$ & 337436 & 446.8 & $2.43 \mathrm{E}-4$ \\
\hline $\mathrm{t}-\mathrm{HCOOH}$ & 337444 & 332.8 & $3.13 \mathrm{E}-4$ \\
\hline $\mathrm{C}_{2} \mathrm{H}_{5} \mathrm{CN}$ & 337445 & 322.4 & $3.23 \mathrm{E}-3$ \\
\hline $\mathrm{H}_{2} \mathrm{C}^{34} \mathrm{~S}$ & 337460 & 299.8 & $4.86 \mathrm{E}-4$ \\
\hline $\mathrm{CH}_{3} \mathrm{OH} v=1$ & 337464 & 357.5 & $1.69 \mathrm{E}-4$ \\
\hline $\mathrm{CH}_{3} \mathrm{OH} v=1$ & 337473 & 908.0 & $3.6 \mathrm{E}-4$ \\
\hline $\mathrm{H}_{2} \mathrm{C}^{34} \mathrm{~S}$ & 337475 & 141.8 & $5.56 \mathrm{E}-4$ \\
\hline $\mathrm{CH}_{3} \mathrm{OCHO} v=0$ & 337490 & 267.1 & $5.34 \mathrm{E}-4$ \\
\hline $\mathrm{CH}_{3} \mathrm{OH} v=1$ & 337491 & 558.2 & $4.34 \mathrm{E}-5$ \\
\hline t-HCOOH & 337492 & 110.5 & $2.35 \mathrm{E}-3$ \\
\hline $\mathrm{CH}_{3} \mathrm{OCHO} v=0$ & 337504 & 267.1 & $5.34 \mathrm{E}-4$ \\
\hline $\mathrm{CH}_{3} \mathrm{OH} v=1$ & 337519 & 482.2 & $1.38 \mathrm{E}-4$ \\
\hline $\mathrm{CH}_{3} \mathrm{OH} v=1$ & 337546 & 485.4 & $8.13 \mathrm{E}-5$ \\
\hline $\mathrm{H}_{2} \mathrm{C}^{34} \mathrm{~S}$ & 337555 & 207.7 & $5.27 \mathrm{E}-4$ \\
\hline $\mathrm{H}_{2} \mathrm{C}^{34} \mathrm{~S}$ & 337559 & 207.7 & $5.27 \mathrm{E}-4$ \\
\hline $\mathrm{CH}_{3} \mathrm{OH} v=1$ & 337582 & 428.2 & $1.13 \mathrm{E}-4$ \\
\hline t-HCOOH & 337590 & 243.9 & $3.68 \mathrm{E}-4$ \\
\hline $\mathrm{CH}_{3} \mathrm{OH} v=1$ & 337605 & 429.4 & $1.56 \mathrm{E}-4$ \\
\hline $\mathrm{CH}_{3} \mathrm{OH} v=1$ & 337611 & 387.4 & $1.37 \mathrm{E}-4$ \\
\hline $\mathrm{CH}_{3} \mathrm{OH} v=1$ & 337626 & 363.5 & $1.55 \mathrm{E}-4$ \\
\hline $\mathrm{CH}_{3} \mathrm{OH} v=1$ & 337636 & 363.5 & $1.55 \mathrm{E}-4$ \\
\hline $\mathrm{CH}_{3} \mathrm{OH} v=1$ & 337642 & 356.3 & $1.65 \mathrm{E}-4$ \\
\hline $\mathrm{CH}_{3} \mathrm{OH} v=1$ & 337644 & 365.4 & $1.69 \mathrm{E}-4$ \\
\hline $\mathrm{CH}_{3} \mathrm{OH} v=1$ & 337646 & 470.2 & $1.14 \mathrm{E}-4$ \\
\hline $\mathrm{CH}_{3} \mathrm{OH} v=1$ & 337648 & 611.0 & $8.23 \mathrm{E}-5$ \\
\hline $\mathrm{CH}_{3} \mathrm{OH} v=1$ & 337655 & 460.9 & $1.38 \mathrm{E}-4$ \\
\hline
\end{tabular}

Table A.1. continued.

\begin{tabular}{|c|c|c|c|}
\hline Species & Frequency $(\mathrm{MHz})$ & $E_{\text {up }}(\mathrm{K})$ & $A_{i j}\left(\mathrm{~s}^{-1}\right)$ \\
\hline$\overline{\mathrm{CH}_{3} \mathrm{OH} v=1}$ & 337671 & 464.7 & $1.56 \mathrm{E}-4$ \\
\hline $\mathrm{CH}_{3} \mathrm{OH} v=1$ & 337685 & 545.9 & $1.14 \mathrm{E}-4$ \\
\hline $\mathrm{CH}_{3} \mathrm{OH} v=1$ & 337708 & 478.2 & $1.65 \mathrm{E}-4$ \\
\hline $\mathrm{CH}_{3} \mathrm{OCH}_{3}$ & 337712 & 48.0 & $7.22 \mathrm{E}-5$ \\
\hline $\mathrm{CH}_{3} \mathrm{OCH}_{3}$ & 337722 & 48.0 & $9.63 \mathrm{E}-5$ \\
\hline $\mathrm{t}-\mathrm{C}_{2} \mathrm{H}_{5} \mathrm{OH}$ & 337727 & 221.2 & $2.13 \mathrm{E}-4$ \\
\hline $\mathrm{CH}_{3} \mathrm{OCH}_{3}$ & 337731 & 48.0 & $1.94 \mathrm{E}-4$ \\
\hline $\mathrm{CH}_{3} \mathrm{OH} v=1$ & 337749 & 488.5 & $1.69 \mathrm{E}-4$ \\
\hline $\mathrm{CH}_{3} \mathrm{OCH}_{3}$ & 337770 & 48.0 & $1.22 \mathrm{E}-4$ \\
\hline $\mathrm{CH}_{3} \mathrm{OCH}_{3}$ & 337779 & 48.0 & $1.94 \mathrm{E}-4$ \\
\hline $\mathrm{CH}_{3} \mathrm{OCH}_{3}$ & 337787 & 48.0 & $1.94 \mathrm{E}-4$ \\
\hline $\mathrm{CH}_{3} \mathrm{OCH}_{3}$ & 337790 & 48.0 & $7.22 \mathrm{E}-5$ \\
\hline $\mathrm{g}-\mathrm{C}_{2} \mathrm{H}_{5} \mathrm{OH}$ & 337801 & 223.1 & $3.45 \mathrm{E}-4$ \\
\hline $\mathrm{aGg}^{\prime}\left(\mathrm{CH}_{2} \mathrm{OH}\right)_{2}$ & 337816 & 294.6 & $9.74 \mathrm{E}-4$ \\
\hline $\mathrm{HC}_{3} \mathrm{~N} v_{7}=1$ & 337825 & 629.0 & $3.07 \mathrm{E}-3$ \\
\hline $\mathrm{CH}_{3} \mathrm{OH} v=0$ & 337838 & 675.9 & $6.04 \mathrm{E}-5$ \\
\hline $\mathrm{CH}_{3} \mathrm{OH} v=2$ & 337878 & 747.7 & $1.65 \mathrm{E}-4$ \\
\hline $\mathrm{H}_{2} \mathrm{C}^{34} \mathrm{~S}$ & 337933 & 141.9 & $5.58 \mathrm{E}-4$ \\
\hline $\mathrm{CH}_{3}^{13} \mathrm{CH}_{2} \mathrm{CN}$ & 337951 & 332.2 & $3.21 \mathrm{E}-3$ \\
\hline $\mathrm{CH}_{3} \mathrm{OH} v=1$ & 337969 & 390.1 & $1.66 \mathrm{E}-4$ \\
\hline $\mathrm{CH}_{2} \mathrm{DOH}$ & 337977 & 202.5 & $5.47 \mathrm{E}-5$ \\
\hline $\mathrm{D}_{2} \mathrm{CO}$ & 338016 & 342.8 & $1.04 \mathrm{E}-6$ \\
\hline $\mathrm{H}_{2} \mathrm{CS}$ & 338083 & 102.4 & $5.77 \mathrm{E}-4$ \\
\hline $\mathrm{t}-\mathrm{C}_{2} \mathrm{H}_{5} \mathrm{OH}$ & 338099 & 205.2 & $2.11 \mathrm{E}-4$ \\
\hline $\mathrm{t}-\mathrm{C}_{2} \mathrm{H}_{5} \mathrm{OH}$ & 338110 & 205.2 & $2.11 \mathrm{E}-4$ \\
\hline $\mathrm{CH}_{3} \mathrm{OH} v=0$ & 338125 & 78.1 & $1.70 \mathrm{E}-4$ \\
\hline $\mathrm{C}_{2} \mathrm{H}_{5} \mathrm{CN}$ & 338142 & 316.8 & $3.27 \mathrm{E}-3$ \\
\hline $\mathrm{t}-\mathrm{HCOOH}$ & 338144 & 180.5 & $4.09 \mathrm{E}-4$ \\
\hline t-HCOOH & 338202 & 158.3 & $4.23 \mathrm{E}-4$ \\
\hline $\mathrm{C}_{2} \mathrm{H}_{3} \mathrm{CN}$ & 338214 & 312.1 & $3.23 \mathrm{E}-3$ \\
\hline $\mathrm{aGg}^{\prime}\left(\mathrm{CH}_{2} \mathrm{OH}\right)_{2}$ & 338214 & 313.4 & $9.40 \mathrm{E}-4$ \\
\hline $\mathrm{aGg}\left(\mathrm{CH}_{2} \mathrm{OH}\right)_{2}$ & 338221 & 292.7 & 8.05E-4 \\
\hline $\mathrm{aGg}^{\prime}\left(\mathrm{CH}_{2} \mathrm{OH}\right)_{2}$ & 338240 & 313.4 & $9.28 \mathrm{E}-4$ \\
\hline $\mathrm{t}-\mathrm{HCOOH}$ & 338249 & 180.5 & $4.09 \mathrm{E}-4$ \\
\hline $\mathrm{C}_{2} \mathrm{H}_{3} \mathrm{CN}$ & 338278 & 300.1 & $3.22 \mathrm{E}-3$ \\
\hline $\mathrm{SO}_{2}$ & 338306 & 196.8 & $3.27 \mathrm{E}-4$ \\
\hline${ }^{34} \mathrm{SO}_{2}$ & 338320 & 92.5 & $2.27 \mathrm{E}-4$ \\
\hline $\mathrm{CH}_{3} \mathrm{OCHO} v=0$ & 338338 & 267.2 & $5.92 \mathrm{E}-3$ \\
\hline $\mathrm{CH}_{3} \mathrm{OH} v=0$ & 338345 & 70.5 & $1.67 \mathrm{E}-4$ \\
\hline $\mathrm{CH}_{3} \mathrm{OCHO} v=0$ & 338356 & 267.2 & $5.39 \mathrm{E}-4$ \\
\hline $\mathrm{CH}_{3} \mathrm{OCHO} v=1$ & 338393 & 443.1 & $4.61 \mathrm{E}-3$ \\
\hline $\mathrm{CH}_{3} \mathrm{OCHO} v=0$ & 338396 & 257.7 & $5.50 \mathrm{E}-4$ \\
\hline $\mathrm{CH}_{3} \mathrm{OH} v=0$ & 338405 & 243.8 & $4.48 \mathrm{E}-5$ \\
\hline $\mathrm{CH}_{3} \mathrm{OH} v=0$ & 338409 & 65.0 & $1.70 \mathrm{E}-4$ \\
\hline $\mathrm{CH}_{3} \mathrm{OCHO} v=0$ & 338414 & 257.7 & $5.50 \mathrm{E}-4$ \\
\hline $\mathrm{CH}_{3} \mathrm{OH} v=0$ & 338431 & 253.9 & $4.51 \mathrm{E}-5$ \\
\hline $\mathrm{CH}_{3} \mathrm{OH} v=0$ & 338442 & 258.7 & $4.50 \mathrm{E}-5$ \\
\hline $\mathrm{C}_{2} \mathrm{H}_{3} \mathrm{CN}$ & 338448 & 312.0 & $3.24 \mathrm{E}-3$ \\
\hline $\mathrm{CH}_{3} \mathrm{OH} v=0$ & 338456 & 189.0 & $8.31 \mathrm{E}-5$ \\
\hline $\mathrm{CH}_{2} \mathrm{DOH}$ & 338463 & 120.0 & $5.87 \mathrm{E}-5$ \\
\hline $\mathrm{CH}_{3} \mathrm{OH} v=0$ & 338475 & 201.1 & $8.30 \mathrm{E}-5$ \\
\hline $\mathrm{CH}_{3} \mathrm{OH} v=0$ & 338486 & 202.9 & $8.35 \mathrm{E}-5$ \\
\hline $\mathrm{CH}_{3} \mathrm{OH} v=0$ & 338504 & 152.9 & $1.14 \mathrm{E}-4$ \\
\hline $\mathrm{CH}_{3} \mathrm{OH} v=0$ & 338512 & 145.3 & $1.15 \mathrm{E}-4$ \\
\hline $\mathrm{CH}_{3} \mathrm{OH} v=0$ & 338530 & 161.0 & $1.15 \mathrm{E}-4$ \\
\hline $\mathrm{CH}_{3} \mathrm{OH} v=0$ & 338541 & 114.8 & $1.39 \mathrm{E}-4$ \\
\hline $\mathrm{CH}_{3} \mathrm{OH} v=0$ & 338543 & 114.8 & $1.39 \mathrm{E}-4$ \\
\hline $\mathrm{CH}_{3} \mathrm{OH} v=0$ & 338560 & 127.7 & $1.40 \mathrm{E}-4$ \\
\hline $\mathrm{CH}_{3} \mathrm{OH} v=0$ & 338583 & 112.7 & $1.39 \mathrm{E}-4$ \\
\hline $\mathrm{SO}_{2}$ & 338612 & 198.9 & $2.87 \mathrm{E}-4$ \\
\hline
\end{tabular}


Table A.1. continued.

\begin{tabular}{|c|c|c|c|}
\hline Species & Frequency $(\mathrm{MHz})$ & $E_{\text {up }}(\mathrm{K})$ & $A_{i j}\left(\mathrm{~s}^{-1}\right)$ \\
\hline$\overline{\mathrm{CH}_{3} \mathrm{OH} v}=0$ & 338615 & 86.1 & $1.71 \mathrm{E}-4$ \\
\hline $\mathrm{CH}_{3} \mathrm{OH} v=0$ & 338640 & 102.7 & $1.57 \mathrm{E}-4$ \\
\hline $\mathrm{HC}_{3} \mathrm{~N} v_{7}=2$ & 338646 & 953.8 & $3.07 \mathrm{E}-3$ \\
\hline $\mathrm{t}-\mathrm{C}_{2} \mathrm{H}_{5} \mathrm{OH}$ & 338672 & 175.7 & $2.04 \mathrm{E}-4$ \\
\hline $\mathrm{t}-\mathrm{C}_{2} \mathrm{H}_{5} \mathrm{OH}$ & 338674 & 175.7 & $2.04 \mathrm{E}-4$ \\
\hline $\mathrm{CH}_{2} \mathrm{DOH}$ & 346924 & 521.6 & $1.30 \mathrm{E}-4$ \\
\hline $\mathrm{C}_{2} \mathrm{H}_{5} \mathrm{CN}$ & 346925 & 161.4 & $1.64 \mathrm{E}-4$ \\
\hline $\mathrm{g}-\mathrm{C}_{2} \mathrm{H}_{5} \mathrm{OH}$ & 346929 & 280.5 & $3.45 \mathrm{E}-4$ \\
\hline $\mathrm{CH}_{3} \mathrm{CHO} v=0$ & 346934 & 268.7 & $1.22 \mathrm{E}-3$ \\
\hline $\mathrm{g}-\mathrm{C}_{2} \mathrm{H}_{5} \mathrm{OH}$ & 346939 & 280.5 & $3.45 \mathrm{E}-4$ \\
\hline $\mathrm{C}_{2} \mathrm{H}_{3} \mathrm{CN}$ & 346943 & 325.0 & $3.46 \mathrm{E}-3$ \\
\hline $\mathrm{HC}_{3} \mathrm{~N} v_{7}=1$ & 346949 & 645.6 & $3.32 \mathrm{E}-3$ \\
\hline $\mathrm{CH}_{3} \mathrm{CHO} v=0$ & 346957 & 268.6 & $1.22 \mathrm{E}-3$ \\
\hline $\mathrm{t}-\mathrm{C}_{2} \mathrm{H}_{5} \mathrm{OH}$ & 346963 & 185.8 & $2.42 \mathrm{E}-4$ \\
\hline $\mathrm{C}_{2} \mathrm{H}_{5} \mathrm{CN}$ & 346970 & 104.6 & $1.20 \mathrm{E}-4$ \\
\hline $\mathrm{C}_{2} \mathrm{H}_{5} \mathrm{CN}$ & 346976 & 129.6 & $1.49 \mathrm{E}-4$ \\
\hline $\mathrm{C}_{2} \mathrm{H}_{5} \mathrm{CN}$ & 346979 & 122.7 & $1.44 \mathrm{E}-4$ \\
\hline $\mathrm{H}_{2} \mathrm{C}^{18} \mathrm{O}$ & 346984 & 239.6 & $4.33 \mathrm{E}-4$ \\
\hline $\mathrm{H}^{13} \mathrm{CO}^{+}$ & 346998 & 41.6 & $3.29 \mathrm{E}-3$ \\
\hline $\mathrm{CH}_{2} \mathrm{DCN}$ & 347043 & 175.0 & $3.65 \mathrm{E}-3$ \\
\hline $\mathrm{CH}_{3} \mathrm{CHO} v=0$ & 347071 & 239.4 & $1.28 \mathrm{E}-3$ \\
\hline $\mathrm{CH}_{3} \mathrm{CHO} v=0$ & 347090 & 239.4 & $1.28 \mathrm{E}-3$ \\
\hline $\mathrm{CH}_{2} \mathrm{DCN}$ & 347110 & 309.7 & $3.42 \mathrm{E}-3$ \\
\hline $\mathrm{H}_{2} \mathrm{C}^{18} \mathrm{O}$ & 347133 & 156.7 & $7.70 \mathrm{E}-4$ \\
\hline $\mathrm{CH}_{3} \mathrm{CHO} v=0$ & 347133 & 239.3 & $1.28 \mathrm{E}-3$ \\
\hline $\mathrm{H}_{2} \mathrm{C}^{18} \mathrm{O}$ & 347144 & 156.7 & $7.70 \mathrm{E}-4$ \\
\hline $\mathrm{g}-\mathrm{C}_{2} \mathrm{H}_{5} \mathrm{OH}$ & 347147 & 275.5 & $3.45 \mathrm{E}-4$ \\
\hline $\mathrm{g}-\mathrm{C}_{2} \mathrm{H}_{5} \mathrm{OH}$ & 347158 & 275.5 & $3.45 \mathrm{E}-4$ \\
\hline $\mathrm{CH}_{2} \mathrm{DCN}$ & 347166 & 261.2 & $3.52 \mathrm{E}-3$ \\
\hline${ }^{13} \mathrm{CH} 3 \mathrm{OH}$ & 347188 & 254.3 & $4.36 \mathrm{E}-4$ \\
\hline $\mathrm{CH}_{2} \mathrm{DCN}$ & 347216 & 223.5 & $3.50 \mathrm{E}-3$ \\
\hline $\mathrm{CH}_{3} \mathrm{CHO} v=1$ & 347217 & 420.4 & $1.33 \mathrm{E}-3$ \\
\hline $\mathrm{CH}_{2} \mathrm{DCN}$ & 347219 & 223.5 & $3.57 \mathrm{E}-3$ \\
\hline $\mathrm{CH}_{2} \mathrm{DOH}$ & 347222 & 521.6 & $1.32 \mathrm{E}-4$ \\
\hline $\mathrm{C}_{2} \mathrm{H}_{3} \mathrm{CN}$ & 347232 & 328.7 & $3.50 \mathrm{E}-3$ \\
\hline $\mathrm{CH}_{3} \mathrm{CHO} v=1$ & 347252 & 419.7 & $1.33 \mathrm{E}-3$ \\
\hline $\mathrm{CH}_{3} \mathrm{CHO} v=0$ & 347288 & 214.7 & $1.33 \mathrm{E}-3$ \\
\hline $\mathrm{CH}_{3} \mathrm{CHO} v=0$ & 347295 & 214.7 & $1.33 \mathrm{E}-3$ \\
\hline $\mathrm{SiO}$ & 347330 & 75.0 & $2.21 \mathrm{E}-3$ \\
\hline $\mathrm{CH}_{3} \mathrm{CHO} v=0$ & 347345 & 214.6 & $1.33 \mathrm{E}-3$ \\
\hline $\mathrm{CH}_{3} \mathrm{CHO} v=0$ & 347349 & 214.6 & $1.33 \mathrm{E}-3$ \\
\hline $\mathrm{t}-\mathrm{C}_{2} \mathrm{H}_{5} \mathrm{OH}$ & 347351 & 99.7 & $1.75 \mathrm{E}-4$ \\
\hline $\mathrm{aGg}^{\prime}\left(\mathrm{CH}_{2} \mathrm{OH}\right)_{2}$ & 347361 & 330.4 & $1.02 \mathrm{E}-3$ \\
\hline $\mathrm{CH}_{3} \mathrm{OH} v=0$ & 347370 & 45.5 & $1.08 \mathrm{E}-8$ \\
\hline $\mathrm{CH}_{2} \mathrm{DOH}$ & 347371 & 478.8 & $1.30 \mathrm{E}-4$ \\
\hline $\mathrm{aGg}^{\prime}\left(\mathrm{CH}_{2} \mathrm{OH}\right)_{2}$ & 347378 & 330.4 & $1.01 \mathrm{E}-3$ \\
\hline $\mathrm{aGg}^{\prime}\left(\mathrm{CH}_{2} \mathrm{OH}\right)_{2}$ & 347387 & 282.6 & $9.81 \mathrm{E}-4$ \\
\hline $\mathrm{CH}_{2} \mathrm{DCN}$ & 347388 & 196.6 & $3.62 \mathrm{E}-3$ \\
\hline $\mathrm{C}_{2} \mathrm{H}_{3} \mathrm{CN}$ & 347434 & 328.7 & $3.46 \mathrm{E}-3$ \\
\hline $\mathrm{t}-\mathrm{C}_{2} \mathrm{H}_{5} \mathrm{OH}$ & 347446 & 185.9 & $2.67 E-4$ \\
\hline $\mathrm{CH}_{3} \mathrm{OH} v=1$ & 347448 & 856.3 & $4.04 \mathrm{E}-5$ \\
\hline $\mathrm{CH}_{3} \mathrm{CHO} v=1$ & 347459 & 473.2 & $1.22 \mathrm{E}-3$ \\
\hline $\mathrm{g}-\mathrm{C}_{2} \mathrm{H}_{5} \mathrm{OH}$ & 347474 & 267.1 & $3.57 \mathrm{E}-4$ \\
\hline $\mathrm{CH}_{3} \mathrm{OCHO} v=0$ & 347478 & 247.3 & $6.14 \mathrm{E}-4$ \\
\hline $\mathrm{aGg}^{\prime}\left(\mathrm{CH}_{2} \mathrm{OH}\right)_{2}$ & 347487 & 317.0 & $9.51 \mathrm{E}-4$ \\
\hline $\mathrm{CH}_{3} \mathrm{OCHO} v=0$ & 347494 & 247.3 & $6.14 \mathrm{E}-4$ \\
\hline $\mathrm{CH}_{3} \mathrm{OH} v=0$ & 347507 & 57.1 & $1.78 \mathrm{E}-8$ \\
\hline $\mathrm{CH}_{3} \mathrm{CHO} v=0$ & 347519 & 178.7 & $1.41 \mathrm{E}-3$ \\
\hline
\end{tabular}

Table A.1. continued.

\begin{tabular}{|c|c|c|c|}
\hline Species & Frequency $(\mathrm{MHz})$ & $E_{\text {up }}(\mathrm{K})$ & $A_{i j}\left(\mathrm{~s}^{-1}\right)$ \\
\hline$\overline{\mathrm{CH}_{3} \mathrm{CHO} v=0}$ & 347563 & 178.1 & $1.41 \mathrm{E}-3$ \\
\hline $\mathrm{CH}_{3} \mathrm{OCHO} v=1$ & 347568 & 460.2 & $4.88 \mathrm{E}-3$ \\
\hline $\mathrm{NH}_{2} \mathrm{CH}^{18} \mathrm{O}$ & 347589 & 161.0 & $3.10 \mathrm{E}-3$ \\
\hline $\mathrm{CH}_{3} \mathrm{OCHO} v=0$ & 347590 & 104.4 & $4.00 \mathrm{E}-5$ \\
\hline $\mathrm{CH}_{3} \mathrm{OCHO} v=0$ & 347599 & 104.4 & $3.40 \mathrm{E}-5$ \\
\hline $\mathrm{CH}_{3} \mathrm{OCHO} v=0$ & 347605 & 306.8 & $5.49 \mathrm{E}-4$ \\
\hline $\mathrm{CH}_{2} \mathrm{DOH}$ & 347610 & 478.8 & $1.31 \mathrm{E}-4$ \\
\hline $\mathrm{CH}_{3} \mathrm{OCHO} v=0$ & 347617 & 306.8 & $5.59 \mathrm{E}-4$ \\
\hline $\mathrm{CH}_{3} \mathrm{OCHO} v=0$ & 347628 & 306.8 & $5.49 \mathrm{E}-4$ \\
\hline $\mathrm{CH}_{3} \mathrm{CHO} v=1$ & 347645 & 507.4 & $2.50 \mathrm{E}-5$ \\
\hline $\mathrm{CH}_{3} \mathrm{CHO} v=0$ & 347650 & 194.5 & $1.38 \mathrm{E}-3$ \\
\hline $\mathrm{CH}_{3} \mathrm{CHO} v=2$ & 347657 & 544.7 & $1.38 \mathrm{E}-3$ \\
\hline $\mathrm{HC}_{3} \mathrm{~N} v_{7}=2$ & 347663 & 967.8 & $3.33 \mathrm{E}-3$ \\
\hline $\mathrm{g}-\mathrm{C}_{2} \mathrm{H}_{5} \mathrm{OH}$ & 347670 & 262.2 & $3.57 \mathrm{E}-4$ \\
\hline $\mathrm{g}-\mathrm{C}_{2} \mathrm{H}_{5} \mathrm{OH}$ & 347675 & 267.1 & $3.57 \mathrm{E}-4$ \\
\hline $\mathrm{C}_{2} \mathrm{H}_{3} \mathrm{CN}$ & 347685 & 707.5 & 1.19E-4 \\
\hline $\mathrm{g}-\mathrm{C}_{2} \mathrm{H}_{5} \mathrm{OH}$ & 347693 & 189.7 & $1.07 \mathrm{E}-4$ \\
\hline $\mathrm{CH}_{3} \mathrm{OCHO} v=1$ & 347698 & 437.8 & $6.73 \mathrm{E}-3$ \\
\hline $\mathrm{NH}_{2} \mathrm{CHO} v=0$ & 347729 & 435.3 & $1.06 \mathrm{E}-4$ \\
\hline $\mathrm{aGg}^{\prime}\left(\mathrm{CH}_{2} \mathrm{OH}\right)_{2}$ & 347732 & 302.2 & $9.92 \mathrm{E}-4$ \\
\hline $\mathrm{aGg}^{\prime}\left(\mathrm{CH}_{2} \mathrm{OH}\right)_{2}$ & 347738 & 317.0 & $9.52 \mathrm{E}-4$ \\
\hline $\mathrm{CH}_{3} \mathrm{OH} v=0$ & 347745 & 71.0 & $2.64 \mathrm{E}-8$ \\
\hline $\mathrm{g}-\mathrm{C}_{2} \mathrm{H}_{5} \mathrm{OH}$ & 347755 & 256.2 & $3.66 \mathrm{E}-4$ \\
\hline $\mathrm{CH}_{3} \mathrm{CHO} v=0$ & 347756 & 194.4 & $1.36 \mathrm{E}-3$ \\
\hline $\mathrm{C}_{2} \mathrm{H}_{3} \mathrm{CN}$ & 347759 & 316.7 & $3.50 \mathrm{E}-3$ \\
\hline $\mathrm{CH}_{2} \mathrm{DOH}$ & 347767 & 438.2 & $1.29 \mathrm{E}-4$ \\
\hline${ }^{13} \mathrm{CH} 3 \mathrm{OH}$ & 347788 & 302.5 & $6.74 \mathrm{E}-5$ \\
\hline $\mathrm{HC}_{3} \mathrm{~N} v_{7}=2$ & 347791 & 970.5 & $3.32 \mathrm{E}-3$ \\
\hline $\mathrm{aGg}^{\prime}\left(\mathrm{CH}_{2} \mathrm{OH}\right)_{2}$ & 347813 & 115.3 & $1.12 \mathrm{E}-4$ \\
\hline $\mathrm{CH}_{3} \mathrm{CHDCN}$ & 347816 & 354.3 & $3.56 \mathrm{E}-3$ \\
\hline $\mathrm{CH}_{3} \mathrm{OCHO} v=0$ & 347818 & 274.0 & $3.40 \mathrm{E}-4$ \\
\hline $\mathrm{aGg}^{\prime}\left(\mathrm{CH}_{2} \mathrm{OH}\right)_{2}$ & 347821 & 115.0 & $1.22 \mathrm{E}-4$ \\
\hline $\mathrm{CH}_{3} \mathrm{CHO} v=0$ & 347830 & 194.5 & $1.36 \mathrm{E}-3$ \\
\hline $\mathrm{CH}_{3} \mathrm{CHO} v=0$ & 347838 & 194.5 & $1.38 \mathrm{E}-3$ \\
\hline${ }^{13} \mathrm{CH} 3 \mathrm{OH}$ & 347848 & 572.9 & $7.63 \mathrm{E}-5$ \\
\hline $\mathrm{CH}_{3}^{18} \mathrm{OH}$ & 347865 & 142.7 & $1.51 \mathrm{E}-4$ \\
\hline $\mathrm{g}-\mathrm{C}_{2} \mathrm{H}_{5} \mathrm{OH}$ & 347887 & 262.2 & $3.58 \mathrm{E}-4$ \\
\hline $\mathrm{g}-\mathrm{C}_{2} \mathrm{H}_{5} \mathrm{OH}$ & 347916 & 251.4 & $3.67 \mathrm{E}-4$ \\
\hline $\mathrm{HC}_{3} \mathrm{~N} v_{7}=2$ & 347924 & 970.6 & $3.33 \mathrm{E}-3$ \\
\hline $\mathrm{CH}_{2} \mathrm{DOH}$ & 347953 & 438.2 & $1.30 \mathrm{E}-4$ \\
\hline $\mathrm{aGg}\left(\mathrm{CH}_{2} \mathrm{OH}\right)_{2}$ & 347963 & 108.4 & $1.39 \mathrm{E}-4$ \\
\hline $\mathrm{t}-\mathrm{C}_{2} \mathrm{H}_{5} \mathrm{OH}$ & 347975 & 222.1 & $1.01 \mathrm{E}-4$ \\
\hline $\mathrm{CH}_{3} \mathrm{OCH}_{3}$ & 347985 & 581.8 & $1.18 \mathrm{E}-4$ \\
\hline $\mathrm{CH}_{3} \mathrm{OCH}_{3}$ & 347989 & 581.8 & $1.87 \mathrm{E}-4$ \\
\hline $\mathrm{CH}_{3} \mathrm{OCH}_{3}$ & 347992 & 581.8 & $1.87 \mathrm{E}-4$ \\
\hline $\mathrm{NH}_{2} \mathrm{CH}^{18} \mathrm{O}$ & 348029 & 154.7 & $3.10 \mathrm{E}-3$ \\
\hline $\mathrm{H}_{2} \mathrm{C}^{18} \mathrm{O}$ & 348032 & 97.5 & $1.02 \mathrm{E}-3$ \\
\hline $\mathrm{CH}_{3} \mathrm{OCHO} v=0$ & 348050 & 266.1 & $6.10 \mathrm{E}-4$ \\
\hline $\mathrm{CH}_{3} \mathrm{OCHO} v=1$ & 348053 & 491.3 & $4.67 \mathrm{E}-5$ \\
\hline $\mathrm{CH}_{3}^{18} \mathrm{OH}$ & 348053 & 283.4 & $1.04 \mathrm{E}-3$ \\
\hline $\mathrm{CH}_{3} \mathrm{OCHO} v=0$ & 348066 & 266.1 & $6.10 \mathrm{E}-4$ \\
\hline $\mathrm{CH}_{3} \mathrm{OCHO} v=1$ & 348084 & 469.7 & $5.58 \mathrm{E}-4$ \\
\hline $\mathrm{CH}_{3} \mathrm{CHO} v=1$ & 348088 & 443.3 & $1.28 \mathrm{E}-3$ \\
\hline${ }^{13} \mathrm{CH} 3 \mathrm{OH}$ & 348100 & 162.4 & $1.08 \mathrm{E}-4$ \\
\hline $\mathrm{CH}_{3} \mathrm{OH} v=0$ & 348123 & 87.3 & $3.27 \mathrm{E}-8$ \\
\hline${ }^{13} \mathrm{CH} 3 \mathrm{CH} 2 \mathrm{CN}$ & 348147 & 352.3 & $3.51 \mathrm{E}-3$ \\
\hline $\mathrm{CH}_{2} \mathrm{DOH}$ & 348161 & 38.2 & $2.03 \mathrm{E}-4$ \\
\hline
\end{tabular}


Table A.1. continued.

\begin{tabular}{|c|c|c|c|}
\hline Species & Frequency $(\mathrm{MHz})$ & $E_{\text {up }}(\mathrm{K})$ & $A_{i j}\left(\mathrm{~s}^{-1}\right)$ \\
\hline $\mathrm{CH}_{3} \mathrm{CHO} v=1$ & 348211 & 383.2 & $1.41 \mathrm{E}-3$ \\
\hline $\mathrm{CH}_{3} \mathrm{CHO} v=1$ & 348229 & 400.0 & $1.38 \mathrm{E}-3$ \\
\hline $\mathrm{CH}_{3} \mathrm{OCHO} v=1$ & 348247 & 267.6 & $1.00 \mathrm{E}-4$ \\
\hline $\mathrm{C}_{2} \mathrm{H}_{5} \mathrm{CN}$ & 348260 & 343.8 & $3.57 \mathrm{E}-3$ \\
\hline $\mathrm{NH}_{2} \mathrm{CDO}$ & 348283 & 162.4 & $3.11 \mathrm{E}-3$ \\
\hline $\mathrm{CH}_{3} \mathrm{CHO} v=1$ & 348288 & 385.2 & $1.41 \mathrm{E}-3$ \\
\hline $\mathrm{aGg}^{\prime}\left(\mathrm{CH}_{2} \mathrm{OH}\right)_{2}$ & 348326 & 325.8 & $4.16 \mathrm{E}-4$ \\
\hline $\mathrm{aGg}^{\prime}\left(\mathrm{CH}_{2} \mathrm{OH}\right)_{2}$ & 348331 & 311.2 & $1.04 \mathrm{E}-3$ \\
\hline $\mathrm{HN}^{13} \mathrm{C}$ & 348340 & 41.8 & $2.03 \mathrm{E}-3$ \\
\hline $\mathrm{C}_{2} \mathrm{H}_{5} \mathrm{CN}$ & 348344 & 351.0 & $3.58 \mathrm{E}-3$ \\
\hline $\mathrm{SO}_{2}$ & 348388 & 292.7 & $1.91 \mathrm{E}-4$ \\
\hline $\mathrm{CH}_{2} \mathrm{DOH}$ & 348427 & 363.3 & $1.27 \mathrm{E}-4$ \\
\hline${ }^{33} \mathrm{SO}_{2}$ & 348492 & 110.2 & $3.19 \mathrm{E}-4$ \\
\hline $\mathrm{CH}_{2} \mathrm{DOH}$ & 348529 & 363.3 & $1.28 \mathrm{E}-4$ \\
\hline $\mathrm{H}_{2} \mathrm{CS}$ & 348532 & 105.2 & $6.30 \mathrm{E}-4$ \\
\hline $\mathrm{aGg}^{\prime}\left(\mathrm{CH}_{2} \mathrm{OH}\right)_{2}$ & 348550 & 329.1 & $6.50 \mathrm{E}-4$ \\
\hline $\mathrm{C}_{2} \mathrm{H}_{5} \mathrm{CN}$ & 348553 & 351.0 & $3.59 \mathrm{E}-3$ \\
\hline $\mathrm{CH}_{3} \mathrm{CHO} v=1$ & 348570 & 418.2 & $1.34 \mathrm{E}-3$ \\
\hline $\mathrm{CH}_{3} \mathrm{CHO} v=1$ & 348578 & 418.2 & $1.34 \mathrm{E}-3$ \\
\hline $\mathrm{CH}_{2} \mathrm{DOH}$ & 348592 & 139.7 & $6.76 \mathrm{E}-5$ \\
\hline $\mathrm{CH}_{2} \mathrm{DOH}$ & 348668 & 219.2 & $2.04 \mathrm{E}-5$ \\
\hline $\mathrm{CH}_{3} \mathrm{OH} v=0$ & 348682 & 105.8 & $3.19 \mathrm{E}-8$ \\
\hline $\mathrm{CH}_{2} \mathrm{DCN}$ & 348691 & 181.2 & $3.69 \mathrm{E}-3$ \\
\hline $\mathrm{CH}_{2} \mathrm{DOH}$ & 348699 & 329.0 & $1.26 \mathrm{E}-4$ \\
\hline $\mathrm{g}-\mathrm{C}_{2} \mathrm{H}_{5} \mathrm{OH}$ & 348720 & 89.6 & $2.33 \mathrm{E}-4$ \\
\hline $\mathrm{CH}_{3}^{13} \mathrm{CN}$ & 348854 & 624.3 & $3.05 \mathrm{E}-3$ \\
\hline $\mathrm{CH}_{3}^{3} \mathrm{CHO} v=1$ & 348855 & 398.3 & $1.38 \mathrm{E}-3$ \\
\hline $\mathrm{CH}_{3} \mathrm{OCHO} v=0$ & 348909 & 294.6 & $4.65 \mathrm{E}-3$ \\
\hline $\mathrm{CH}_{3} \mathrm{CN} v=0$ & 348911 & 745.4 & $2.87 \mathrm{E}-3$ \\
\hline $\mathrm{CH}_{3} \mathrm{OCHO} v=0$ & 348915 & 294.6 & $5.72 \mathrm{E}-4$ \\
\hline $\mathrm{CH}_{2} \mathrm{DOH}$ & 348939 & 296.9 & $1.24 \mathrm{E}-4$ \\
\hline $\mathrm{CH}_{3}^{13} \mathrm{CN}$ & 348954 & 517.3 & $3.20 \mathrm{E}-3$ \\
\hline $\mathrm{CH}_{2}^{3} \mathrm{DOH}$ & 348990 & 296.9 & $1.25 \mathrm{E}-4$ \\
\hline $\mathrm{C}_{2} \mathrm{H}_{3} \mathrm{CN}$ & 348991 & 325.1 & $3.19 \mathrm{E}-2$ \\
\hline $\mathrm{CH}_{3} \mathrm{OCHO} v=0$ & 349015 & 257.3 & $4.08 \mathrm{E}-4$ \\
\hline $\mathrm{NH} 2 \mathrm{CHO}(v=1)$ & 349020 & 568.5 & $3.09 \mathrm{E}-3$ \\
\hline $\mathrm{CH}_{3} \mathrm{CN} v=0$ & 349025 & 624.0 & $2.10 \mathrm{E}-3$ \\
\hline $\mathrm{CH}_{3}^{13} \mathrm{CN}$ & 349040 & 424.6 & $3.34 \mathrm{E}-3$ \\
\hline $\mathrm{CH}_{3} \mathrm{OCHO} v=0$ & 349049 & 294.6 & $5.72 \mathrm{E}-4$ \\
\hline $\mathrm{NH}_{2} \mathrm{CHO} v=0$ & 349053 & 220.7 & $9.00 \mathrm{E}-5$ \\
\hline $\mathrm{CH}_{3} \mathrm{OCHO} v=0$ & 349066 & 294.6 & $5.82 \mathrm{E}-4$ \\
\hline $\mathrm{CH}_{3} \mathrm{OH} v=0$ & 349107 & 260.2 & $4.41 \mathrm{E}-4$ \\
\hline $\mathrm{CH}_{3}^{13} \mathrm{CN}$ & 349114 & 346.1 & $3.45 \mathrm{E}-3$ \\
\hline $\mathrm{CH}_{3} \mathrm{CN} v=0$ & 349125 & 517.0 & $3.21 \mathrm{E}-3$ \\
\hline $\mathrm{CH}_{2} \mathrm{DOH}$ & 349149 & 267.0 & $1.23 \mathrm{E}-4$ \\
\hline $\mathrm{CH}_{3}^{13} \mathrm{CN}$ & 349174 & 281.9 & $3.55 \mathrm{E}-3$ \\
\hline $\mathrm{CH}_{2} \mathrm{DOH}$ & 349184 & 267.0 & $1.23 \mathrm{E}-4$ \\
\hline $\mathrm{CH}_{3} \mathrm{CN} v=0$ & 349212 & 424.7 & $3.34 \mathrm{E}-3$ \\
\hline $\mathrm{CH}_{3}^{13} \mathrm{CN}$ & 349222 & 231.9 & $3.62 \mathrm{E}-3$ \\
\hline $\mathrm{CH}_{3}^{13} \mathrm{CN}$ & 349254 & 196.2 & $3.67 \mathrm{E}-3$ \\
\hline $\mathrm{CH}_{3}^{13} \mathrm{CN}$ & 349274 & 174.8 & $2.38 \mathrm{E}-3$ \\
\hline $\mathrm{CH}_{3}^{3} \mathrm{CN}$ & 349280 & 167.6 & $1.47 \mathrm{E}-3$ \\
\hline $\mathrm{CH}_{3} \mathrm{CN} v=0$ & 349286 & 346.2 & $2.38 \mathrm{E}-3$ \\
\hline $\mathrm{NH}_{2}^{13} \mathrm{CHO}$ & 349309 & 152.6 & $3.1 \mathrm{E}-3$ \\
\hline $\mathrm{CH}_{3} \mathrm{CHO} v=1$ & 349320 & 369.3 & $1.47 \mathrm{E}-3$ \\
\hline c-HCOOH & 349326 & 157.4 & $1.66 \mathrm{E}-3$ \\
\hline $\mathrm{CH}_{2} \mathrm{DOH}$ & 349334 & 239.1 & $1.21 \mathrm{E}-4$ \\
\hline
\end{tabular}

Table A.1. continued.

\begin{tabular}{|c|c|c|c|}
\hline Species & Frequency $(\mathrm{MHz})$ & $E_{\text {up }}(\mathrm{K})$ & $A_{i j}\left(\mathrm{~s}^{-1}\right)$ \\
\hline $\mathrm{CH}_{3} \mathrm{CN} v=0$ & 349346 & 282.0 & $2.45 \mathrm{E}-3$ \\
\hline $\mathrm{aGg}^{\prime}\left(\mathrm{CH}_{2} \mathrm{OH}\right)_{2}$ & 349355 & 309.2 & $6.03 \mathrm{E}-4$ \\
\hline $\mathrm{CH}_{2} \mathrm{DOH}$ & 349356 & 239.1 & $1.21 \mathrm{E}-4$ \\
\hline $\mathrm{C}_{2} \mathrm{H}_{5} \mathrm{CN}$ & 349380 & 495.2 & $3.29 \mathrm{E}-3$ \\
\hline $\mathrm{CH}_{3} \mathrm{CN} v=0$ & 349393 & 232.0 & $2.50 \mathrm{E}-3$ \\
\hline $\mathrm{CH}_{2} \mathrm{DOH}$ & 349411 & 230.3 & $7.95 \mathrm{E}-5$ \\
\hline $\mathrm{CH}_{3} \mathrm{CN} v=0$ & 349427 & 196.3 & $2.54 \mathrm{E}-3$ \\
\hline $\mathrm{CH}_{3} \mathrm{CN} v=0$ & 349447 & 174.9 & $2.56 \mathrm{E}-3$ \\
\hline $\mathrm{CH}_{3} \mathrm{CN} v=0$ & 349453 & 167.7 & $2.56 \mathrm{E}-3$ \\
\hline $\mathrm{CH}_{3} \mathrm{OH} v=0$ & 349470 & 118.8 & $1.92 \mathrm{E}-8$ \\
\hline $\mathrm{NH}_{2} \mathrm{CHO} v=0$ & 349482 & 153.0 & $3.10 \mathrm{E}-3$ \\
\hline $\mathrm{CH}_{3} \mathrm{OCH}_{3}$ & 349487 & 475.7 & $6.54 \mathrm{E}-5$ \\
\hline $\mathrm{CH}_{2} \mathrm{DOH}$ & 349495 & 213.4 & $1.18 \mathrm{E}-4$ \\
\hline $\mathrm{CH}_{2} \mathrm{DOH}$ & 349509 & 213.4 & $1.18 \mathrm{E}-4$ \\
\hline $\mathrm{aGg}^{\prime}\left(\mathrm{CH}_{2} \mathrm{OH}\right)_{2}$ & 349541 & 294.9 & 8.31E-4 \\
\hline $\mathrm{C}_{2} \mathrm{H}_{5} \mathrm{CN}$ & 349547 & 425.4 & $3.44 \mathrm{E}-3$ \\
\hline $\mathrm{C}_{2} \mathrm{H}_{5} \mathrm{CN}$ & 349566 & 618.9 & $3.03 \mathrm{E}-3$ \\
\hline $\mathrm{D}_{2} \mathrm{CO}$ & 349630 & 80.4 & $1.11 \mathrm{E}-3$ \\
\hline $\mathrm{CH}_{2} \mathrm{DOH}$ & 349636 & 189.9 & $1.15 \mathrm{E}-4$ \\
\hline $\mathrm{CH}_{2} \mathrm{DOH}$ & 349644 & 189.9 & $1.15 \mathrm{E}-4$ \\
\hline $\mathrm{C}_{2} \mathrm{H}_{5} \mathrm{CN}$ & 349652 & 655.3 & $2.95 \mathrm{E}-3$ \\
\hline $\mathrm{CH}_{3} \mathrm{OCHO} v=1$ & 349685 & 459.9 & $6.26 \mathrm{E}-4$ \\
\hline $\mathrm{C}_{2} \mathrm{H}_{5} \mathrm{CN}$ & 349730 & 406.6 & $3.49 \mathrm{E}-3$ \\
\hline $\mathrm{C}_{2} \mathrm{H}_{5} \mathrm{CN}$ & 349751 & 693.8 & $2.87 \mathrm{E}-3$ \\
\hline $\mathrm{CH}_{3} \mathrm{CHO} v=2$ & 349752 & 565.7 & $1.40 \mathrm{E}-3$ \\
\hline $\mathrm{CH}_{2} \mathrm{DOH}$ & 349757 & 168.5 & $1.11 \mathrm{E}-4$ \\
\hline $\mathrm{CH}_{2} \mathrm{DOH}$ & 349762 & 168.5 & $1.11 \mathrm{E}-4$ \\
\hline $\mathrm{C}_{2} \mathrm{H}_{5} \mathrm{CN}$ & 349796 & 353.9 & $3.61 \mathrm{E}-3$ \\
\hline $\mathrm{CH}_{3} \mathrm{OCH}_{3}$ & 349803 & 66.5 & $3.30 \mathrm{E}-5$ \\
\hline $\mathrm{CH}_{3} \mathrm{OCH}_{3}$ & 349806 & 66.5 & $3.30 \mathrm{E}-5$ \\
\hline $\mathrm{CH}_{3} \mathrm{OCH}_{3}$ & 349809 & 66.5 & $3.30 \mathrm{E}-5$ \\
\hline $\mathrm{CH}_{3} \mathrm{OCH}_{3}$ & 349823 & 326.0 & $1.15 \mathrm{E}-5$ \\
\hline $\mathrm{CH}_{3} \mathrm{OCH}_{3}$ & 349826 & 326.0 & $1.15 \mathrm{E}-5$ \\
\hline $\mathrm{CH}_{3} \mathrm{OCH}_{3}$ & 349828 & 326.0 & $1.15 \mathrm{E}-5$ \\
\hline $\mathrm{CH}_{3} \mathrm{OCH}_{3}$ & 349830 & 326.0 & $1.15 \mathrm{E}-5$ \\
\hline $\mathrm{CH}_{3} \mathrm{OCHO} v=1$ & 349836 & 401.3 & $3.32 \mathrm{E}-5$ \\
\hline $\mathrm{CH}_{2} \mathrm{DOH}$ & 349862 & 149.2 & $1.07 \mathrm{E}-4$ \\
\hline $\mathrm{CH}_{2} \mathrm{DOH}$ & 349864 & 149.2 & $1.07 \mathrm{E}-4$ \\
\hline $\mathrm{aGg}^{\prime}\left(\mathrm{CH}_{2} \mathrm{OH}\right)_{2}$ & 349867 & 338.1 & $1.04 \mathrm{E}-3$ \\
\hline $\mathrm{CH}_{3} \mathrm{CHDCN}$ & 349907 & 360.9 & $3.63 \mathrm{E}-3$ \\
\hline $\mathrm{CH}_{2} \mathrm{DOH}$ & 349952 & 132.1 & $1.00 \mathrm{E}-4$ \\
\hline $\mathrm{g}-\mathrm{C}_{2} \mathrm{H}_{5} \mathrm{OH}$ & 349997 & 256.5 & $3.73 \mathrm{E}-4$ \\
\hline $\mathrm{aGg}^{\prime}\left(\mathrm{CH}_{2} \mathrm{OH}\right)_{2}$ & 350023 & 305.1 & $1.11 \mathrm{E}-3$ \\
\hline $\mathrm{CH}_{2} \mathrm{DOH}$ & 350027 & 117.1 & $9.06 \mathrm{E}-5$ \\
\hline $\mathrm{C}_{2} \mathrm{H}_{5} \mathrm{CN}$ & 350039 & 390.1 & $3.54 \mathrm{E}-3$ \\
\hline $\mathrm{C}_{2} \mathrm{H}_{5} \mathrm{CN}$ & 350051 & 390.1 & $3.54 \mathrm{E}-3$ \\
\hline $\mathrm{CH}_{3} \mathrm{CN} v_{8}=1$ & 350059 & 1136.0 & $3.01 \mathrm{E}-3$ \\
\hline $\mathrm{CH}_{2} \mathrm{DOH}$ & 350090 & 104.2 & $7.58 \mathrm{E}-5$ \\
\hline${ }^{13} \mathrm{CH} 3 \mathrm{OH}$ & 350103 & 16.8 & $3.29 \mathrm{E}-4$ \\
\hline $\mathrm{CH}_{3} \mathrm{CHO} v=0$ & 350135 & 179.2 & $1.44 \mathrm{E}-3$ \\
\hline $\mathrm{CH}_{2} \mathrm{DOH}$ & 350141 & 93.5 & $5.04 \mathrm{E}-5$ \\
\hline $\mathrm{aGg}^{\prime}\left(\mathrm{CH}_{2} \mathrm{OH}\right)_{2}$ & 350142 & 326.2 & $7.96 \mathrm{E}-4$ \\
\hline $\mathrm{C}_{2} \mathrm{H}_{5} \mathrm{CN}$ & 350145 & 356.1 & $3.65 \mathrm{E}-3$ \\
\hline $\mathrm{CH}_{3} \mathrm{CN} v_{8}=1$ & 350160 & 1030.0 & $3.13 \mathrm{E}-3$ \\
\hline $\mathrm{CH}_{3} \mathrm{CN} v_{8}=1$ & 350168 & 687.1 & $3.46 \mathrm{E}-3$ \\
\hline $\mathrm{CH}_{3} \mathrm{CN} v_{8}=1$ & 350190 & 1142.9 & $2.87 \mathrm{E}-3$ \\
\hline $\mathrm{CH}_{3}^{18} \mathrm{OH}$ & 350246 & 43.0 & $2.96 \mathrm{E}-4$ \\
\hline
\end{tabular}


Table A.1. continued.

\begin{tabular}{lccc}
\hline \hline Species & Frequency $(\mathrm{MHz})$ & $E_{\text {up }}(\mathrm{K})$ & $A_{i j}\left(\mathrm{~s}^{-1}\right)$ \\
\hline $\mathrm{CH}_{3} \mathrm{CN} v_{8}=1$ & 350247 & 938.3 & $3.23 \mathrm{E}-3$ \\
$\mathrm{CH}_{3} \mathrm{CN} v_{8}=1$ & 350277 & 949.5 & $3.00 \mathrm{E}-3$ \\
$\mathrm{CH}_{3} \mathrm{OH} v=1$ & 350288 & 694.8 & $2.10 \mathrm{E}-4$ \\
${ }^{33} \mathrm{SO}_{2} \$$ & 350303 & 89.1 & $3.07 \mathrm{E}-4$ \\
$\mathrm{CH}_{3} \mathrm{CN} v_{8}=1$ & 350320 & 860.8 & $3.55 \mathrm{E}-3$ \\
$\mathrm{HNCO}$ & 350333 & 186.2 & $5.97 \mathrm{E}-4$ \\
$\mathrm{CH}_{3} \mathrm{CN} v_{8}=1$ & 350352 & 870.2 & $3.14 \mathrm{E}-3$ \\
$\mathrm{CH}_{3} \mathrm{CHO} v=0$ & 350363 & 163.5 & $1.47 \mathrm{E}-3$ \\
$\mathrm{~g}_{-} \mathrm{C}_{2} \mathrm{H}_{5} \mathrm{OH}$ & 350365 & 251.7 & $3.75 \mathrm{E}-4$ \\
$\mathrm{CH}_{3} \mathrm{CN} v_{8}=1$ & 350380 & 797.5 & $3.39 \mathrm{E}-3$ \\
$\mathrm{aGg}^{2}\left(\mathrm{CH} \mathrm{OH}_{2} \mathrm{OH}\right)_{2}$ & 350402 & 327.7 & $1.91 \mathrm{E}-4$ \\
$\mathrm{CH}_{3} \mathrm{CN} v_{8}=1$ & 350415 & 805.2 & $3.24 \mathrm{E}-3$ \\
${ }^{13} \mathrm{CH}_{3} \mathrm{OH}$ & 350422 & 102.6 & $7.03 \mathrm{E}-5$ \\
$\mathrm{CH}_{3} \mathrm{OCHO} v=0$ & 350442 & 283.9 & $4.91 \mathrm{E}-3$ \\
$\mathrm{CH}_{3} \mathrm{CHO} v=0$ & 350445 & 163.4 & $1.47 \mathrm{E}-3$ \\
$\mathrm{CH}_{3} \mathrm{CN} v_{8}=1$ & 350450 & 713.8 & $3.47 \mathrm{E}-3$ \\
$\mathrm{CH}_{2} \mathrm{DOH}$ & 350454 & 71.6 & $1.39 \mathrm{E}-4$ \\
$\mathrm{CH}_{3} \mathrm{OCHO} v=0$ & 350458 & 283.9 & $4.91 \mathrm{E}-3$ \\
$\mathrm{CH}_{3} \mathrm{CN} v_{8}=1$ & 350465 & 754.4 & $3.33 \mathrm{E}-3$ \\
$\mathrm{CH}_{3} \mathrm{CN} v_{8}=1$ & 350507 & 717.7 & $3.40 \mathrm{E}-3$ \\
$\mathrm{C}_{2} \mathrm{H}_{5} \mathrm{CN}$ & 350512 & 375.9 & $3.58 \mathrm{E}-3$ \\
$\mathrm{t}-\mathrm{C}_{2} \mathrm{H} \mathrm{H}_{5} \mathrm{OH}$ & 350534 & 179.0 & $1.51 \mathrm{E}-4$ \\
$\mathrm{CH}_{3} \mathrm{CN} v_{8}=1$ & 350552 & 695.4 & $3.45 \mathrm{E}-3$ \\
$\mathrm{CH}_{2} \mathrm{DOH}$ & 350632 & 49.0 & $2.07 \mathrm{E}-4$ \\
\hline & & & \\
& & &
\end{tabular}



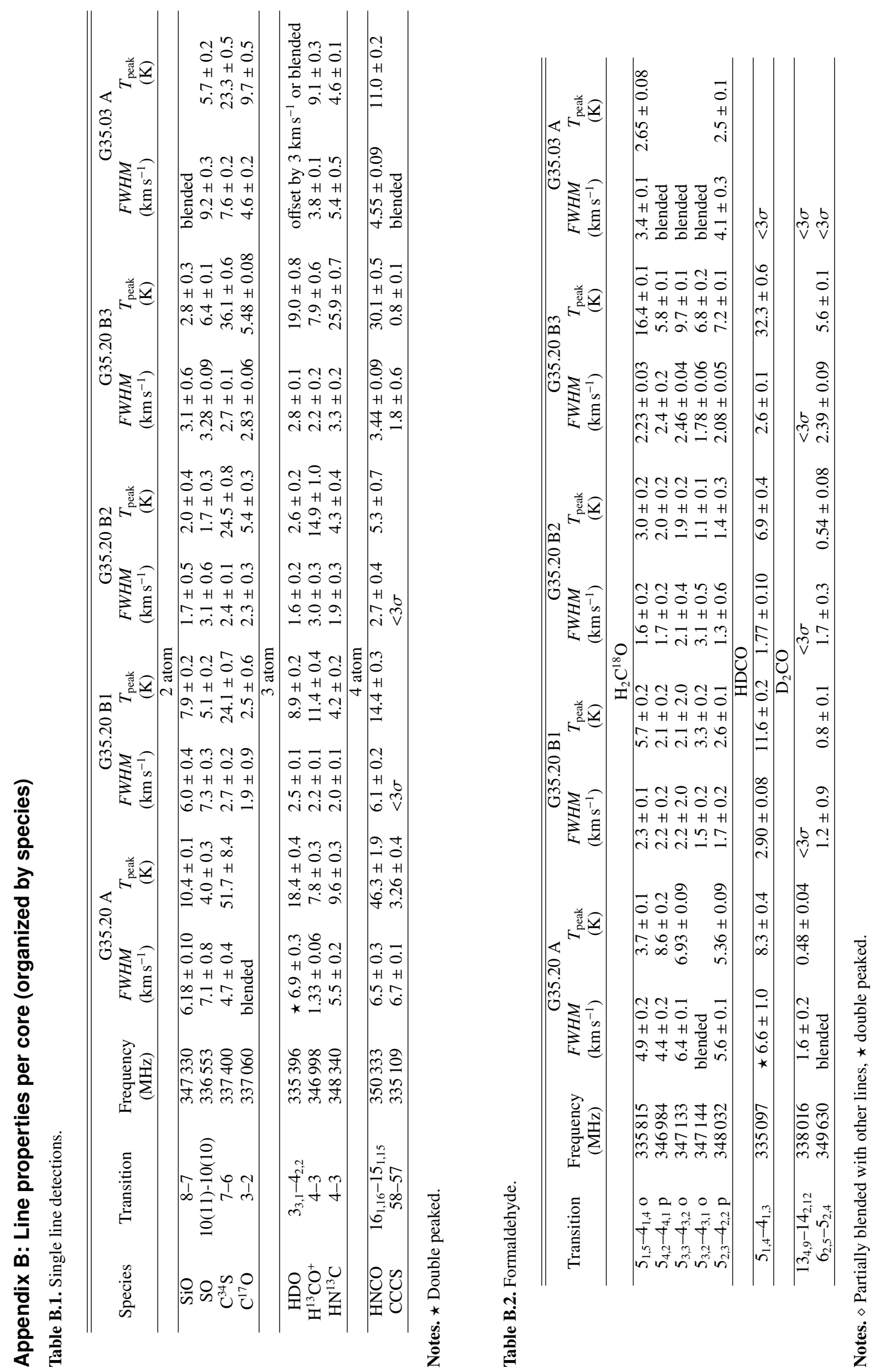


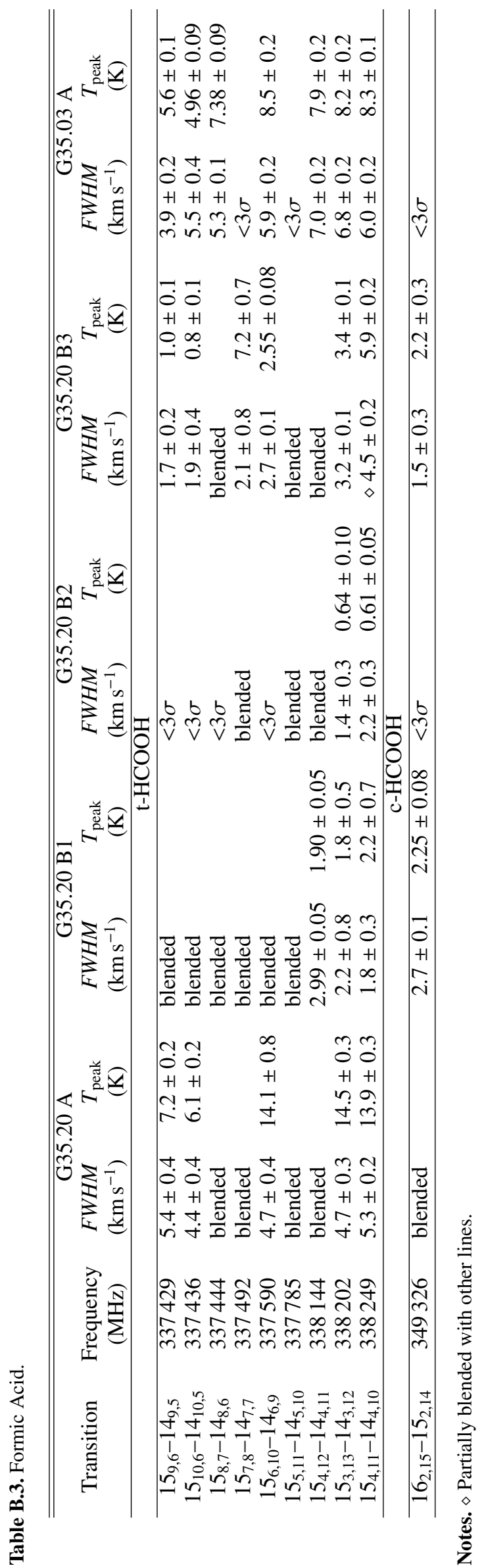




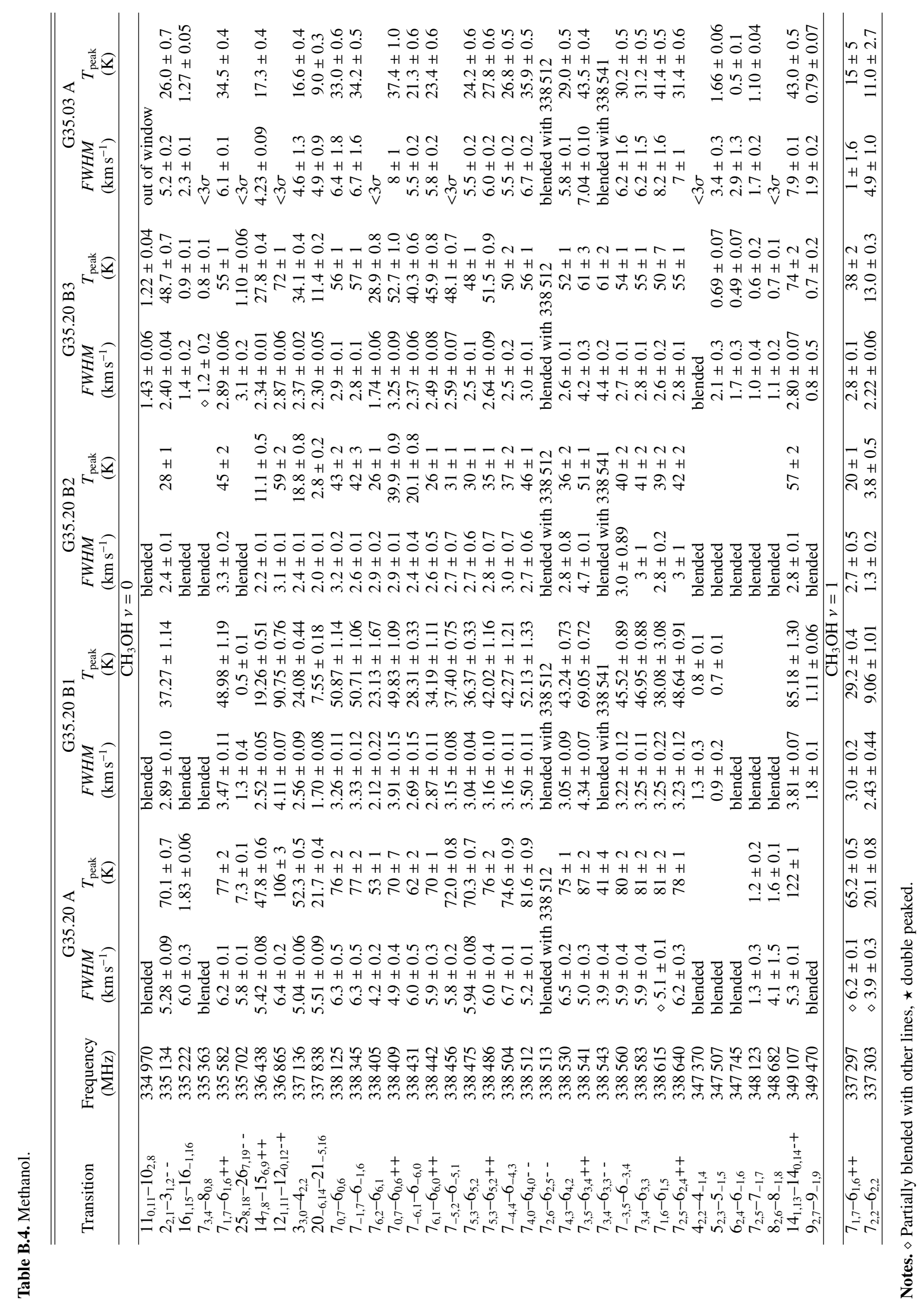




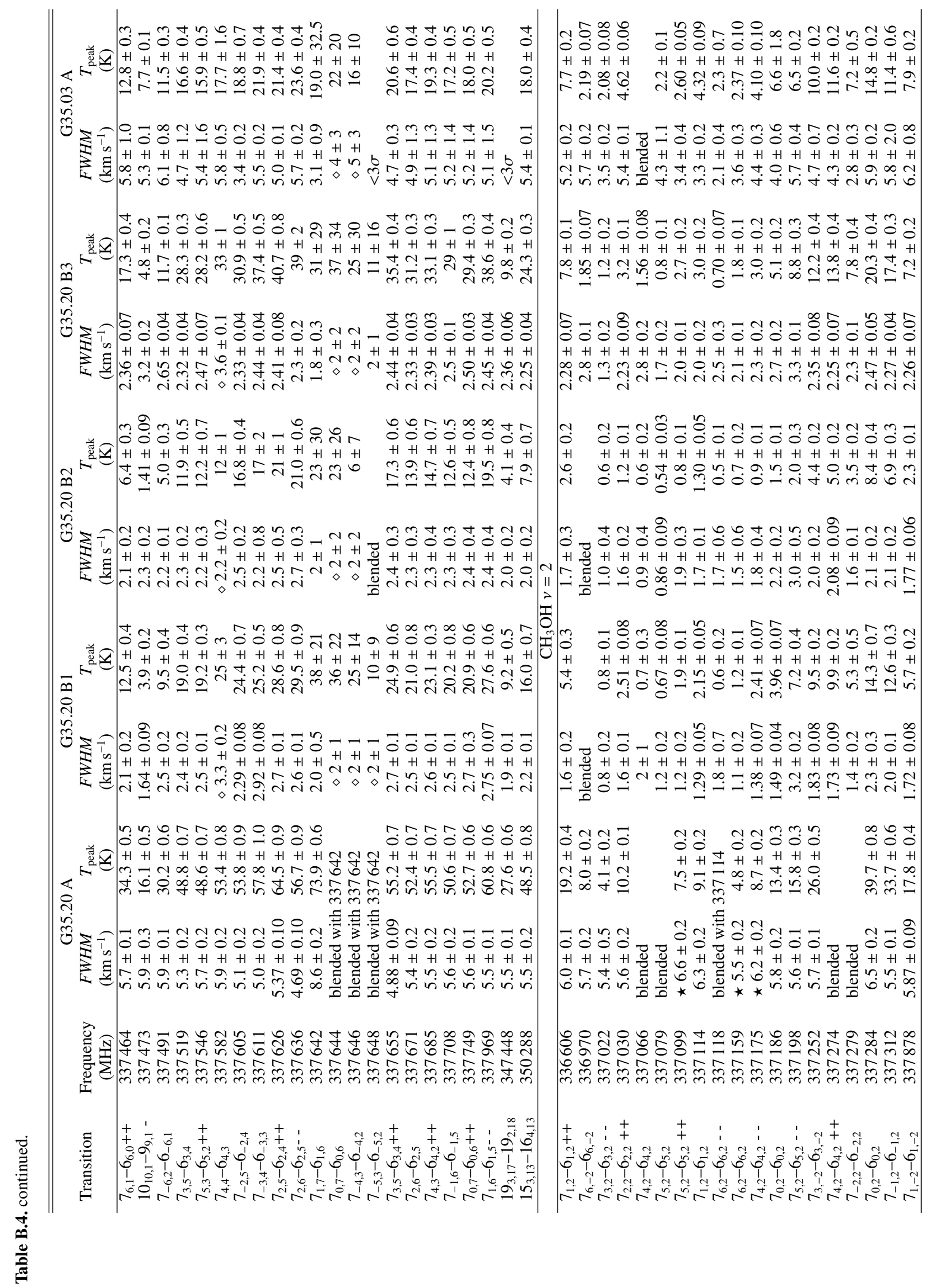




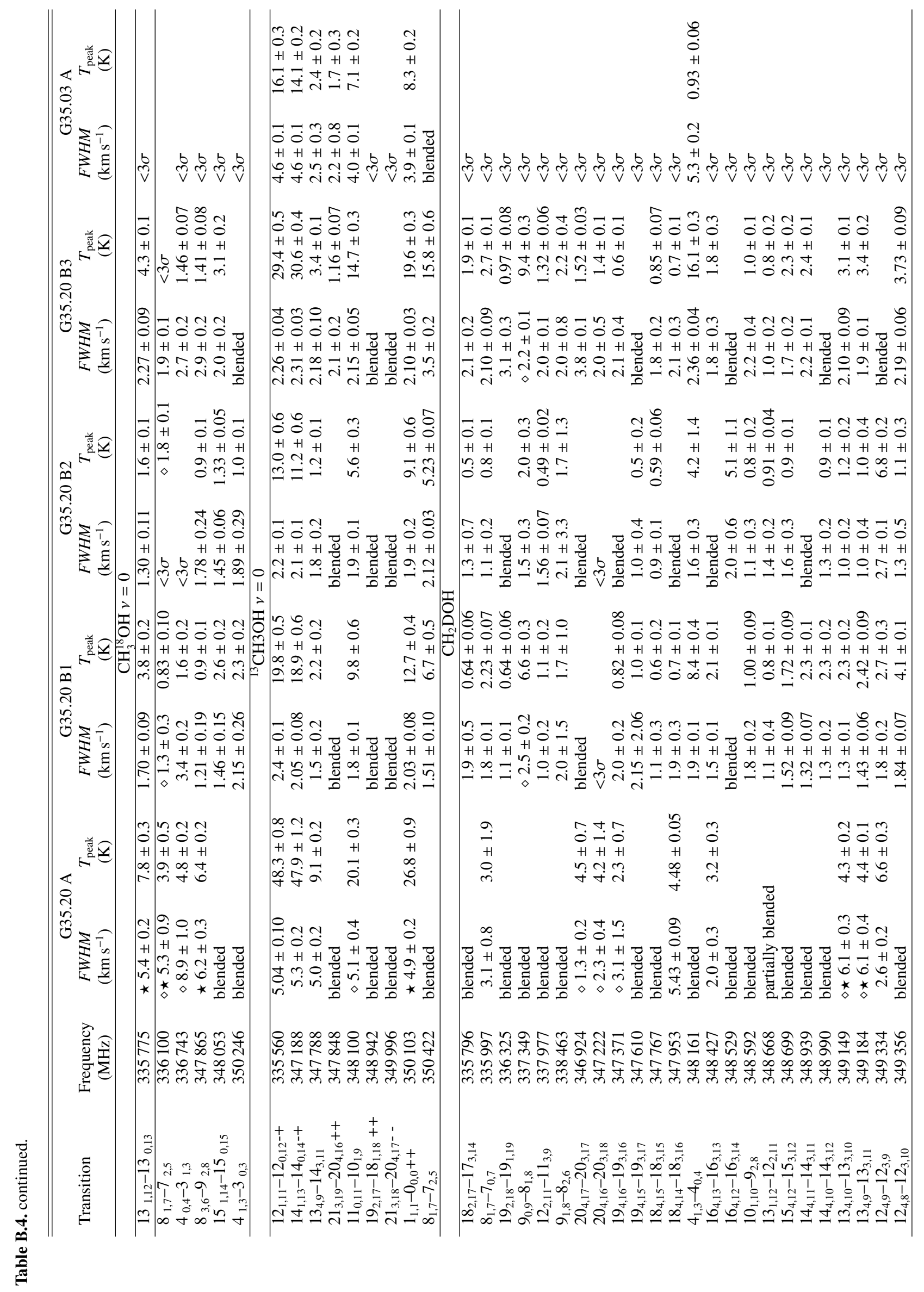




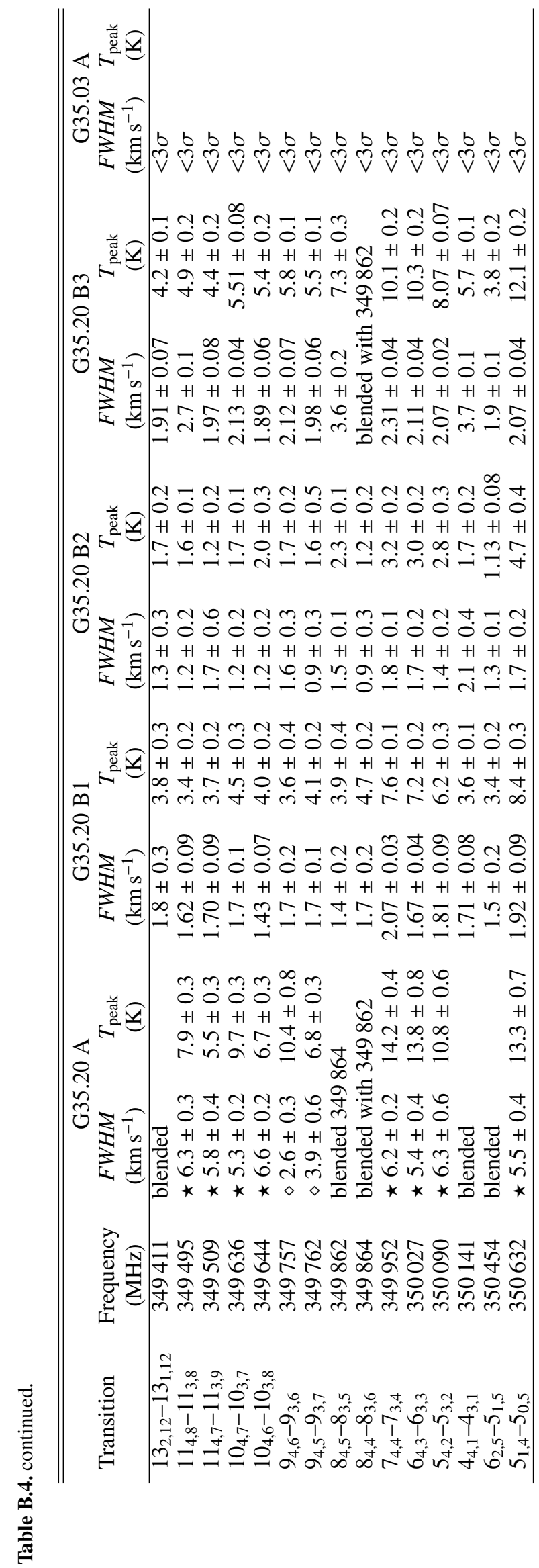




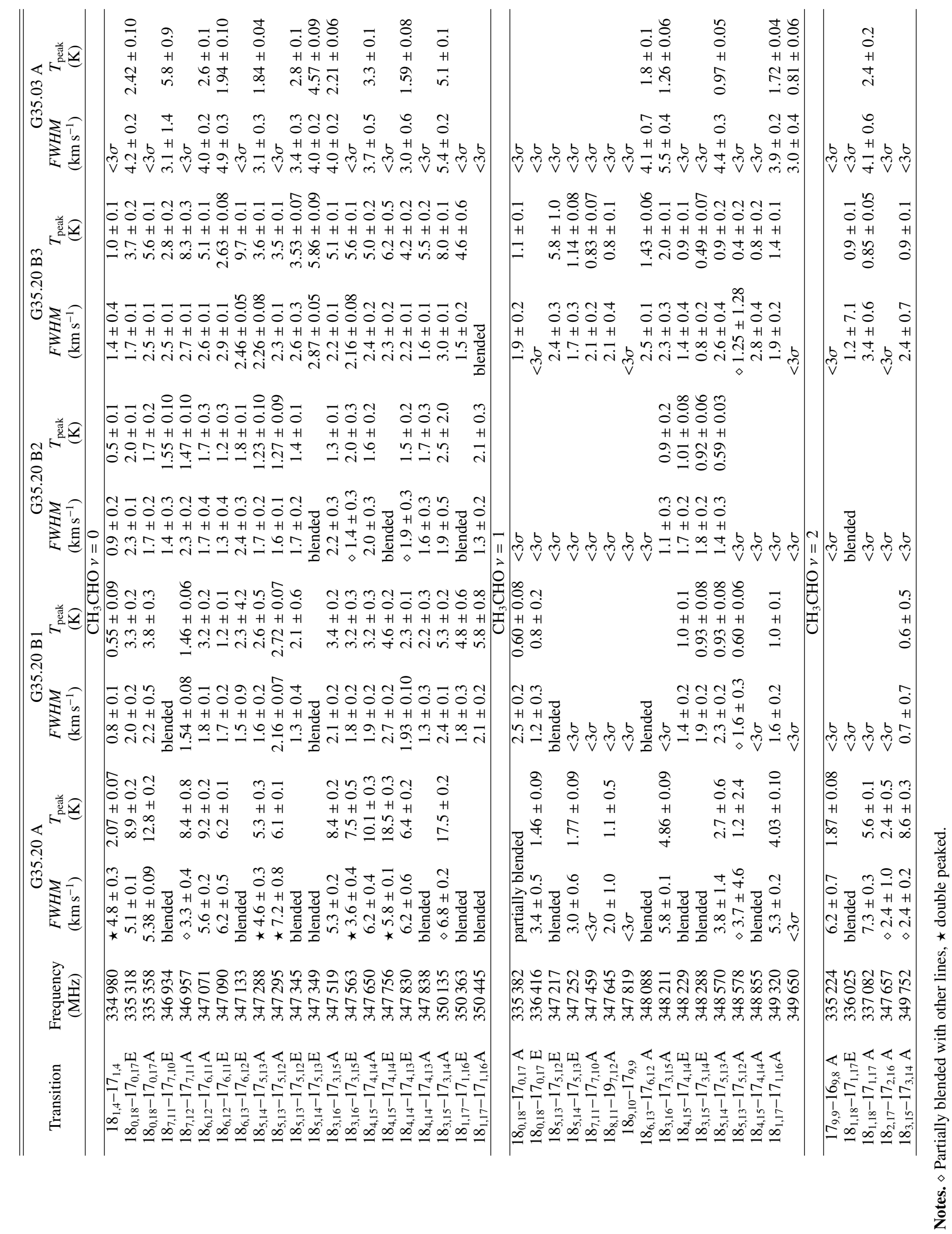


V. Allen et al.: Chemical segregation in hot cores with disk candidates

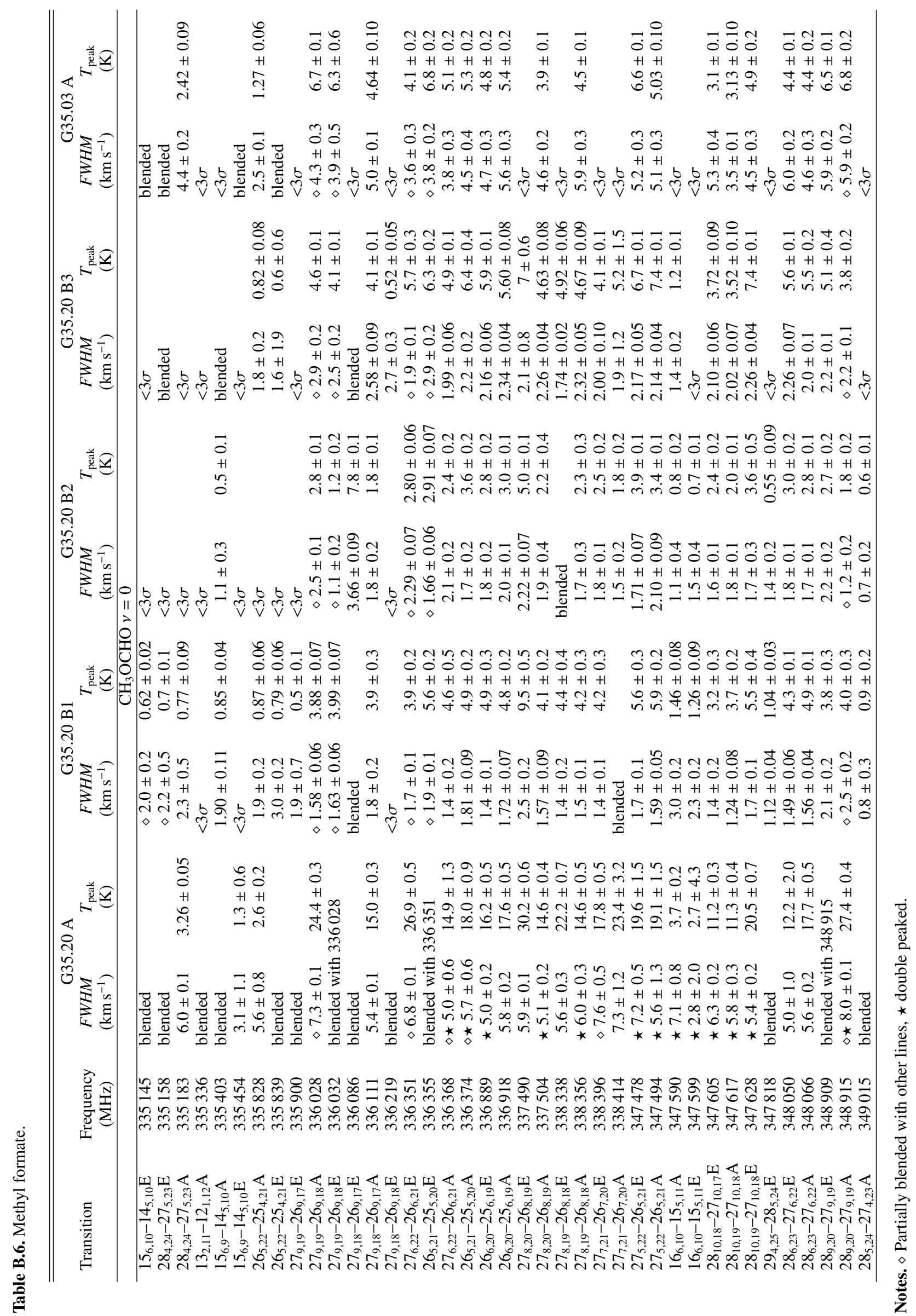



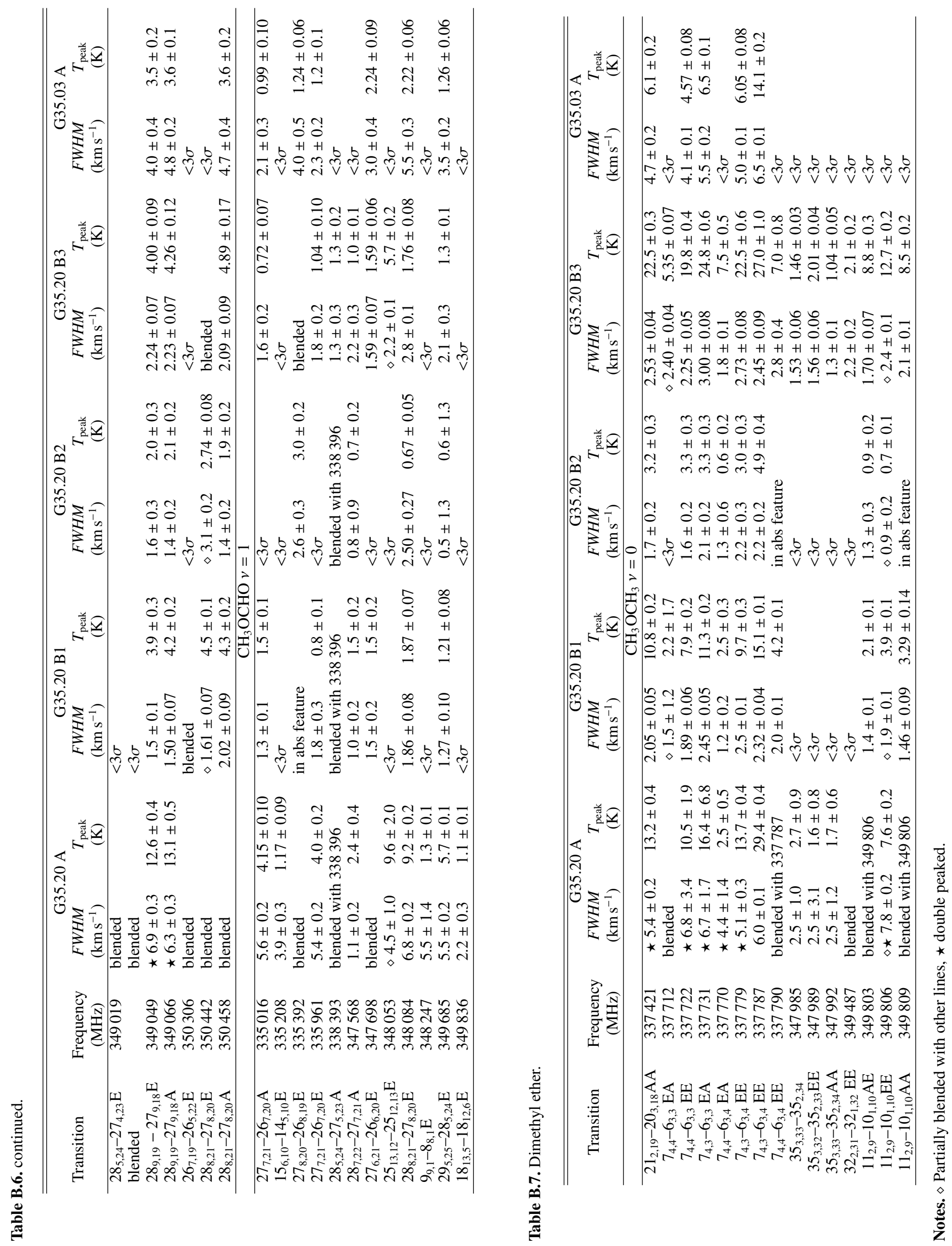


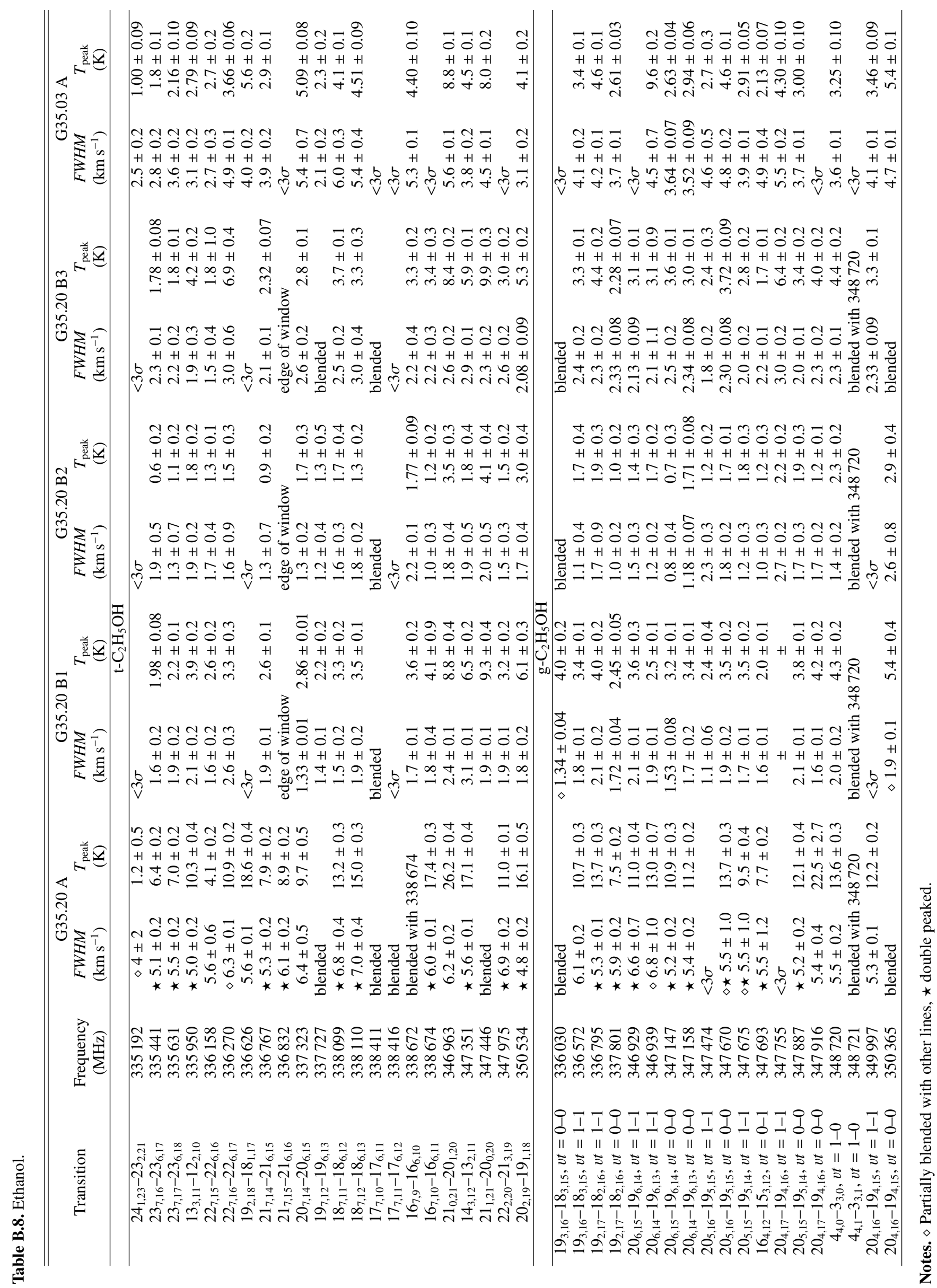




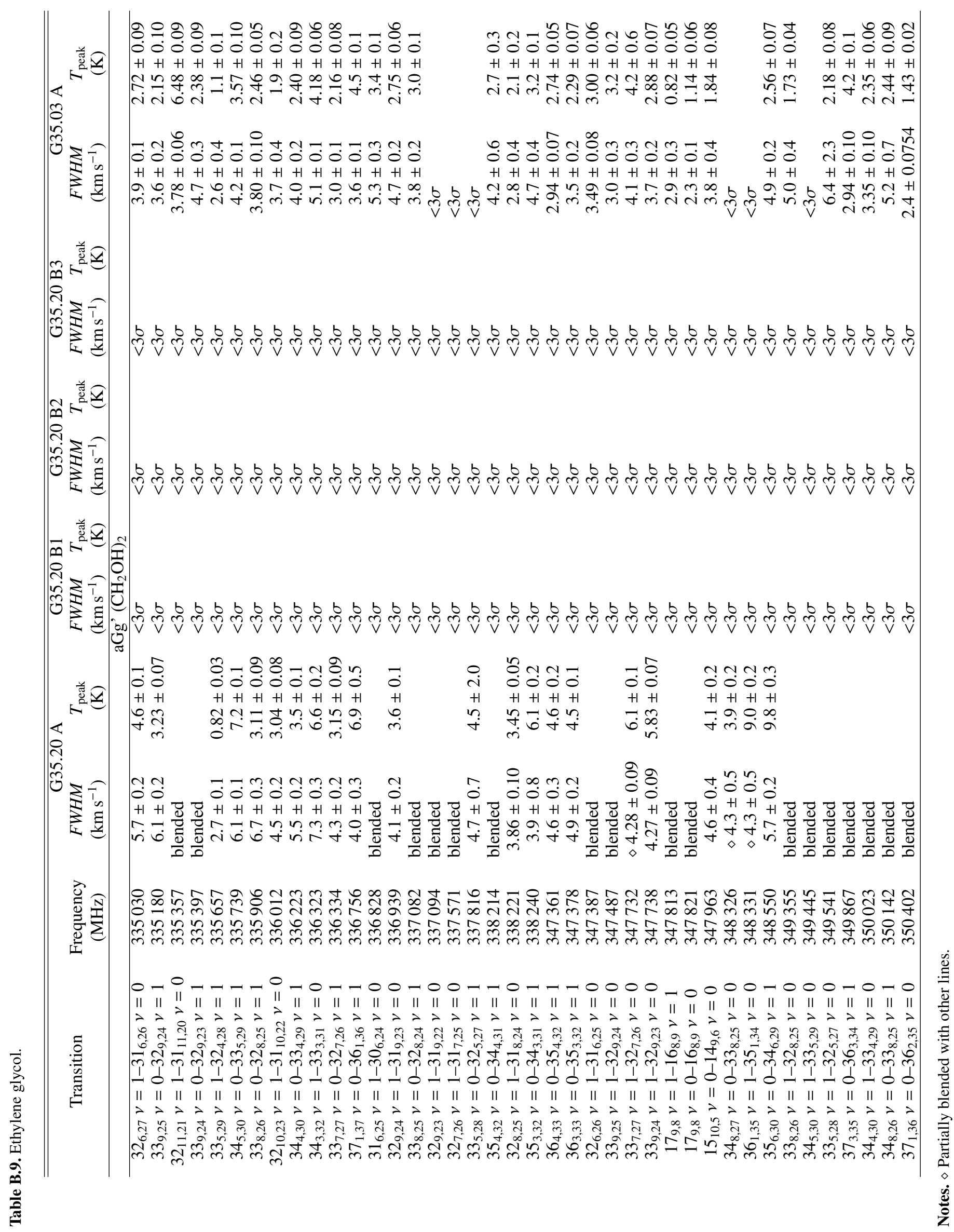




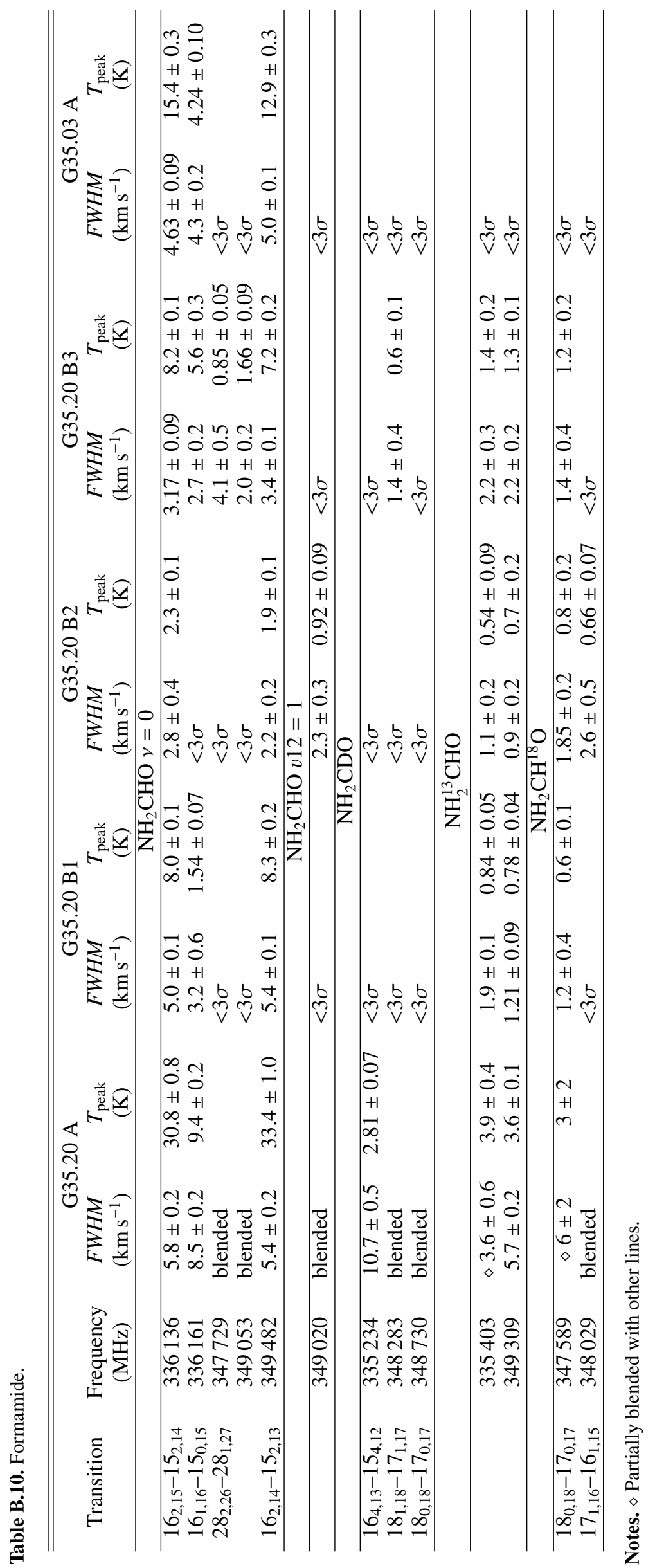


A\&A 603, A133 (2017)

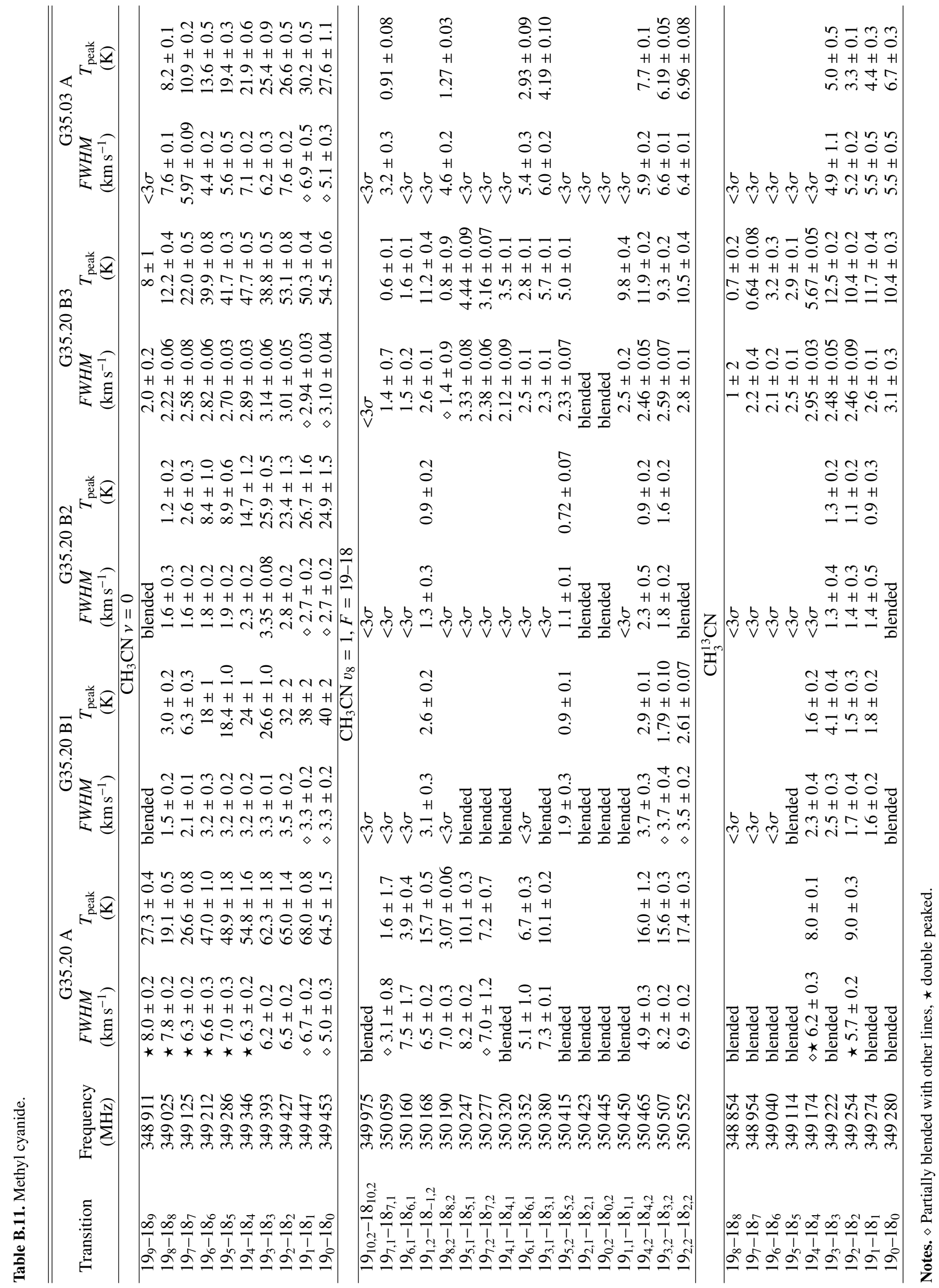



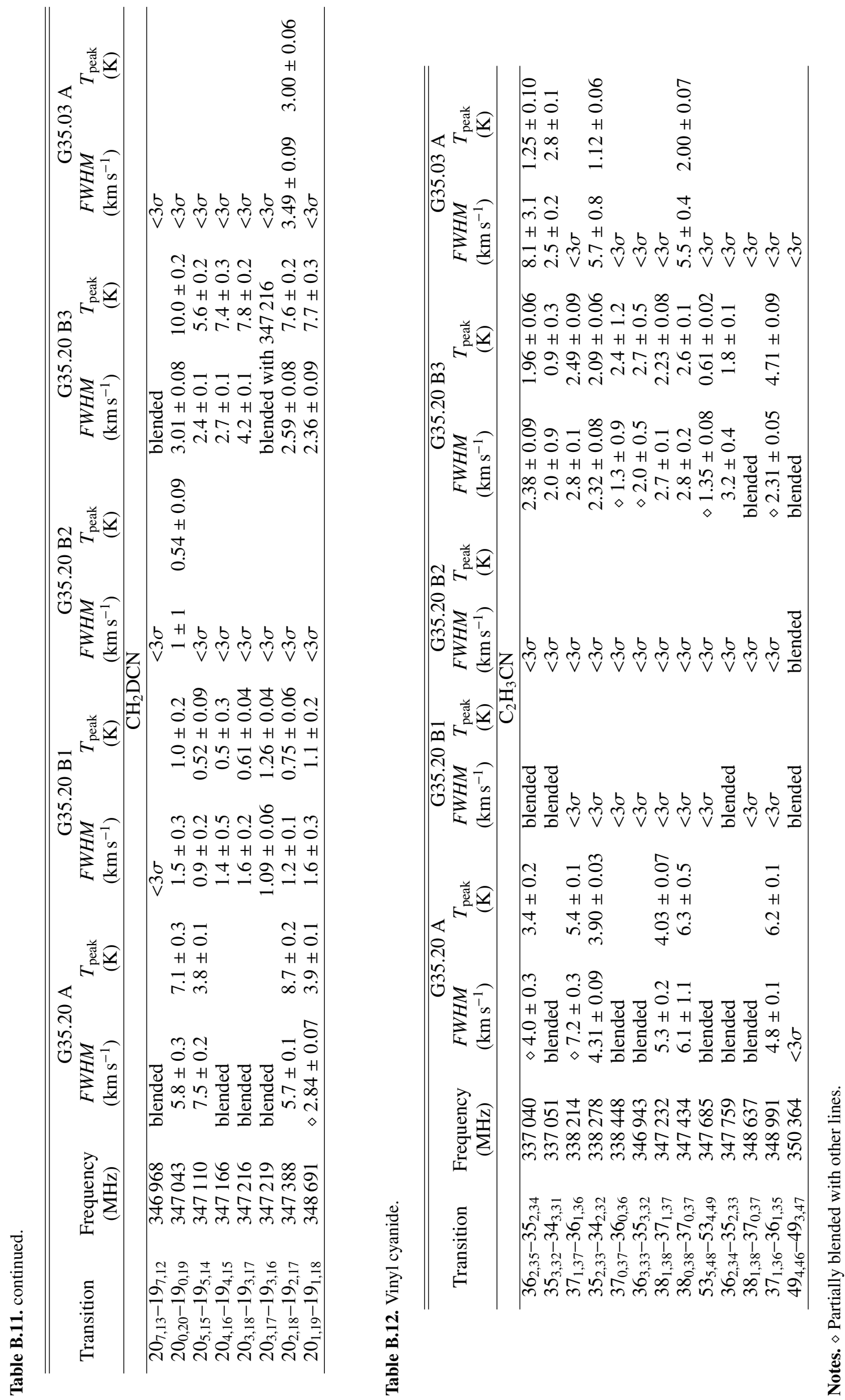


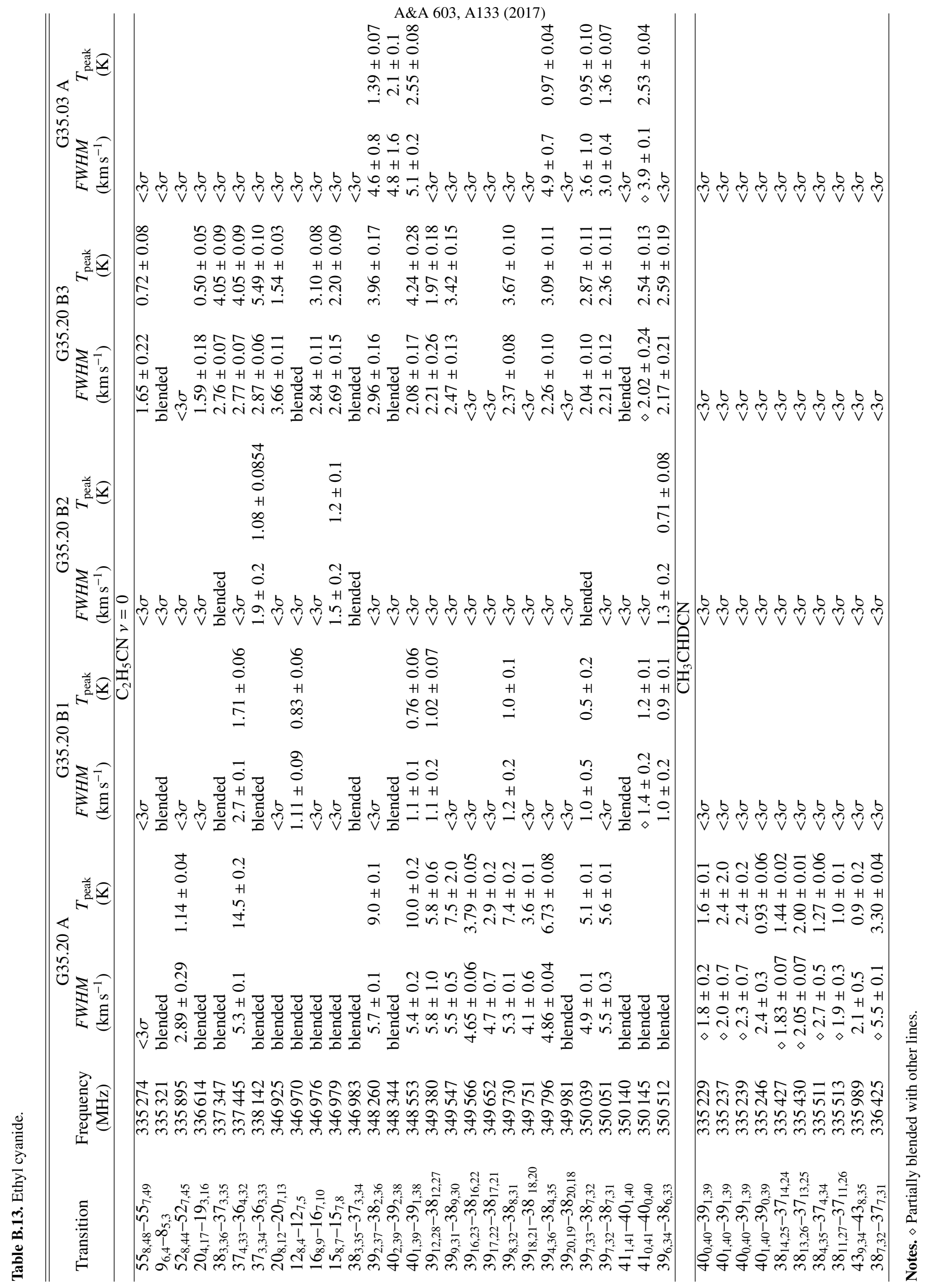




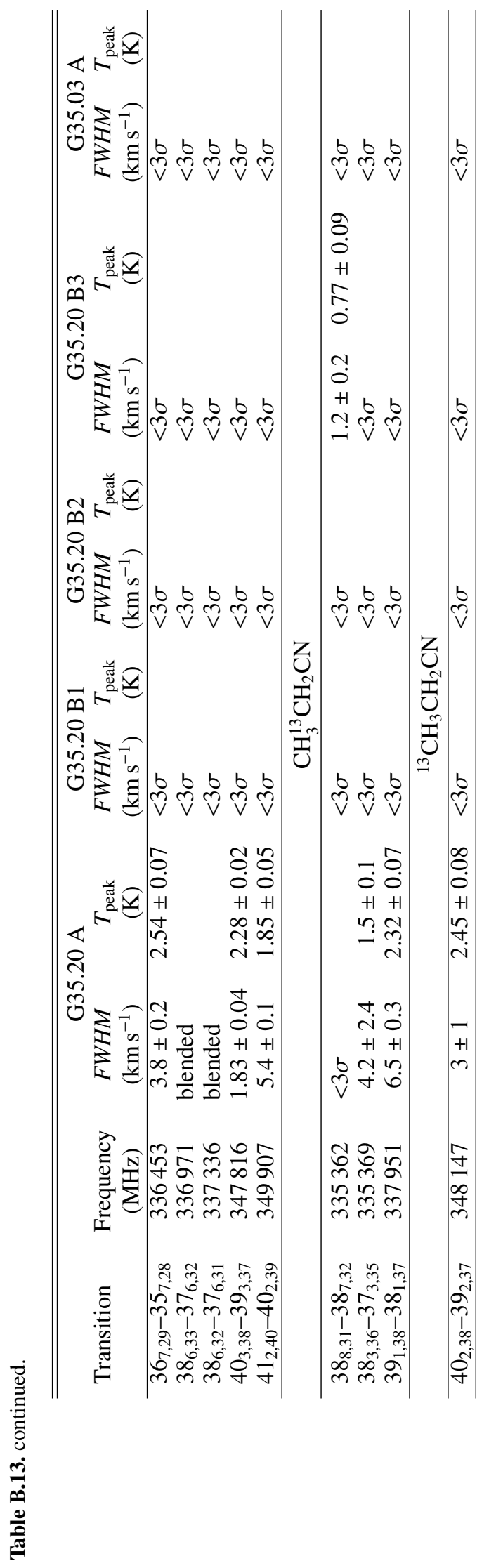


A\&A 603, A133 (2017)

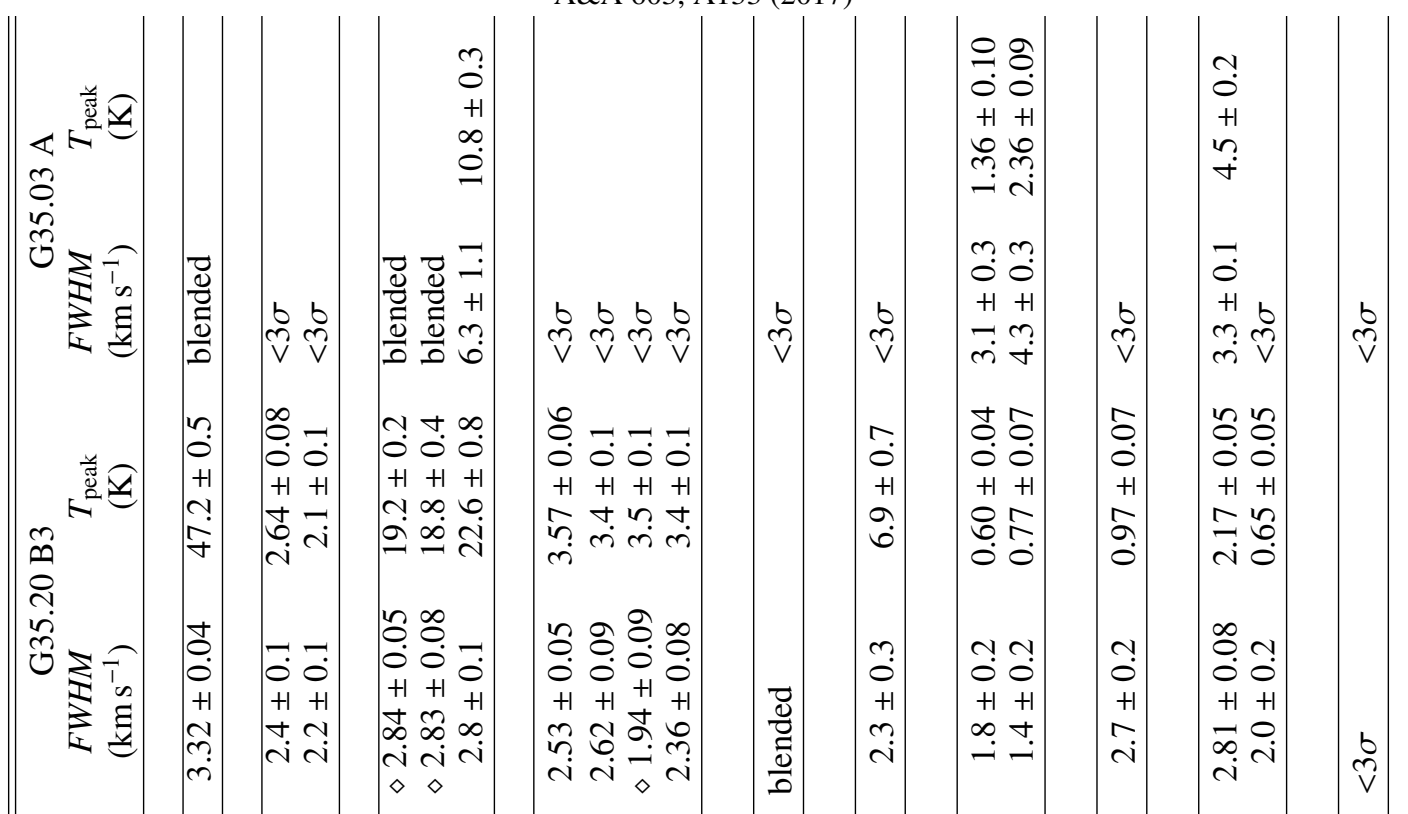

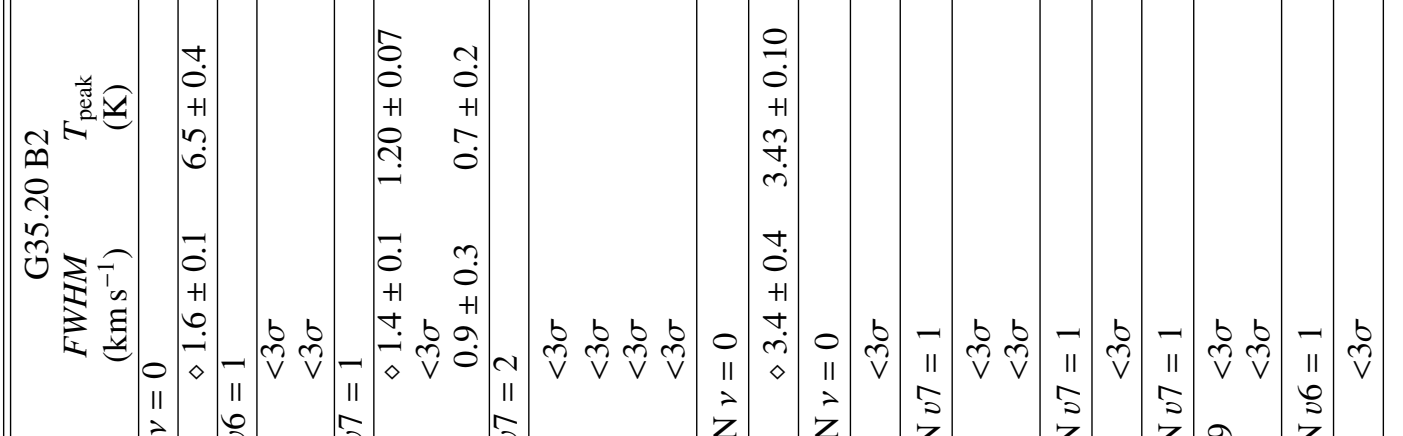

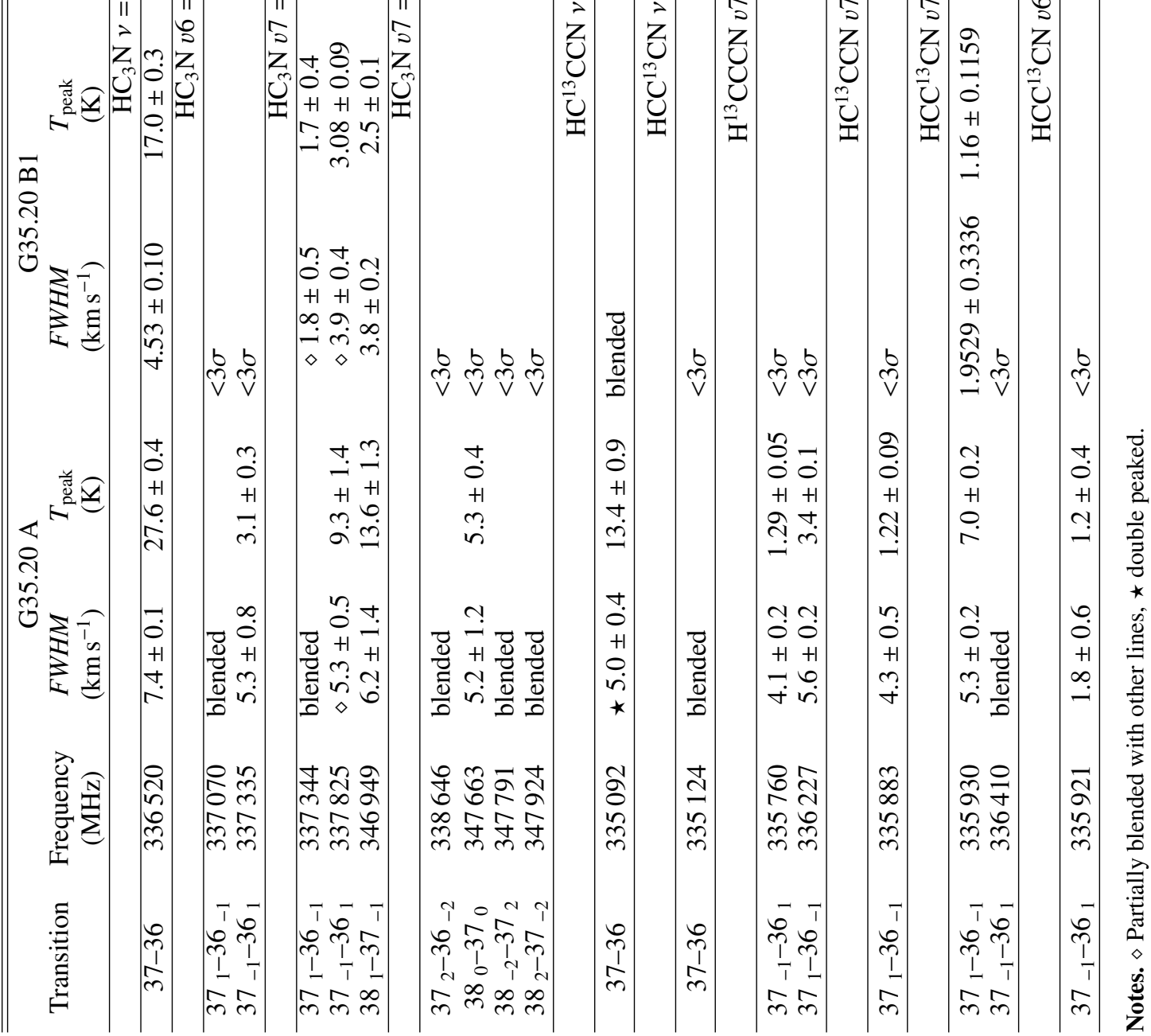


V. Allen et al.: Chemical segregation in hot cores with disk candidates
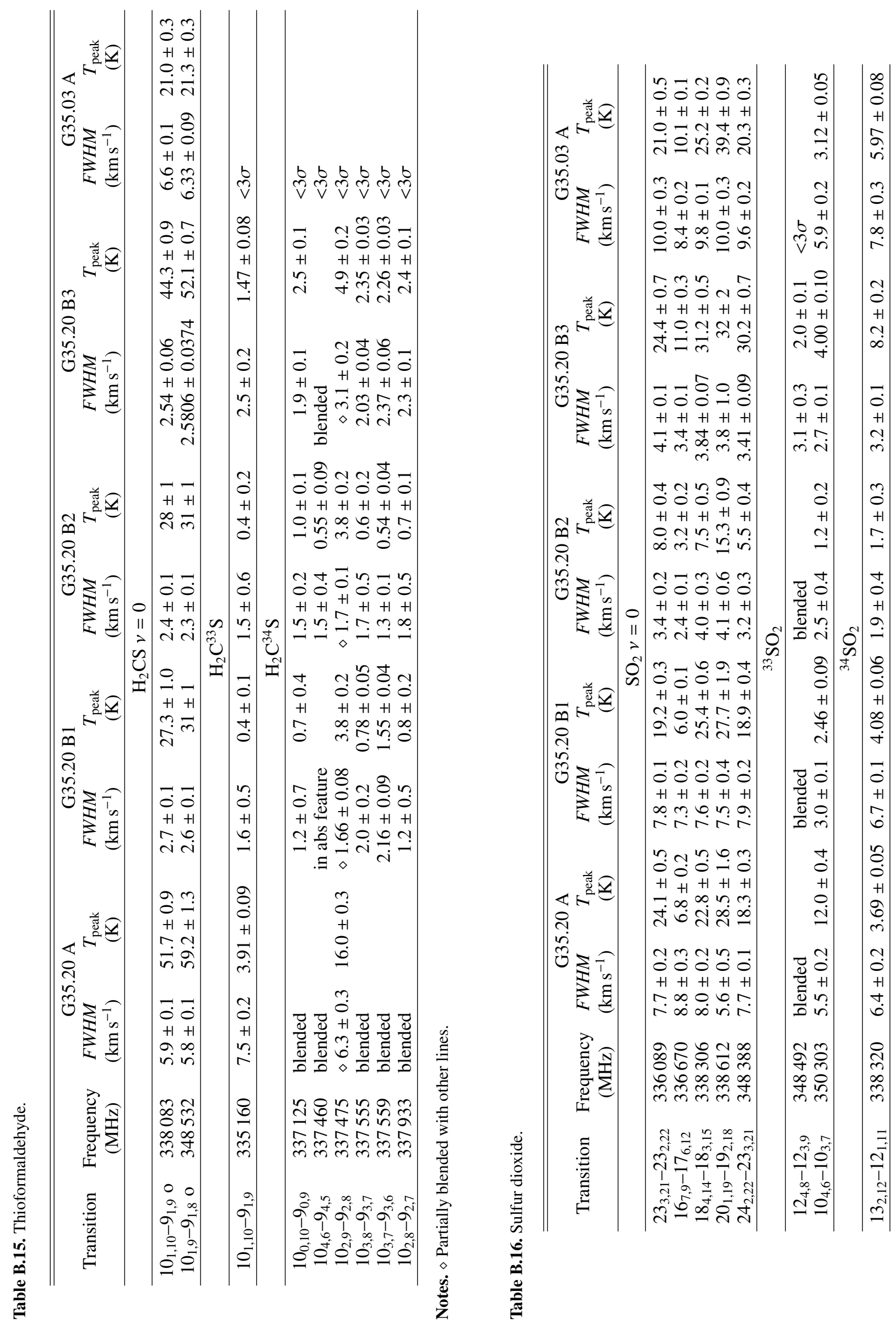

A133, page 37 of 52 


\section{Appendix C: XCLASS fit errors}

In this section we give the error values on each of our XCLASS fit results. They are rarely symmetrical, so they are reported in the format, value, lower error (-), and upper error (+), except for column density, which is listed as value, lower limit (valueerror), and upper limit (value+error). The errors were calculated using the interval nested sampling (INS) error estimator algorithm in XCLASS.

Table C.1. Error values for G35.20 A.

\begin{tabular}{|c|c|c|c|c|c|c|c|c|c|}
\hline Catalog entry & Source size & Error left & Error right & $T_{\text {ex }}$ & Error left & Error right & $N_{\text {col }}$ & Lower limit & Upper limit \\
\hline $\mathrm{CH} 3 \mathrm{OH} ; v=0$ & 0.6 & 0.2 & 0.3 & 164 & 18 & 36 & $3.52 \mathrm{E}+18$ & $6.88 \mathrm{E}+17$ & $7.00 \mathrm{E}+18$ \\
\hline $\mathrm{CH} 3 \mathrm{OH} ; v 12=1$ & 0.5 & 0.1 & 0.2 & 218 & 24 & 32 & $4.79 E+18$ & $9.77 \mathrm{E}+17$ & $3.00 \mathrm{E}+19$ \\
\hline $\mathrm{CH} 3 \mathrm{OH} ; v 12=2$ & 0.39 & 0.09 & 0.11 & 227 & 18 & 73 & $3.78 \mathrm{E}+18$ & $7.93 \mathrm{E}+17$ & $1.00 \mathrm{E}+19$ \\
\hline $\mathrm{C}-13-\mathrm{H} 3 \mathrm{OH} ; v=0$ & 1.0 & 0.3 & 0.2 & 121 & 70 & 39 & $1.62 \mathrm{E}+17$ & $4.27 \mathrm{E}+16$ & $3.00 \mathrm{E}+17$ \\
\hline СH3O-18-H; $v=0$; & 1.1 & 0.2 & 0.1 & 121 & 62 & 49 & $4.42 E+16$ & $1.35 \mathrm{E}+16$ & $7.00 \mathrm{E}+16$ \\
\hline $\mathrm{CH} 3 \mathrm{CN} ; v=0$ & 0.45 & 0.10 & 0.15 & 208 & 23 & 32 & $3.91 \mathrm{E}+16$ & $1.16 \mathrm{E}+16$ & $3.00 \mathrm{E}+17$ \\
\hline $\mathrm{CH} 3 \mathrm{CN} ; v 8=1 ;$ & 0.6 & 0.1 & 0.2 & 359 & 54 & 41 & $3.22 \mathrm{E}+16$ & $1.10 \mathrm{E}+16$ & $6.00 \mathrm{E}+16$ \\
\hline $\mathrm{CH} 2 \mathrm{DCN} ; v=0$ & 0.5 & 0.2 & 0.3 & 82 & 12 & 63 & $4.14 \mathrm{E}+15$ & $1.16 \mathrm{E}+15$ & $8.00 \mathrm{E}+15$ \\
\hline $\mathrm{CH} 3 \mathrm{C}-13-\mathrm{N} ; v=0 ;$ & 1.0 & 0.4 & 0.0 & 263 & 73 & 37 & $5.00 \mathrm{E}+14$ & $1.19 \mathrm{E}+14$ & $8.00 \mathrm{E}+14$ \\
\hline $\mathrm{CH} 3 \mathrm{OCHO} ; v=0 ;$ & 0.98 & 0.20 & 0.02 & 103 & 17 & 77 & $8.10 \mathrm{E}+16$ & $1.03 \mathrm{E}+16$ & $1.00 \mathrm{E}+17$ \\
\hline $\mathrm{CH} 3 \mathrm{OCH} 3 ; v=0 ;$ & 0.34 & 0.09 & 0.62 & 229 & 43 & 71 & $3.67 \mathrm{E}+17$ & $4.13 E+16$ & $8.00 \mathrm{E}+17$ \\
\hline $\mathrm{CH} 3 \mathrm{CHO} ; v=0 ;$ & 0.4 & 0.3 & 0.2 & 234 & 8 & 66 & $1.69 \mathrm{E}+16$ & $6.78 \mathrm{E}+14$ & $8.00 \mathrm{E}+16$ \\
\hline $\mathrm{CH} 3 \mathrm{CHO} ; v 15=1$; & 1.102 & 0.576 & 0.002 & 278 & 38 & 22 & $5.45 E+15$ & $1.09 \mathrm{E}+14$ & $1.00 \mathrm{E}+16$ \\
\hline СH3CHO; $v 15=2$; & 0.7 & 0.6 & 0.5 & 295 & 92 & 5 & $4.33 \mathrm{E}+15$ & $3.88 \mathrm{E}+13$ & $1.00 \mathrm{E}+16$ \\
\hline $\mathrm{HC}(\mathrm{O}) \mathrm{NH} 2 ; v=0$ & 0.7 & 0.2 & 0.8 & 98 & 9 & 62 & $7.58 \mathrm{E}+15$ & $2.34 \mathrm{E}+15$ & $3.00 \mathrm{E}+16$ \\
\hline $\mathrm{C} 2 \mathrm{H} 5 \mathrm{OH} ; v=0$ & 0.8 & 0.2 & 0.4 & 281 & 35 & 19 & $7.13 \mathrm{E}+16$ & $2.23 \mathrm{E}+16$ & $8.00 \mathrm{E}+17$ \\
\hline $\mathrm{H} 2 \mathrm{CS} ; v=0$ & 1.3 & 0.2 & 0.3 & 165 & 14 & 65 & $1.41 E+16$ & $4.10 \mathrm{E}+15$ & $3.00 \mathrm{E}+16$ \\
\hline $\mathrm{SO} 2 ; v=0$ & 1.36 & 0.10 & 0.30 & 260 & 52 & 40 & $1.74 \mathrm{E}+16$ & $4.43 \mathrm{E}+15$ & $1.50 \mathrm{E}+17$ \\
\hline $\mathrm{C} 2 \mathrm{H} 5 \mathrm{CN} ; v=0$; & 0.9 & 0.3 & 0.3 & 125 & 15 & 35 & $1.53 \mathrm{E}+16$ & $2.56 \mathrm{E}+15$ & $3.00 \mathrm{E}+16$ \\
\hline CH3CHDCN & 0.6 & 0.1 & 0.3 & 97 & 4 & 63 & $2.90 \mathrm{E}+15$ & $4.64 E+14$ & $5.00 \mathrm{E}+15$ \\
\hline $\mathrm{C} 2 \mathrm{H} 3 \mathrm{CN} ; v=0$; & 0.6 & 0.5 & 0.3 & 77 & 6 & 53 & $1.28 \mathrm{E}+16$ & $3.46 \mathrm{E}+15$ & $3.50 \mathrm{E}+16$ \\
\hline $\mathrm{HCCCN} ; v=0$ & 1.2 & 0.3 & 0.003 & 176 & 41 & 61 & $1.69 \mathrm{E}+15$ & $7.47 \mathrm{E}+14$ & $2.00 \mathrm{E}+16$ \\
\hline $\mathrm{HCCCN} ; v 6=1 ;$ & 0.6 & 0.1 & 0.3 & 200 & 22 & 68 & $3.08 \mathrm{E}+15$ & $1.04 \mathrm{E}+15$ & $8.00 \mathrm{E}+15$ \\
\hline $\mathrm{HCCCN} ; v 7=1 ;$ & 0.37 & 0.08 & 0.23 & 251 & 35 & 49 & $5.31 E+15$ & $1.22 \mathrm{E}+15$ & $9.00 \mathrm{E}+15$ \\
\hline $\mathrm{HCCCN} ; v 7=2$ & 0.20 & 0.03 & 0.40 & 350 & 51 & 105 & $2.22 \mathrm{E}+15$ & $3.93 \mathrm{E}+14$ & $7.00 \mathrm{E}+15$ \\
\hline $\mathrm{aGg}-(\mathrm{CH} 2 \mathrm{OH}) 2 ; v=0 ;$ & 0.6 & 0.2 & 0.6 & 172 & 27 & 28 & $3.47 \mathrm{E}+16$ & $9.06 \mathrm{E}+15$ & $6.00 \mathrm{E}+17$ \\
\hline $\mathrm{HCOOH}$ & 0.6 & 0.5 & 0.2 & 103 & 37 & 97 & $1.37 \mathrm{E}+16$ & $3.42 \mathrm{E}+15$ & $3.00 \mathrm{E}+17$ \\
\hline $\mathrm{H} 2 \mathrm{CO}-18 ; v=0$ & 0.6 & 0.2 & 0.4 & 188 & 53 & 66 & $8.51 \mathrm{E}+14$ & $3.56 \mathrm{E}+14$ & $5.00 \mathrm{E}+15$ \\
\hline
\end{tabular}


Table C.2. Error values for G35.20 B1.

\begin{tabular}{|c|c|c|c|c|c|c|c|c|c|}
\hline Catalog entry & Source size & Error left & Error right & $T_{\mathrm{ex}}$ & Error left & Error right & $N_{\mathrm{col}}$ & Lower limit & Upper limit \\
\hline $\mathrm{CH} 3 \mathrm{OH} ; v=0$ & 0.3 & 0.2 & 0.2 & 234 & 35 & 63 & $6.99 \mathrm{E}+17$ & $2.16 \mathrm{E}+17$ & $5.00 \mathrm{E}+18$ \\
\hline $\mathrm{CH} 3 \mathrm{OH} ; v 12=1$ & 0.36 & 0.06 & 0.12 & 153 & 3 & 25 & $1.07 \mathrm{E}+18$ & $3.34 \mathrm{E}+17$ & $5.00 \mathrm{E}+19$ \\
\hline $\mathrm{CH} 3 \mathrm{OH} ; v 12=2$ & 0.18 & 0.01 & 0.22 & 154 & 1 & 46 & $2.23 \mathrm{E}+18$ & $6.90 \mathrm{E}+17$ & $6.80 \mathrm{E}+18$ \\
\hline $\mathrm{C}-13-\mathrm{H} 3 \mathrm{OH} ; v=0$ & 0.3 & 0.2 & 0.2 & 113 & 41 & 36 & $3.87 E+16$ & $1.57 \mathrm{E}+16$ & $1.50 \mathrm{E}+17$ \\
\hline $\mathrm{CH} 3 \mathrm{O}-18-\mathrm{H} ; v=0 ;$ & 0.3 & 0.1 & 0.2 & 82 & 19 & 35 & $1.45 \mathrm{E}+16$ & $8.20 \mathrm{E}+15$ & $1.20 \mathrm{E}+17$ \\
\hline $\mathrm{CH} 3 \mathrm{CN} ; v=0$ & 0.32 & 0.09 & 0.16 & 129 & 78 & 20 & $7.24 \mathrm{E}+15$ & $5.45 \mathrm{E}+15$ & $1.32 \mathrm{E}+16$ \\
\hline $\mathrm{CH} 3 \mathrm{CN} ; v 8=1$ & 0.29 & 0.04 & 0.11 & 283 & 43 & 17 & $3.50 \mathrm{E}+15$ & $2.94 \mathrm{E}+15$ & $7.00 \mathrm{E}+16$ \\
\hline $\mathrm{CH} 2 \mathrm{DCN} ; v=0$ & 0.1 & 0.0 & 0.3 & 180 & 59 & 101 & $3.00 \mathrm{E}+13$ & $1.77 \mathrm{E}+13$ & $2.05 \mathrm{E}+15$ \\
\hline $\mathrm{CH} 3 \mathrm{C}-13-\mathrm{N} ; v=0$; & 0.7 & 0.2 & 0.3 & 262 & 34 & 38 & $2.01 E+14$ & $5.59 \mathrm{E}+13$ & $8.00 \mathrm{E}+14$ \\
\hline $\mathrm{CH} 3 \mathrm{OCHO} ; v=0$ & 0.5 & 0.1 & 0.2 & 285 & 79 & 15 & $4.49 E+16$ & $5.63 \mathrm{E}+15$ & $1.00 \mathrm{E}+17$ \\
\hline $\mathrm{CH} 3 \mathrm{OCH} 3 ; v=0 ;$ & 0.22 & 0.02 & 0.28 & 156 & 8 & 34 & $3.76 \mathrm{E}+17$ & $1.05 \mathrm{E}+17$ & $6.00 \mathrm{E}+17$ \\
\hline $\mathrm{CH} 3 \mathrm{CHO} ; v=0$ & 0.25 & 0.06 & 0.50 & 100 & 0 & 30 & $1.11 \mathrm{E}+16$ & $1.12 \mathrm{E}+15$ & $3.39 \mathrm{E}+16$ \\
\hline $\mathrm{CH} 3 \mathrm{CHO} ; v 15=1$; & 0.25 & 0.15 & 0.08 & 150 & 26 & 25 & $8.94 \mathrm{E}+14$ & $1.99 \mathrm{E}+13$ & $1.16 \mathrm{E}+16$ \\
\hline $\mathrm{CH} 3 \mathrm{CHO} ; v 15=2$ & $\star$ & & & & & & & & \\
\hline $\mathrm{HC}(\mathrm{O}) \mathrm{NH} 2 ; v=0$ & 0.3 & 0.2 & 0.2 & 50 & 0 & 100 & $5.67 \mathrm{E}+15$ & $2.15 E+15$ & $7.00 \mathrm{E}+16$ \\
\hline $\mathrm{C} 2 \mathrm{H} 5 \mathrm{OH} ; v=0$ & 0.7 & 0.2 & 0.3 & 78 & 24 & 63 & $6.03 E+15$ & $4.39 \mathrm{E}+15$ & $1.00 \mathrm{E}+17$ \\
\hline $\mathrm{H} 2 \mathrm{CS} ; v=0$ & 2.0 & 0.2 & 0.5 & 230 & 35 & 61 & $3.29 E+15$ & $1.48 \mathrm{E}+15$ & $7.00 \mathrm{E}+16$ \\
\hline $\mathrm{SO} 2 ; v=0$ & 1.44 & 0.09 & 0.95 & 279 & 36 & 21 & $3.28 \mathrm{E}+16$ & $8.15 E+15$ & $6.00 \mathrm{E}+17$ \\
\hline $\mathrm{C} 2 \mathrm{H} 5 \mathrm{CN} ; v=0$ & $\star$ & & & & & & & & \\
\hline $\mathrm{C} 2 \mathrm{H} 3 \mathrm{CN} ; v=0$ & $\star$ & & & & & & & & \\
\hline $\mathrm{HCCCN} ; v=0$ & 0.9 & 0.2 & 0.3 & 119 & 43 & 70 & $9.29 \mathrm{E}+14$ & $5.50 \mathrm{E}+14$ & $8.00 \mathrm{E}+15$ \\
\hline $\mathrm{HCCCN} ; v 6=1$ & $\star$ & & & & & & & & \\
\hline $\mathrm{HCCCN} ; v 7=1$ & 0.8 & 0.2 & 0.2 & 219 & 49 & 45 & $5.84 \mathrm{E}+14$ & $3.39 \mathrm{E}+14$ & $6.00 \mathrm{E}+14$ \\
\hline $\mathrm{HCCCN} ; v 7=2$ & $\star$ & & & & & & & & \\
\hline $\mathrm{H} 2 \mathrm{CO}-18 ; v=0$ & 0.3 & 0.1 & 0.3 & 41 & 1 & 61 & $5.66 \mathrm{E}+14$ & $3.46 \mathrm{E}+14$ & $7.00 \mathrm{E}+15$ \\
\hline $\mathrm{HCOOH}$ & 0.3 & 0.2 & 0.2 & 156 & 30 & 99 & $1.11 \mathrm{E}+15$ & $2.79 \mathrm{E}+14$ & $7.00 \mathrm{E}+16$ \\
\hline
\end{tabular}

Notes. Star $(\star)$ indicates a catalog entry that was not modeled.

Table C.3. Error values for G35.20 B2.

\begin{tabular}{|c|c|c|c|c|c|c|c|c|c|}
\hline Catalog entry & Source size & Error left & Error right & $T_{\mathrm{ex}}$ & Error left & Error right & $N_{\text {col }}$ & Lower limit & Upper limit \\
\hline $\mathrm{CH} 3 \mathrm{OH} ; v=0$ & 0.36 & 0.05 & 0.84 & 136 & 5 & 164 & $5.25 \mathrm{E}+17$ & $1.75 \mathrm{E}+17$ & $5.00 \mathrm{E}+19$ \\
\hline $\mathrm{CH} 3 \mathrm{OH} ; v 12=1$ & 0.32 & 0.05 & 0.38 & 145 & 0 & 155 & $6.18 \mathrm{E}+17$ & $2.24 \mathrm{E}+17$ & $5.00 \mathrm{E}+19$ \\
\hline $\mathrm{CH} 3 \mathrm{OH} ; v 12=2$ & 0.15 & 0.03 & 0.24 & 152 & 0 & 148 & $1.06 \mathrm{E}+18$ & $2.77 \mathrm{E}+17$ & $5.00 \mathrm{E}+19$ \\
\hline $\mathrm{C}-13-\mathrm{H} 3 \mathrm{OH} ; v=0$; & 1.1 & 0.2 & 0.1 & 97 & 34 & 36 & $7.99 \mathrm{E}+15$ & $4.94 \mathrm{E}+15$ & $1.00 \mathrm{E}+18$ \\
\hline $\mathrm{CH} 3 \mathrm{O}-18-\mathrm{H} ; v=0$ & 0.9 & 0.3 & 0.2 & 75 & 26 & 40 & $1.36 \mathrm{E}+15$ & $1.34 \mathrm{E}+15$ & $2.00 \mathrm{E}+17$ \\
\hline $\mathrm{CH} 3 \mathrm{CN} ; v=0$ & 0.62 & 0.08 & 0.08 & 132 & 7 & 10 & $1.30 \mathrm{E}+15$ & $1.20 \mathrm{E}+15$ & $1.74 \mathrm{E}+15$ \\
\hline $\mathrm{CH} 3 \mathrm{CN} ; v 8=1$ & $\star$ & & & & & & & & \\
\hline $\mathrm{CH} 2 \mathrm{DCN} ; v=0$ & $\star$ & & & & & & & & \\
\hline $\mathrm{CH} 3 \mathrm{C}-13-\mathrm{N} ; v=0 ;$ & 0.44 & 0.19 & 0.07 & 55 & 5 & 66 & $1.40 \mathrm{E}+14$ & $7.24 \mathrm{E}+13$ & $1.00 \mathrm{E}+16$ \\
\hline $\mathrm{CH} 3 \mathrm{OCHO} ; v=0 ;$ & 0.5 & 0.1 & 0.2 & 64 & 14 & 59 & $2.02 \mathrm{E}+16$ & $3.10 \mathrm{E}+15$ & $1.00 \mathrm{E}+17$ \\
\hline $\mathrm{CH} 3 \mathrm{OCH} 3 ; v=0 ;$ & 0.4 & 0.1 & 0.3 & 67 & 17 & 62 & $1.30 \mathrm{E}+16$ & $3.94 \mathrm{E}+15$ & $1.00 \mathrm{E}+18$ \\
\hline $\mathrm{CH} 3 \mathrm{CHO} ; v=0$ & 0.26 & 0.08 & 0.35 & 88 & 38 & 40 & $2.28 \mathrm{E}+15$ & $1.89 \mathrm{E}+14$ & $1.00 \mathrm{E}+17$ \\
\hline $\mathrm{CH} 3 \mathrm{CHO} ; v 15=1$; & $\star$ & & & & & & & & \\
\hline $\mathrm{CH} 3 \mathrm{CHO} ; v 15=2$; & $\star$ & & & & & & & & \\
\hline $\mathrm{HC}(\mathrm{O}) \mathrm{NH} 2 ; v=0$ & 0.6 & 0.2 & 0.3 & 45 & 30 & 55 & $2.32 \mathrm{E}+14$ & $2.01 \mathrm{E}+14$ & $4.79 E+16$ \\
\hline $\mathrm{C} 2 \mathrm{H} 5 \mathrm{OH} ; v=0$ & 0.12 & 0.02 & 0.31 & 297 & 247 & 0 & $1.01 \mathrm{E}+15$ & $1.01 \mathrm{E}+15$ & $4.17 \mathrm{E}+16$ \\
\hline $\mathrm{H} 2 \mathrm{CS} ; v=0$ & 1.0 & 0.0 & 1.0 & 50 & 0 & 183 & $1.18 \mathrm{E}+15$ & $5.01 \mathrm{E}+14$ & $1.00 \mathrm{E}+17$ \\
\hline $\mathrm{SO} 2 ; v=0$ & 2.42 & 0.69 & 0.08 & 114 & 66 & 48 & $6.58 \mathrm{E}+15$ & $2.25 \mathrm{E}+15$ & $1.00 \mathrm{E}+18$ \\
\hline $\mathrm{C} 2 \mathrm{H} 5 \mathrm{CN} ; v=0$ & $\star$ & & & & & & & & \\
\hline $\mathrm{C} 2 \mathrm{H} 3 \mathrm{CN} ; v=0$ & $\star$ & & & & & & & & \\
\hline $\mathrm{HCCCN} ; v=0$ & 0.8 & 0.3 & 0.3 & 122 & 44 & 99 & $1.96 \mathrm{E}+14$ & $1.58 \mathrm{E}+14$ & $1.00 \mathrm{E}+16$ \\
\hline $\mathrm{HCCCN} ; v 6=1$ & $\star$ & & & & & & & & \\
\hline $\mathrm{HCCCN} ; v 7=1$ & $\star$ & & & & & & & & \\
\hline $\mathrm{HCCCN} ; v 7=2$ & $\star$ & & & & & & & & \\
\hline $\mathrm{H} 2 \mathrm{CO}-18 ; v=0$ & 0.32 & 0.02 & 0.98 & 29 & 2 & 183 & $1.51 \mathrm{E}+15$ & $6.71 \mathrm{E}+14$ & $1.00 \mathrm{E}+16$ \\
\hline
\end{tabular}

Notes. Star $(\star)$ indicates a catalog entry that was not modeled. 
Table C.4. Error values for G35.20 B3

\begin{tabular}{|c|c|c|c|c|c|c|c|c|c|}
\hline Catalog entry & Source size & Error left & Error right & $T_{\mathrm{ex}}$ & Error left & Error right & $N_{\text {col }}$ & Lower limit & Upper limit \\
\hline $\mathrm{CH} 3 \mathrm{OH} ; v=0$ & 0.35 & 0.04 & 0.02 & 155 & 6 & 36 & $6.23 \mathrm{E}+17$ & $5.55 \mathrm{E}+17$ & $8.13 \mathrm{E}+17$ \\
\hline $\mathrm{CH} 3 \mathrm{OH} ; v 12=1$ & 0.36 & 0.02 & 0.07 & 189 & 14 & 14 & $9.81 \mathrm{E}+17$ & $7.62 \mathrm{E}+17$ & $1.12 \mathrm{E}+18$ \\
\hline $\mathrm{CH} 3 \mathrm{OH} ; v 12=2$ & 0.20 & 0.02 & 0.02 & 172 & 5 & 20 & $1.80 \mathrm{E}+18$ & $1.32 \mathrm{E}+18$ & $2.33 \mathrm{E}+18$ \\
\hline $\mathrm{C}-13-\mathrm{H} 3 \mathrm{OH} ; v=0$ & 1.20 & 0.06 & 0.03 & 89 & 10 & 9 & $1.63 \mathrm{E}+16$ & $1.20 \mathrm{E}+16$ & $1.93 \mathrm{E}+16$ \\
\hline $\mathrm{CH} 3 \mathrm{O}-18-\mathrm{H} ; v=0$ & 1.20 & 0.01 & 0.00 & 111 & 43 & 18 & $5.75 \mathrm{E}+15$ & $4.17 \mathrm{E}+15$ & $1.21 \mathrm{E}+16$ \\
\hline $\mathrm{CH} 3 \mathrm{CN} ; v=0$ & 0.35 & 0.06 & 0.04 & 208 & 30 & 30 & $6.46 \mathrm{E}+15$ & $5.21 \mathrm{E}+15$ & $1.06 \mathrm{E}+16$ \\
\hline $\mathrm{CH} 3 \mathrm{CN} ; v 8=1$ & 0.8 & 0.2 & 0.2 & 213 & 47 & 27 & $1.30 \mathrm{E}+15$ & $5.69 \mathrm{E}+14$ & $1.00 \mathrm{E}+18$ \\
\hline $\mathrm{CH} 2 \mathrm{DCN} ; v=0$ & 0.8 & 0.2 & 0.2 & 90 & 5 & 203 & $1.12 \mathrm{E}+15$ & $2.40 \mathrm{E}+14$ & $1.00 \mathrm{E}+16$ \\
\hline $\mathrm{CH} 3 \mathrm{C}-13-\mathrm{N} ; v=0$; & 0.7 & 0.1 & 0.3 & 118 & 14 & 156 & $5.44 \mathrm{E}+14$ & $1.97 \mathrm{E}+14$ & $1.00 \mathrm{E}+16$ \\
\hline $\mathrm{CH} 3 \mathrm{OCHO} ; v=0$; & 0.59 & 0.28 & 0.01 & 67 & 5 & 2 & $2.74 \mathrm{E}+16$ & $2.36 \mathrm{E}+16$ & $4.30 \mathrm{E}+16$ \\
\hline $\mathrm{CH} 3 \mathrm{OCH} 3 ; v=0 ;$ & 0.49 & 0.10 & 0.23 & 97 & 4 & 13 & $1.66 \mathrm{E}+17$ & $6.31 \mathrm{E}+16$ & $4.37 \mathrm{E}+17$ \\
\hline $\mathrm{CH} 3 \mathrm{CHO} ; v=0$ & 1.16 & 0.05 & 0.05 & 170 & 49 & 33 & $2.14 \mathrm{E}+15$ & $1.90 \mathrm{E}+15$ & $2.68 \mathrm{E}+15$ \\
\hline $\mathrm{CH} 3 \mathrm{CHO} ; v 15=1$; & 0.56 & 0.05 & 0.21 & 224 & 114 & 74 & $1.44 \mathrm{E}+15$ & $8.65 \mathrm{E}+14$ & $2.19 \mathrm{E}+15$ \\
\hline $\mathrm{CH} 3 \mathrm{CHO} ; v 15=2 ;$ & 0.12 & 0.02 & 0.03 & 102 & 1 & 2 & $8.07 \mathrm{E}+14$ & $2.46 \mathrm{E}+13$ & $1.40 \mathrm{E}+16$ \\
\hline $\mathrm{HC}(\mathrm{O}) \mathrm{NH} 2 ; v=0$ & 0.3 & 0.1 & 0.5 & 53 & 8 & 19 & $1.62 \mathrm{E}+15$ & $9.12 \mathrm{E}+14$ & $1.66 \mathrm{E}+16$ \\
\hline $\mathrm{C} 2 \mathrm{H} 5 \mathrm{OH} ; v=0$ & 0.43 & 0.03 & 0.06 & 178 & 35 & 87 & $1.29 \mathrm{E}+16$ & $1.02 \mathrm{E}+16$ & $1.51 \mathrm{E}+16$ \\
\hline $\mathrm{H} 2 \mathrm{CS} ; v=0$ & 0.9 & 0.1 & 1.1 & 87 & 23 & 123 & $6.05 \mathrm{E}+15$ & $1.99 \mathrm{E}+15$ & $1.00 \mathrm{E}+17$ \\
\hline $\mathrm{SO} 2 ; v=0$ & 1.3 & 0.2 & 1.2 & 288 & 73 & 12 & $3.92 \mathrm{E}+16$ & $8.92 \mathrm{E}+15$ & $1.00 \mathrm{E}+18$ \\
\hline $\mathrm{C} 2 \mathrm{H} 5 \mathrm{CN} ; v=0$ & 0.8 & 0.2 & 0.2 & 90 & 0 & 16 & $1.29 \mathrm{E}+15$ & $8.51 \mathrm{E}+14$ & $2.00 \mathrm{E}+15$ \\
\hline $\mathrm{C} 2 \mathrm{H} 3 \mathrm{CN} ; v=0$ & 0.8 & 0.3 & 0.1 & 207 & 77 & 49 & $7.29 E+14$ & $4.08 \mathrm{E}+14$ & $1.00 \mathrm{E}+16$ \\
\hline $\mathrm{HCCCN} ; v=0$ & 1.2 & 0.6 & 0.0 & 251 & 11 & 13 & $1.76 \mathrm{E}+15$ & $1.64 \mathrm{E}+15$ & $1.93 \mathrm{E}+15$ \\
\hline $\mathrm{HCCCN} ; v 6=1 ;$ & 0.4 & 0.3 & 0.3 & 256 & 34 & 34 & $2.43 \mathrm{E}+15$ & $1.53 \mathrm{E}+15$ & $3.54 \mathrm{E}+15$ \\
\hline $\mathrm{HCCCN} ; v 7=1 ;$ & 0.98 & 0.17 & 0.02 & 288 & 27 & 32 & $2.12 \mathrm{E}+15$ & $1.85 \mathrm{E}+15$ & $2.25 \mathrm{E}+15$ \\
\hline $\mathrm{HCCCN} ; v 7=2$ & 0.35 & 0.06 & 0.35 & 473 & 10 & 4 & $1.31 \mathrm{E}+15$ & $9.70 \mathrm{E}+14$ & $1.65 \mathrm{E}+15$ \\
\hline $\mathrm{HCOOH}$ & 0.4 & 0.3 & 0.5 & 173 & 38 & 22 & $3.82 \mathrm{E}+15$ & $1.70 \mathrm{E}+15$ & $1.00 \mathrm{E}+16$ \\
\hline $\mathrm{H} 2 \mathrm{CO}-18 ; v=0$ & 1.09 & 0.06 & 0.06 & 125 & 18 & 18 & $4.18 \mathrm{E}+14$ & $3.78 \mathrm{E}+14$ & $4.74 \mathrm{E}+14$ \\
\hline
\end{tabular}

Table C.5. Error values for G35.03 A.

\begin{tabular}{|c|c|c|c|c|c|c|c|c|c|}
\hline Catalog entry & Source size & Error left & Error right & $T_{\mathrm{ex}}$ & Error left & Error right & $N_{\mathrm{col}}$ & Lower limit & Upper limit \\
\hline $\mathrm{CH} 3 \mathrm{OH} ; v=0$ & 0.40 & 0.09 & 0.71 & 142 & 18 & 68 & $1.80 \mathrm{E}+18$ & $3.99 \mathrm{E}+17$ & $1.00 \mathrm{E}+19$ \\
\hline $\mathrm{CH} 3 \mathrm{OH} ; v 12=1$ & 0.30 & 0.06 & 0.62 & 239 & 40 & 61 & $2.64 \mathrm{E}+18$ & $6.01 \mathrm{E}+17$ & $1.00 \mathrm{E}+19$ \\
\hline $\mathrm{CH} 3 \mathrm{OH} ; v 12=2$ & 0.20 & 0.05 & 0.52 & 192 & 19 & 108 & $5.06 \mathrm{E}+18$ & $9.95 \mathrm{E}+17$ & $1.00 \mathrm{E}+19$ \\
\hline $\mathrm{C}-13-\mathrm{H} 3 \mathrm{OH} ; v=0$ & 0.6 & 0.1 & 0.6 & 120 & 24 & 51 & $5.00 \mathrm{E}+16$ & $1.58 \mathrm{E}+16$ & $1.00 \mathrm{E}+18$ \\
\hline $\mathrm{CH} 3 \mathrm{O}-18-\mathrm{H} ; v=0$; & 1.2 & 0.3 & 0.3 & 130 & 21 & 41 & $9.99 E+15$ & $3.48 \mathrm{E}+15$ & $1.00 \mathrm{E}+16$ \\
\hline $\mathrm{CH} 3 \mathrm{CN} ; v=0$ & 0.30 & 0.06 & 0.40 & 186 & 21 & 114 & $3.04 \mathrm{E}+16$ & $1.04 \mathrm{E}+16$ & $1.00 \mathrm{E}+19$ \\
\hline $\mathrm{CH} 3 \mathrm{CN} ; \mathrm{v} 8=1 ;$ & 0.30 & 0.05 & 0.20 & 216 & 19 & 54 & $3.57 \mathrm{E}+16$ & $1.35 \mathrm{E}+16$ & $1.29 \mathrm{E}+19$ \\
\hline $\mathrm{CH} 2 \mathrm{DCN} ; v=0 ;$ & $\star$ & & & & & & & & \\
\hline $\mathrm{CH} 3 \mathrm{C}-13-\mathrm{N} ; v=0 ;$ & 0.35 & 0.08 & 0.55 & 70 & 1 & 80 & $1.44 \mathrm{E}+15$ & $3.48 \mathrm{E}+14$ & $1.00 \mathrm{E}+18$ \\
\hline $\mathrm{CH} 3 \mathrm{OCHO} ; v=0$; & 0.2 & 0.1 & 0.2 & 100 & 21 & 66 & $2.29 \mathrm{E}+15$ & $2.13 \mathrm{E}+15$ & $1.00 \mathrm{E}+18$ \\
\hline $\mathrm{CH} 3 \mathrm{OCH} 3 ; v=0 ;$ & 0.7 & 0.2 & 0.1 & 150 & 39 & 56 & $8.27 \mathrm{E}+16$ & $2.45 \mathrm{E}+16$ & $2.68 \mathrm{E}+17$ \\
\hline $\mathrm{CH} 3 \mathrm{CHO} ; v=0$ & 0.5 & 0.3 & 0.3 & 120 & 21 & 77 & $1.29 \mathrm{E}+15$ & $8.11 \mathrm{E}+14$ & $1.00 \mathrm{E}+18$ \\
\hline $\mathrm{CH} 3 \mathrm{CHO} ; v 15=1$; & 0.5 & 0.3 & 0.3 & 220 & 53 & 91 & $1.29 \mathrm{E}+15$ & $9.55 \mathrm{E}+14$ & $1.00 \mathrm{E}+17$ \\
\hline $\mathrm{CH} 3 \mathrm{CHO} ; v 15=2$; & $\star$ & & & & & & & & \\
\hline $\mathrm{HC}(\mathrm{O}) \mathrm{NH} 2 ; v=0 ;$ & 0.8 & 0.2 & 0.4 & 43 & 1 & 78 & $4.68 \mathrm{E}+15$ & $1.74 \mathrm{E}+15$ & $1.86 \mathrm{E}+16$ \\
\hline $\mathrm{C} 2 \mathrm{H} 5 \mathrm{OH} ; v=0$ & 0.4 & 0.1 & 0.7 & 150 & 29 & 150 & $4.88 \mathrm{E}+16$ & $1.56 \mathrm{E}+16$ & $4.88 \mathrm{E}+17$ \\
\hline $\mathrm{H} 2 \mathrm{CS} ; v=0$ & 1.7 & 0.4 & 0.3 & 96 & 3 & 105 & $3.65 \mathrm{E}+15$ & $1.40 \mathrm{E}+15$ & $2.51 \mathrm{E}+16$ \\
\hline $\mathrm{SO} 2 ; v=0$ & 1.2 & 0.2 & 0.8 & 281 & 72 & 19 & $7.47 \mathrm{E}+16$ & $1.55 \mathrm{E}+16$ & $5.01 \mathrm{E}+17$ \\
\hline $\mathrm{C} 2 \mathrm{H} 5 \mathrm{CN} ; v=0$; & 0.5 & 0.1 & 0.3 & 78 & 7 & 70 & $4.98 \mathrm{E}+15$ & $1.20 \mathrm{E}+15$ & $2.07 \mathrm{E}+16$ \\
\hline $\operatorname{HCCCN} ; v=0$ & 0.6 & 0.2 & 0.2 & 140 & 27 & 61 & $2.28 \mathrm{E}+15$ & $9.95 \mathrm{E}+14$ & $1.00 \mathrm{E}+16$ \\
\hline $\mathrm{HCCCN} ; v 7=1$ & 0.8 & 0.2 & 0.2 & 194 & 21 & 32 & $5.87 \mathrm{E}+15$ & $1.87 \mathrm{E}+15$ & $1.84 \mathrm{E}+16$ \\
\hline $\mathrm{HCOOH}$ & 0.7 & 0.3 & 0.2 & 100 & 48 & 82 & $5.00 \mathrm{E}+15$ & $1.70 \mathrm{E}+15$ & $1.00 \mathrm{E}+16$ \\
\hline $\mathrm{aGg}^{\prime}-(\mathrm{CH} 2 \mathrm{OH}) 2 ; v=0$; & 0.70 & 0.10 & 0.50 & 100 & 3 & 50 & $2.81 \mathrm{E}+16$ & $4.99 \mathrm{E}+15$ & $1.00 \mathrm{E}+17$ \\
\hline $\mathrm{H} 2 \mathrm{CO}-18 ; v=0$ & 0.50 & 0.03 & 0.20 & 52 & 0 & 128 & $2.10 \mathrm{E}+14$ & $1.56 \mathrm{E}+14$ & $1.00 \mathrm{E}+15$ \\
\hline
\end{tabular}

Notes. Star $(\star)$ indicates a catalog entry that was not modeled. 


\section{Appendix D: XCLASS analysis details}

\section{D.1. S-bearing}

We detected two S-bearing species with more than one transition in our sources.

- Sulfur dioxide $\left(\mathrm{SO}_{2}\right)$ - as a species with extended emission, the source size ranges from $1.2^{\prime \prime}$ at G35.03 to $2.4^{\prime \prime}$ at B2. The column densities for this species are relatively consistent at $0.6-4.3 \times 10^{16} \mathrm{~cm}^{-2}$ across G35.20 and $7.5 \times 10^{16} \mathrm{~cm}^{-2}$ at G35.03. The $T_{\text {ex }}$ values are from $114 \mathrm{~K}$ in $\mathrm{B} 2$ to $288 \mathrm{~K}$ in B3. The fits were based on 24 different transitions within the spectral window, five of which were measured in the survey (others were not present or within the noise).

- Thioformaldehyde $\left(\mathrm{H}_{2} \mathrm{CS}\right)$ - this species was observed to have fairly extended emission so the source size ranged from $0.9^{\prime \prime}$ for $\mathrm{B} 3$ to $2.5^{\prime \prime}$ for $\mathrm{B} 1$. The $T_{\mathrm{ex}}$ range is on the cooler side at $50 \mathrm{~K}$ for B2, less than $100 \mathrm{~K}$ for B1, B3, and $\mathrm{G} 35.03$, and $165 \mathrm{~K}$ at $\mathrm{A}$. A had the highest column density at $1.4 \times 10^{16} \mathrm{~cm}^{-2}$, where the others ranged from $1.2-$ $6.1 \times 10^{15} \mathrm{~cm}^{-2}$.

\section{D.2. O-bearing organics}

- Formaldehyde $\left(\mathrm{H}_{2} \mathrm{CO}\right)$ - only the isotopologues $\mathrm{H}_{2} \mathrm{C}^{18} \mathrm{O}$, $\mathrm{HDCO}$, and $\mathrm{D}_{2} \mathrm{CO}$ were in the spectral range of these observations. See Appendix D.6.

- Formic acid $(\mathrm{HCOOH})$ - this species was detected at all peaks, but it was not modeled for B2 because the emission lines were only just above $3 \sigma$.

- Methanol $\left(\mathrm{CH}_{3} \mathrm{OH}\right)$ - the $v=0$ state of $\mathrm{CH}_{3} \mathrm{OH}$ was modeled to a maximum source size of $1^{\prime \prime}$, so the source size fits were $0.4-0.6^{\prime \prime}$. The temperature range was from 132$268 \mathrm{~K}$. The column densities for this species ranged from $0.3-4.8 \times 10^{18} \mathrm{~cm}^{-2}$. The vibrationally excited states and isotopologues were modeled separately as their spatial extents are different from the main state and are likely part of different gas; see Appendices C.5 and C.6.

- Acetaldehyde $\left(\mathrm{CH}_{3} \mathrm{CHO}\right)$ - the $v=0$ state was modeled separately from the vibrationally excited states (see subsection D.5). This species was observed to have a fairly compact emitting region, so the source size was limited to $1.5^{\prime \prime}$. The best-fit source sizes were $0.3-1.2^{\prime \prime}$ with relatively high excitation temperatures between $193 \mathrm{~K}$ and $300 \mathrm{~K}$. The column densities ranged from $1.5-17 \times 10^{15} \mathrm{~cm}^{-2}$.

- Methyl formate $\left(\mathrm{CH}_{3} \mathrm{OCHO}\right)$ - only the $v=0$ state was fit as the $v=1$ transitions were not in the XCLASS database. The emission from this species was fairly compact so the model was allowed a maximum source size of $1.2^{\prime \prime}$. The final source sizes were $0.2-1.0^{\prime \prime}$ and column densities ranged from 1.9$29 \times 10^{16} \mathrm{~cm}^{-2}$. Generally the $T_{\mathrm{ex}}$ values were high $(182-$ $295 \mathrm{~K}$ for B1, B2, and B3), but the excitation temperatures of $\mathrm{A}$ and $\mathrm{G} 35.03$ were $103 \mathrm{~K}$ and $151 \mathrm{~K}$, respectively.

- Dimethyl ether $\left(\mathrm{CH}_{3} \mathrm{OCH}_{3}\right)$ - there was a lot of variation between the sources for this species. The source size was very compact for $\mathrm{A}, \mathrm{B} 1$, and $\mathrm{B} 2\left(0.3,0.4\right.$, and $0.5^{\prime \prime}$, respectively), but more extended for B3 and G35.03 at $0.8^{\prime \prime}$. The temperature differences were also large. The $T_{\mathrm{ex}}$ for B3 was $90 \mathrm{~K}, 170$, and $180 \mathrm{~K}$ for B2 and B1, $229 \mathrm{~K}$ at A, and $260 \mathrm{~K}$ at G35.03. The column densities were lower for B2 $\left(1.6 \times 10^{16} \mathrm{~cm}^{-2}\right)$ and higher for the other peaks $\left(8.8 \times 10^{16}\right.$ $\left.9.7 \times 10^{17} \mathrm{~cm}^{-2}\right)$.

- Ethanol $\left(\mathrm{C}_{2} \mathrm{H}_{5} \mathrm{OH}\right)$ - the trans- and gauche- transitions for ethanol were modeled from a single JPL database entry. The temperatures varied widely with best-fit values of $88 \mathrm{~K}$ for B1 and $120 \mathrm{~K}$ for B2, and much higher values of 260, 281, and $300 \mathrm{~K}$ for B3, A and G35.03, respectively. The column densities ranged between 0.6 and $7.1 \times 10^{16} \mathrm{~cm}^{-2}$ range with the lowest at B1 and B2 and the highest at A. The source sizes were $0.4-0.8^{\prime \prime}$.

- Ethylene glycol $\left(\left(\mathrm{CH}_{2} \mathrm{OH}\right)_{2}\right)$ - this species was only modeled for G35.20 core A and for G35.03 as it was not detected in any part of core B. In G35.20 core A and G35.03, the best-fit source sizes are $0.6^{\prime \prime}$ and $0.2^{\prime \prime}$, respectively, and the $T_{\text {ex }}$ was $172 \mathrm{~K}$ for $\mathrm{G} 35.20$ and $75 \mathrm{~K}$ in G35.03. The column densities were $3.5 \times 10^{16} \mathrm{~cm}^{-2}$ in G35.20 core $A$ and $7.8 \times 10^{16} \mathrm{~cm}^{-2}$ in $\mathrm{G} 35.03$.

\section{D.3. N-bearing organics}

- Cyanoacetylene $\left(\mathrm{HC}_{3} \mathrm{~N}\right)$ - the $v=0$ state was modeled for all regions and the isotopologue $\mathrm{HC}^{13} \mathrm{CCN} v=0$ was coupled with $\mathrm{HC}_{3} \mathrm{~N} v=0$ to improve the uncertainty (from fitting one transition to fitting two). The fit for $\mathrm{HCC}^{13} \mathrm{CN}$ $v=0$ was also coupled for B3, as this is the only location where this species was detected. When fits of species are coupled together they share the same temperature and source size, but the isotope ratio (and therefore the column density) vary. See Appendix C.5 for excited states. The column densities for this species ranged from $2.1 \times 10^{14} \mathrm{~cm}^{-2}$ at B2 to $2.2 \times 10^{15} \mathrm{~cm}^{-2}$ at G35.03. The source sizes were fairly consistent, ranging between 0.9 and $1.2^{\prime \prime}$ and the $T_{\text {ex }}$ range was 132-208 K.

- Methyl cyanide $\left(\mathrm{CH}_{3} \mathrm{CN}\right)$ - the $v=0$ state was modeled for all regions, but the isotopologues were not coupled with the main species because their spatial extents were dramatically different. The modeled source sizes for this species were quite compact, i.e., 0.3-0.6"; the temperature range was $124-235 \mathrm{~K}$. The range of column densities was 1.8 $7.2 \times 10^{16} \mathrm{~cm}^{-2}$. See Appendices D.5 and D.6 for excited states and isotopologues.

- Vinyl cyanide $\left(\mathrm{C}_{2} \mathrm{H}_{3} \mathrm{CN}\right)$ - the results for vinyl cyanide are very different for the two regions where it was detected. G35.20 A has a source size of $0.6^{\prime \prime}$, an excitation temperature of $77 \mathrm{~K}$, and a column density of $1.3 \times 10^{16} \mathrm{~cm}^{-2}$. On the other end of this source, B3 has a size of $0.8^{\prime \prime}$, a $T_{\mathrm{ex}}$ of $207 \mathrm{~K}$, and a column density of $7.3 \times 10^{14} \mathrm{~cm}^{-2}$.

- Ethyl cyanide $\left(\mathrm{C}_{2} \mathrm{H}_{5} \mathrm{CN}\right)$ - this species was only modeled for $\mathrm{G} 35.20$ core A, region B3, and G35.03 core A. The temperatures for this species were all low compared to many of the other species. At B3, the $T_{\mathrm{ex}}$ was $50 \mathrm{~K}$, at $\mathrm{A}$ it was $71 \mathrm{~K}$, and at $\mathrm{G} 35.03$ it was $78 \mathrm{~K}$. Column densities were 5.0$45 \times 10^{15} \mathrm{~cm}^{-2}$ with the highest value at B3 and the source sizes were somewhat similar at $0.3^{\prime \prime}$ for $\mathrm{B} 3,0.5^{\prime \prime}$ for $\mathrm{G} 35.03$, and $0.6^{\prime \prime}$ for $\mathrm{A}$.

\section{D.4. $\mathrm{H}-, \mathrm{N}-$, and O-bearing organics}

- Isocyanic acid (HNCO) - the fit was based on a single strong transition so some assumptions were made. The source size was fixed based on the $3 \sigma$ level emission and the column density was modeled at temperatures of $50 \mathrm{~K}$ and $100 \mathrm{~K}$. These temperatures are reasonable for a more extended emitting region, as the bulk of the emission is not likely to come from very near the heating source. The resulting column densities are between $2.2 \times 10^{15} \mathrm{~cm}^{-2}$ and $2.0 \times 10^{16} \mathrm{~cm}^{-2}$ at 
$50 \mathrm{~K}$ and range from $9.4 \times 10^{14} \mathrm{~cm}^{-2}$ to $7.5 \times 10^{16} \mathrm{~cm}^{-2}$ at $100 \mathrm{~K}$.

- Formamide $\left(\mathrm{NH}_{2} \mathrm{CHO}\right)$ - the $v=0$ transitions were fit with the $\mathrm{NH}_{2}{ }^{13} \mathrm{CHO}$ transitions coupled with the same parameters except abundance. The temperatures for this species were comparatively low, ranging from $43-100 \mathrm{~K}$. The best-fit source sizes were between $0.5^{\prime \prime}$ (at B1) and $0.8^{\prime \prime}$ at G35.03. The range of column densities is $0.3-7.6 \times 10^{15} \mathrm{~cm}^{-2}$.

\section{D.5. Vibrationally excited transitions}

High energy transitions were modeled uncoupled to the main state as those in our sources are observed to emit from a much smaller area than lower energy transitions (see Figs. 3 and 4) and many are not observed in B1 or B2. Vibrationally excited emission from $\mathrm{HC}_{3} \mathrm{~N}$ is only found toward cores $\mathrm{A}$ and $\mathrm{B} 3$ and weakly toward B1. See Fig. 8 .

- Methanol $\left(\mathrm{CH}_{3} \mathrm{OH}\right)$ - the $v_{12}=1$ and $v_{12}=2$ excited states were modeled separately on the assumption that the different excited states are emitted in different gas, since the spatial extent of each excited state grows more compact with increased energy (see Sect. 2.3 and Sánchez-Monge et al. 2014, Fig. 6). The source sizes for the $v_{12}=2$ are more compact than the $v_{12}=1$ states and generally have a higher temperature. The range of column densities between the two states are similar at $0.3-4.8 \times 10^{18} \mathrm{~cm}^{-2}$ for $v_{12}=1$ and 1.9$5.1 \times 10^{18} \mathrm{~cm}^{-2}$ for $v_{12}=2$.

- Cyanoacetylene $\left(\mathrm{HC}_{3} \mathrm{~N}\right)$ - each of the vibrational states $\left(v_{6}=1, v_{7}=1, v_{7}=2\right)$ were modeled separately and the source size was more compact with higher excitation. No vibrationally excited states were modeled for B2, as they were not detected in the observations and only the $v_{7}=1$ state was modeled for B1 and G35.03. The $v_{6}=1$ state was modeled for $\mathrm{A}$ and $\mathrm{B} 3$ and was coupled with $\mathrm{HCC}^{13} \mathrm{CN}$ with the ${ }^{12} \mathrm{C} /{ }^{13} \mathrm{C}$ isotope ratio fixed at 50 . The resulting temperatures based on these 2-3 transitions was $200 \mathrm{~K}$ at $\mathrm{A}$ and $365 \mathrm{~K}$ at B3 with source sizes of 0.6 and $0.4^{\prime \prime}$. Both peaks had similar column densities at 3.1 and $2.7 \times 10^{15} \mathrm{~cm}^{-2}$, only slightly more than those of the $v=0$ state. The $v_{7}=1$ state was also modeled coupled with the three different ${ }^{13} \mathrm{C}$ isotopologues for $\mathrm{A}$ and $\mathrm{B} 3$ with the isotope ratio fixed at 50. The $v_{7}=1$ source size is more compact for all modeled sources, but still somewhat extended at $0.8-1.0^{\prime \prime}$. The excitation temperatures are $25-80 \mathrm{~K}$ higher than the $v=0$ state, ranging from $194 \mathrm{~K}$ at $\mathrm{G} 35.03$ to $283 \mathrm{~K}$ for both $\mathrm{A}$ and B3. The abundances of the $v_{7}=1$ state are similar to those of the $v=0$ state, but for A, the abundance is about 0.45 ; for B1 and B3 the abundances are almost equal, and for G35.03, the $v_{7}=1$ abundance is about twice the abundance of the $v=0$ state. The $v_{7}=2$ state was only modeled for A and B3 where the emission becomes very compact, i.e., 0.1 and $0.3^{\prime \prime}$, the temperature is very hot, i.e., $420-450 \mathrm{~K}$, and the abundances are 1.3 and 0.7 times higher than the $v=0$ state.

- Methyl cyanide $-\mathrm{CH}_{3} \mathrm{CN} v_{8}=1$ was modeled separately since its spatial distribution was significantly different from that of the $v=0$ transitions. The $v_{8}=1$ emission was not modeled for region B2 since it was not detected to a significant degree. Temperatures for this species are generally high, ranging from $215-360 \mathrm{~K}$ with compact source sizes of $0.3-$ $0.6^{\prime \prime}$. The column densities for this excited species are 0.4 $3.6 \times 10^{16} \mathrm{~cm}^{-2}$, which are similar to those of the $v=0$ state.

- Acetaldehyde $\left(\mathrm{CH}_{3} \mathrm{CHO}\right)-$ the $v_{15}=1$ and $v_{15}=2$ excited states were modeled as more compact emission sources than the $v=0$ state. Fits were made for the $v_{15}=1$ state for all sources except B2, but only for A and B3 for the $v_{15}=2$ state. In all sources the temperature increases with increasing excitation and the source size decreases. The column densities for both excited states range from 3.5-9.8 $\times 10^{15} \mathrm{~cm}^{-2}$ though the column density for the $v_{15}=2$ state at B3 is $5.2 \times 10^{16} \mathrm{~cm}^{-2}$.

\section{D.6. Isotopologues and deuteration}

- Formaldehyde $\left(\mathrm{H}_{2} \mathrm{CO}\right)$ - only the isotopologues HDCO, $\mathrm{D}_{2} \mathrm{CO}$, and $\mathrm{H}_{2} \mathrm{C}^{18} \mathrm{O}$ were in the spectral range of these observations. These were modeled separately where the $\mathrm{H}_{2} \mathrm{C}^{18} \mathrm{O}$ fit was based on six transitions and the HDCO fit was based on a single transition. For $\mathrm{H}_{2} \mathrm{C}^{18} \mathrm{O}$ the size ranges from 0.24 $0.75^{\prime \prime}$ and the temperatures are $26 \mathrm{~K}$ for $\mathrm{B} 2$ to $275 \mathrm{~K}$ for A. The range of column densities is $0.4-4.6 \times 10^{15} \mathrm{~cm}^{-2}$. The abundances for HDCO are also on the order of $0.15-$ $1.6 \times 10^{15} \mathrm{~cm}^{-2}$ at $50 \mathrm{~K}$ and $0.3-16 \times 10^{14} \mathrm{~cm}^{-2}$ at $100 \mathrm{~K}$ with the source size fixed at $1.5^{\prime \prime} . \mathrm{D}_{2} \mathrm{CO}$ was not fitted as only single weak lines were detected.

- Methanol $-\mathrm{CH}_{3}{ }^{18} \mathrm{OH}$ and ${ }^{13} \mathrm{CH}_{3} \mathrm{OH}$ were modeled uncoupled to the main isotopologue because their spatial extents differ somewhat from the main isotopologue. The isotope ratios reached were $20-80$ for $\mathrm{CH}_{3} \mathrm{OH} /{ }^{13} \mathrm{CH}_{3} \mathrm{OH}$ and $180-320$ for $\mathrm{CH}_{3} \mathrm{OH} / \mathrm{CH}_{3}{ }^{18} \mathrm{OH}$ at peaks $\mathrm{B} 2, \mathrm{~B} 3$, and $\mathrm{G} 35.03$. The isotope ratios are less ideal for G35.30N A and B1 at 40 and 80, respectively, but the source size is also significantly different. Deuterated methanol $\left(\mathrm{CH}_{2} \mathrm{DOH}\right)$ was not modeled because it was not in the XCLASS database, so analysis for this species was completed using Cassis.

- Methyl cyanide - $\mathrm{CH}_{3}{ }^{13} \mathrm{CN}$, and $\mathrm{CH}_{2} \mathrm{DCN}$ were modeled separately from the $v=0$ emission because of their differing spatial distribution. The $\mathrm{CH}_{2} \mathrm{DCN}$ was not modeled for region $\mathrm{B} 2$ since it was not detected to a significant degree.

- Ethyl cyanide - $\mathrm{CH}_{3} \mathrm{CHDCN}$ was only detected at G35.20 A and was modeled for that location.

\section{Appendix E: Line ID xclass fits}

Presented below are the spectra of each peak with the original data, the full XCLASS fit, and fits of selected species alone in different colors. 


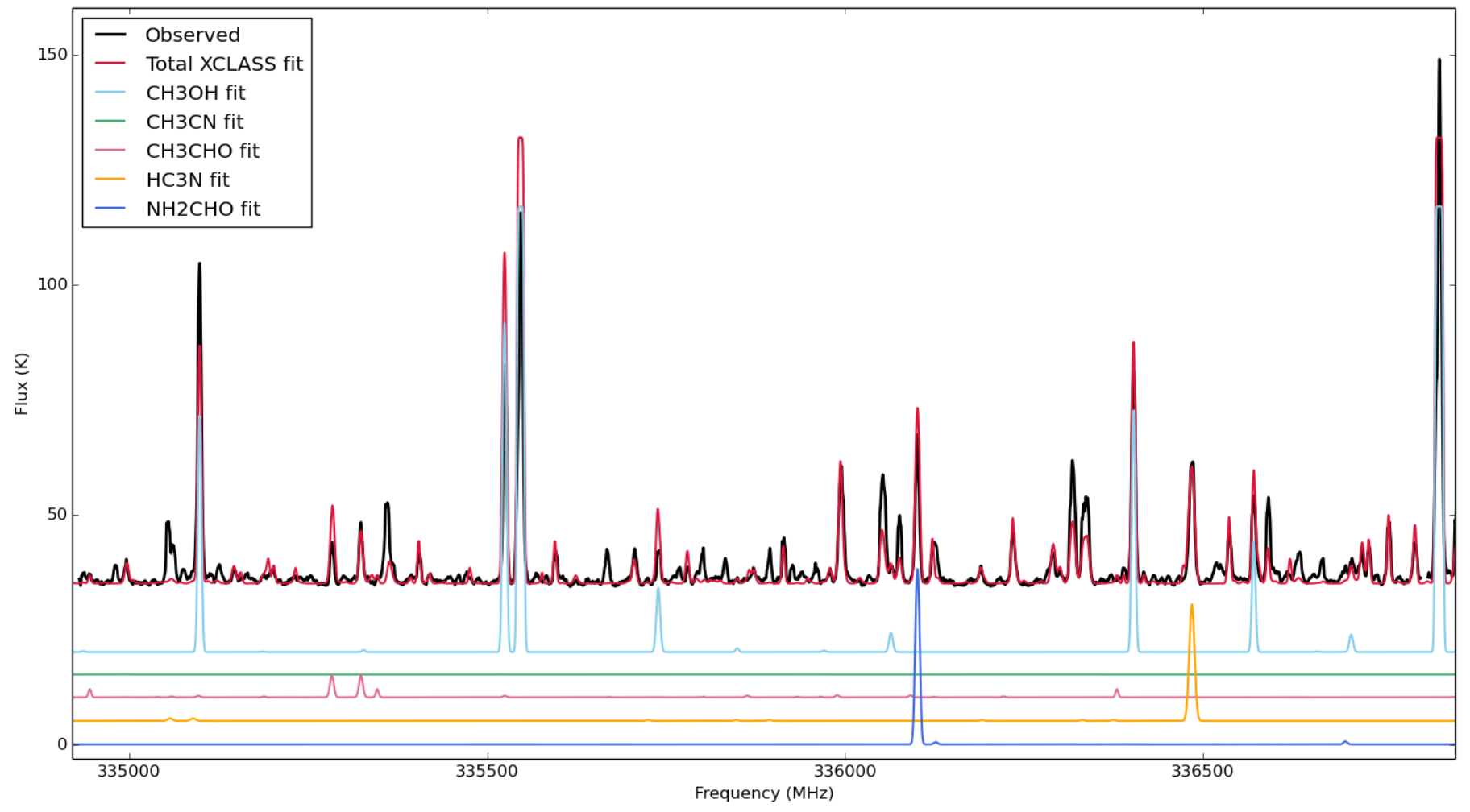

Fig. E.1. G35.20 peak A spectral window 1 (334.9-336.8 GHz), XCLASS total fit, plus selected species.

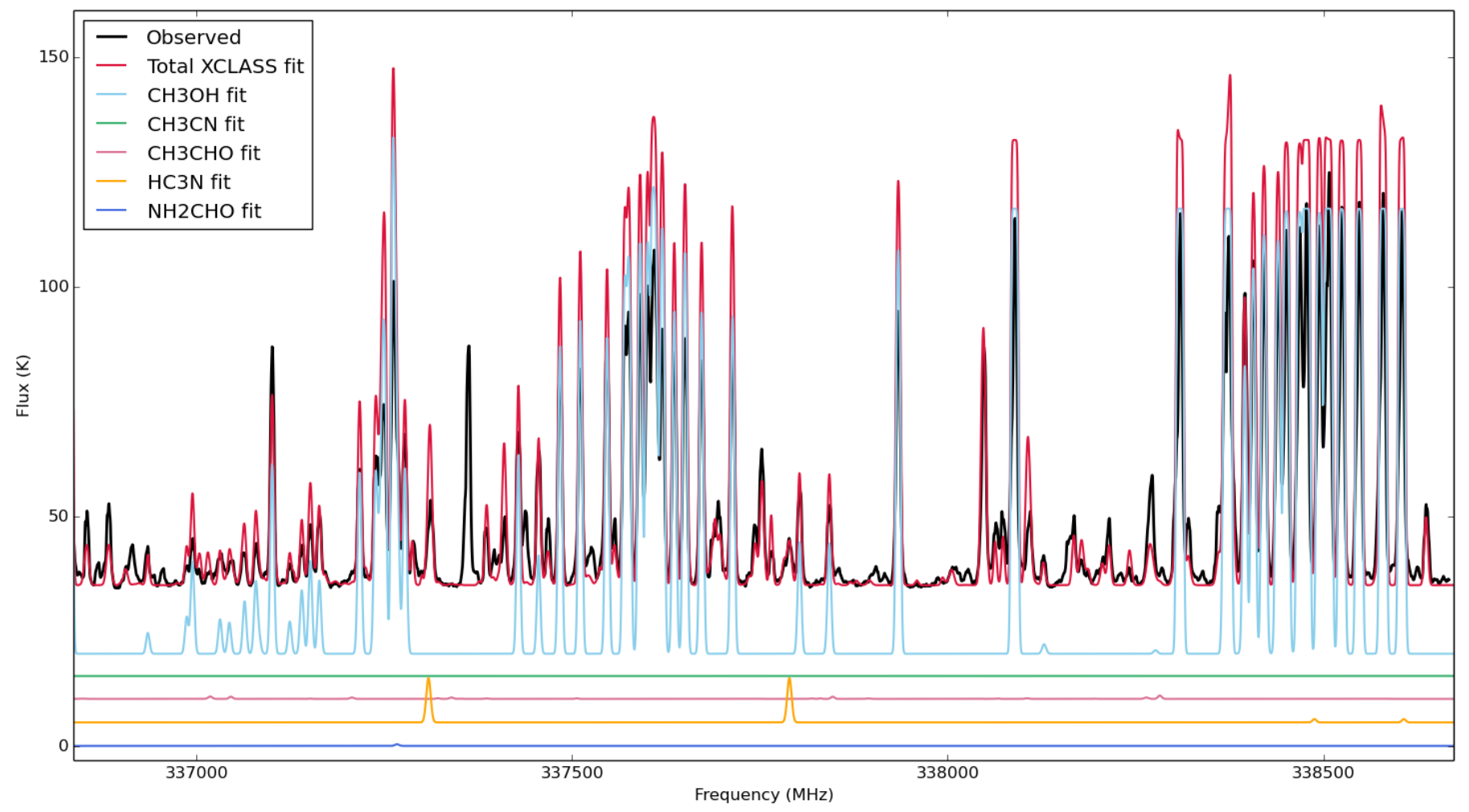

Fig. E.2. G35.20 peak A spectral window 0 (336.8-338.7 GHz), XCLASS total fit, plus selected species. 


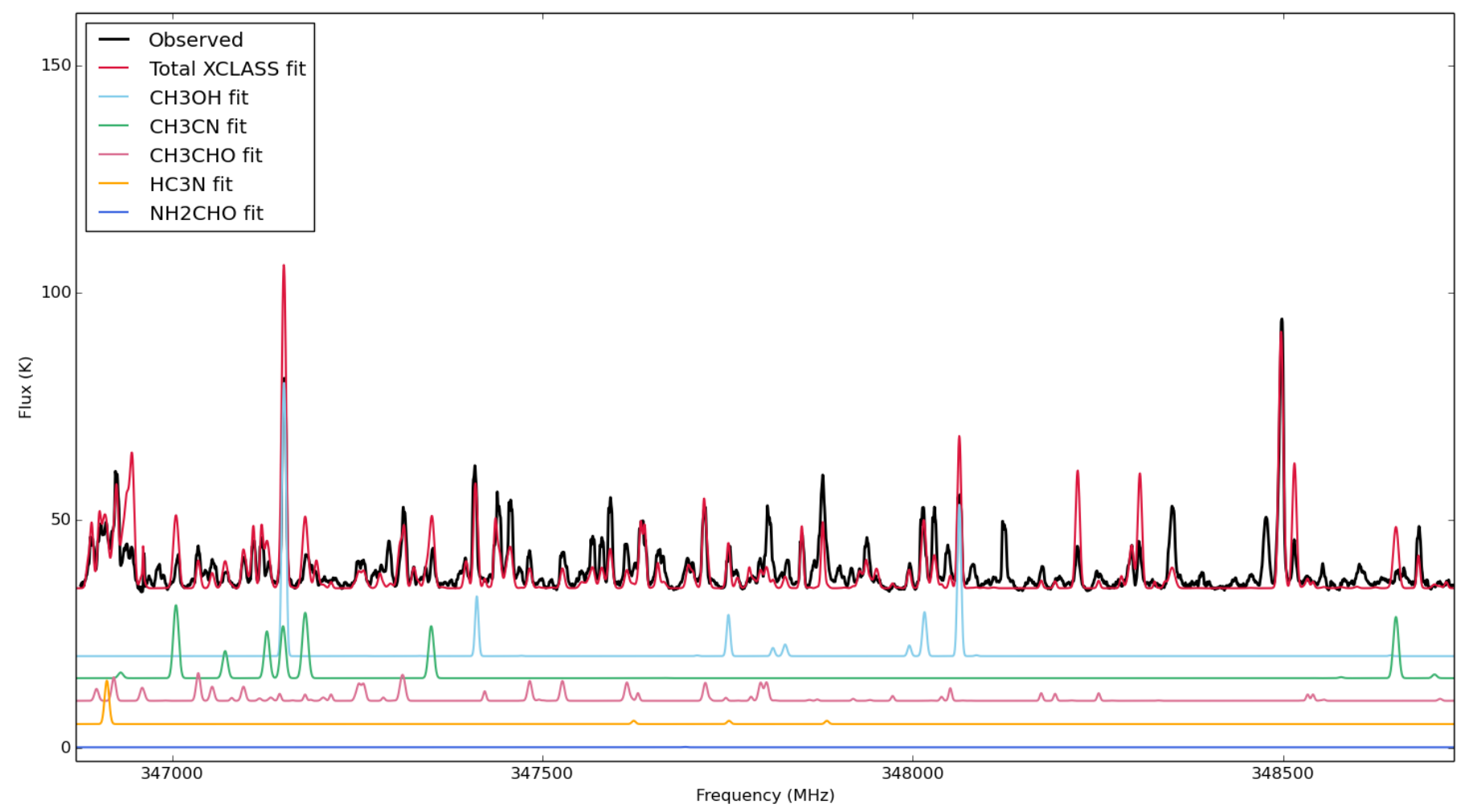

Fig. E.3. G35.20 peak A spectral window 3 (346.9-348.7 GHz), XCLASS total fit, plus selected species.

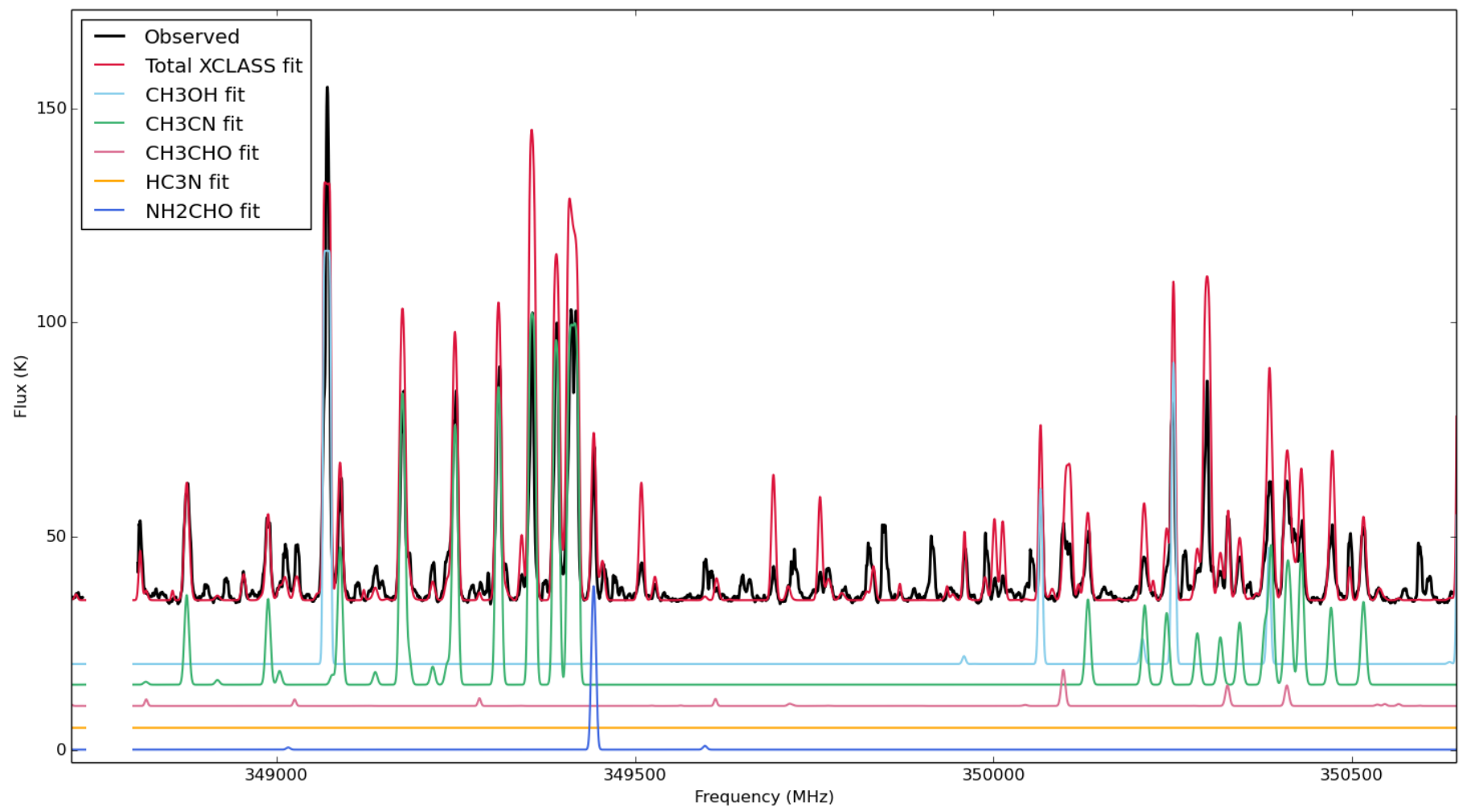

Fig. E.4. G35.20 peak A spectral window 2 (348.8-350.7 GHz), XCLASS total fit, plus selected species. 
V. Allen et al.: Chemical segregation in hot cores with disk candidates

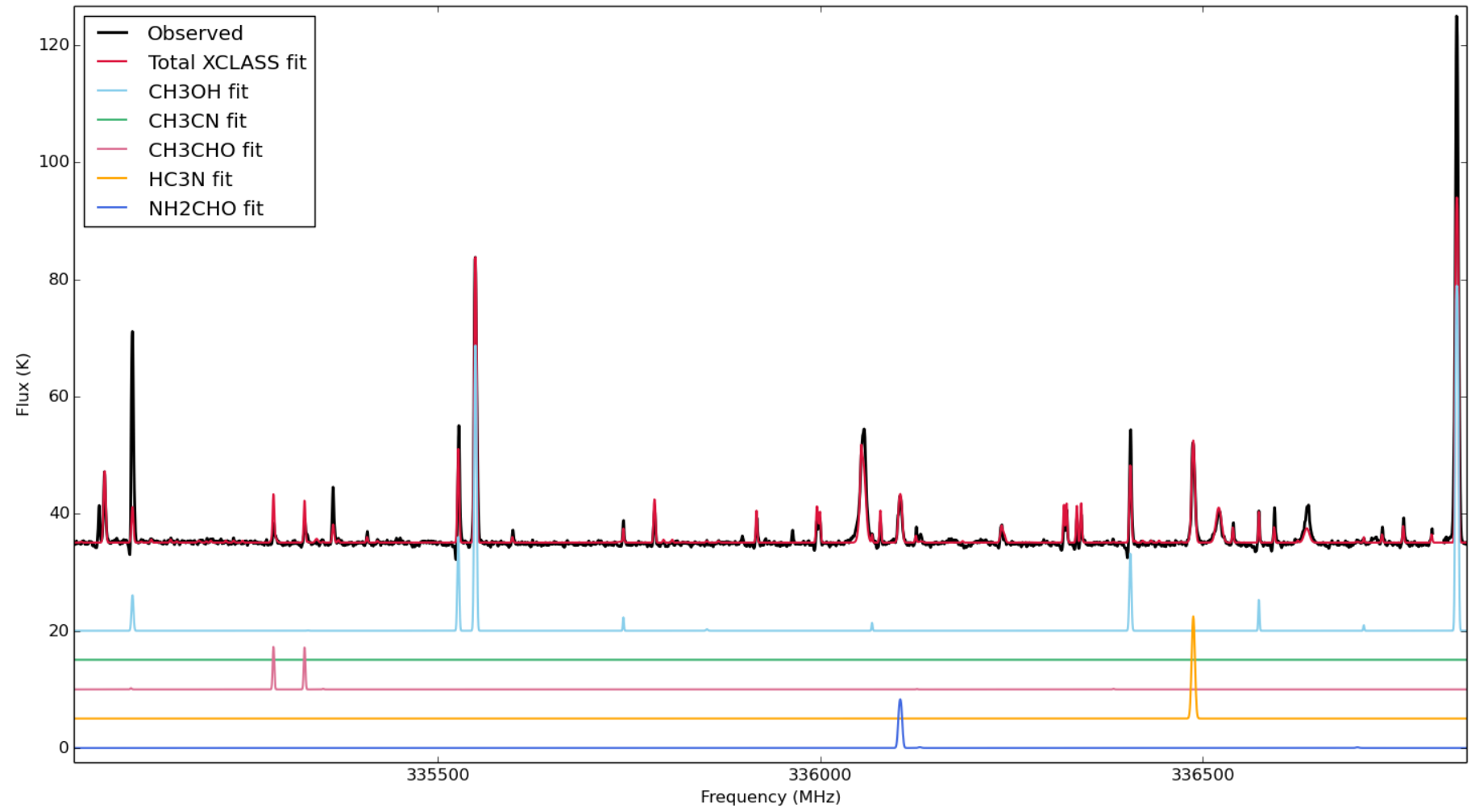

Fig. E.5. G35.20 peak B1 spectral window 1 (334.9-336.8 GHz), XCLASS total fit, plus selected species.

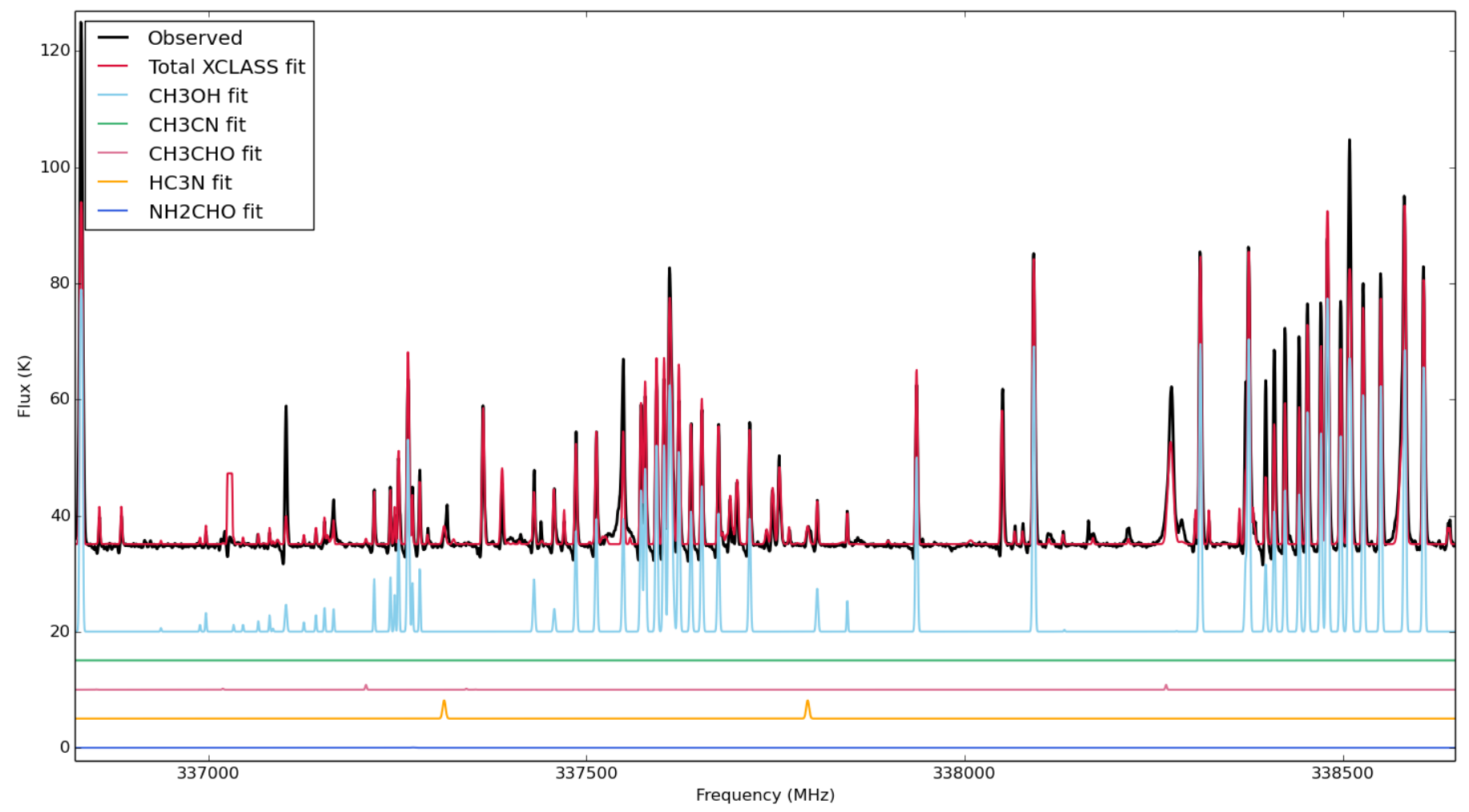

Fig. E.6. G35.20 peak B1 spectral window 0 (336.8-338.7 GHz), XCLASS total fit, plus selected species. 


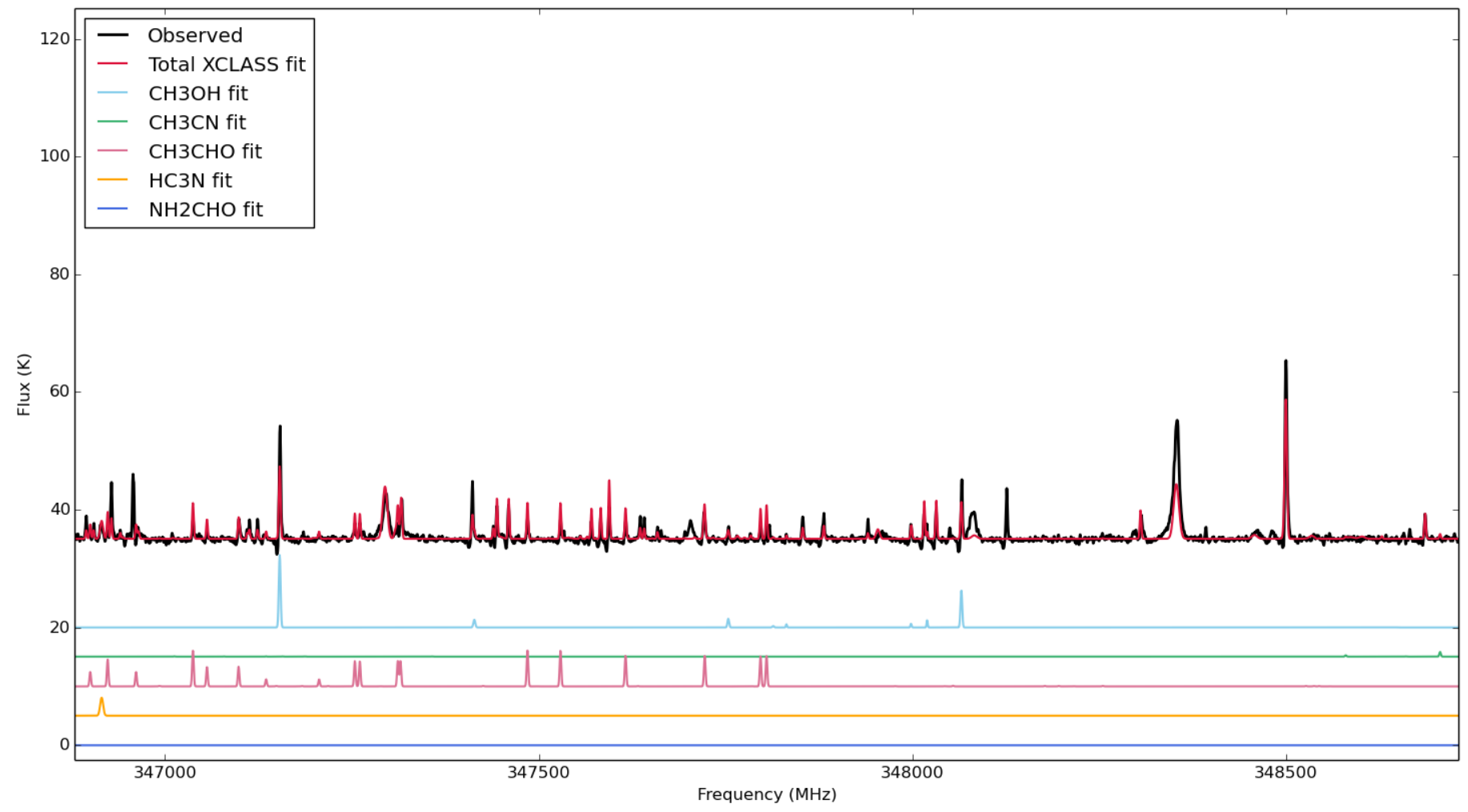

Fig. E.7. G35.20 peak B1 spectral window 3 (346.9-348.7 GHz), XCLASS total fit, plus selected species.

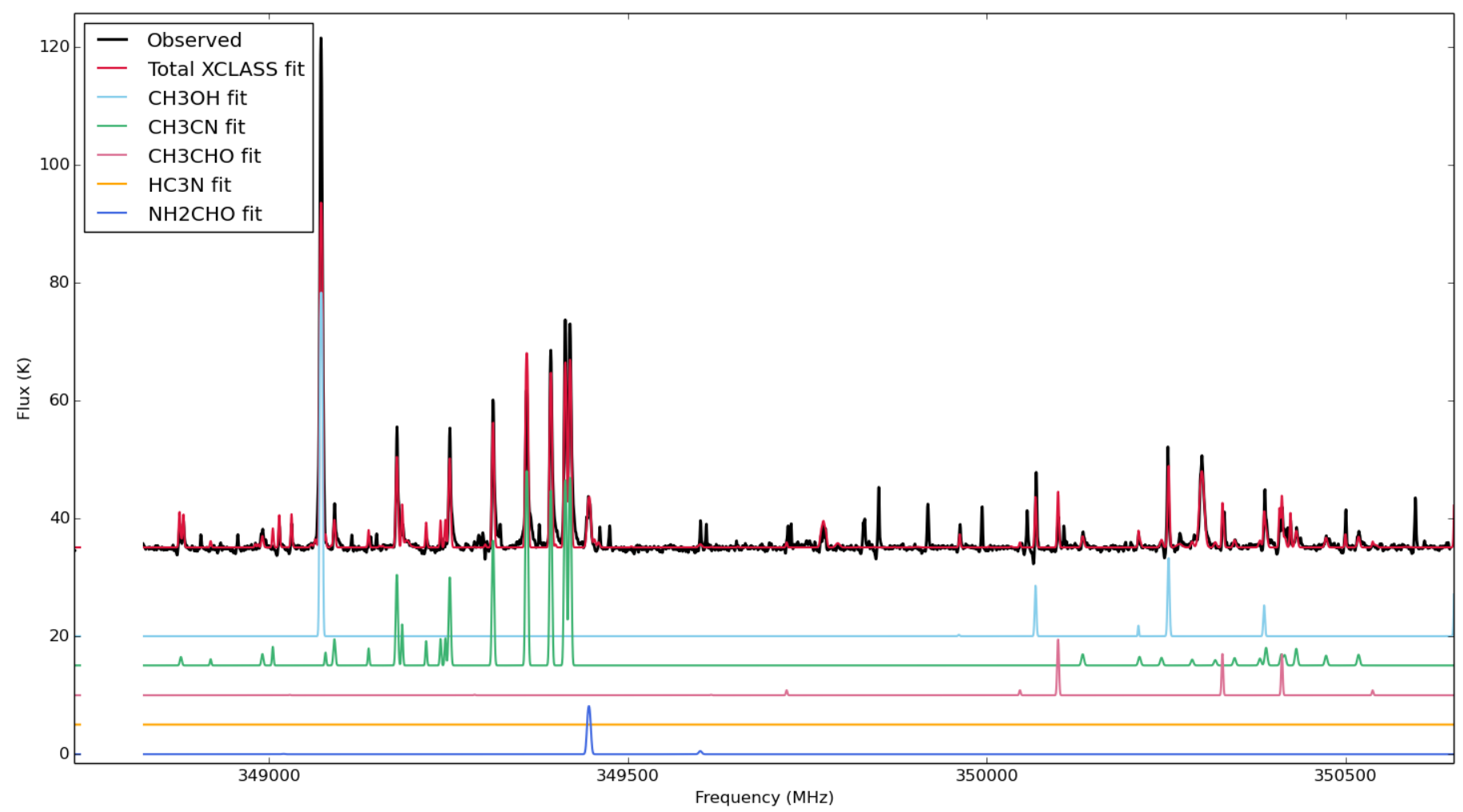

Fig. E.8. G35.20 peak B1 spectral window 2 (348.8-350.7 GHz), XCLASS total fit, plus selected species. 


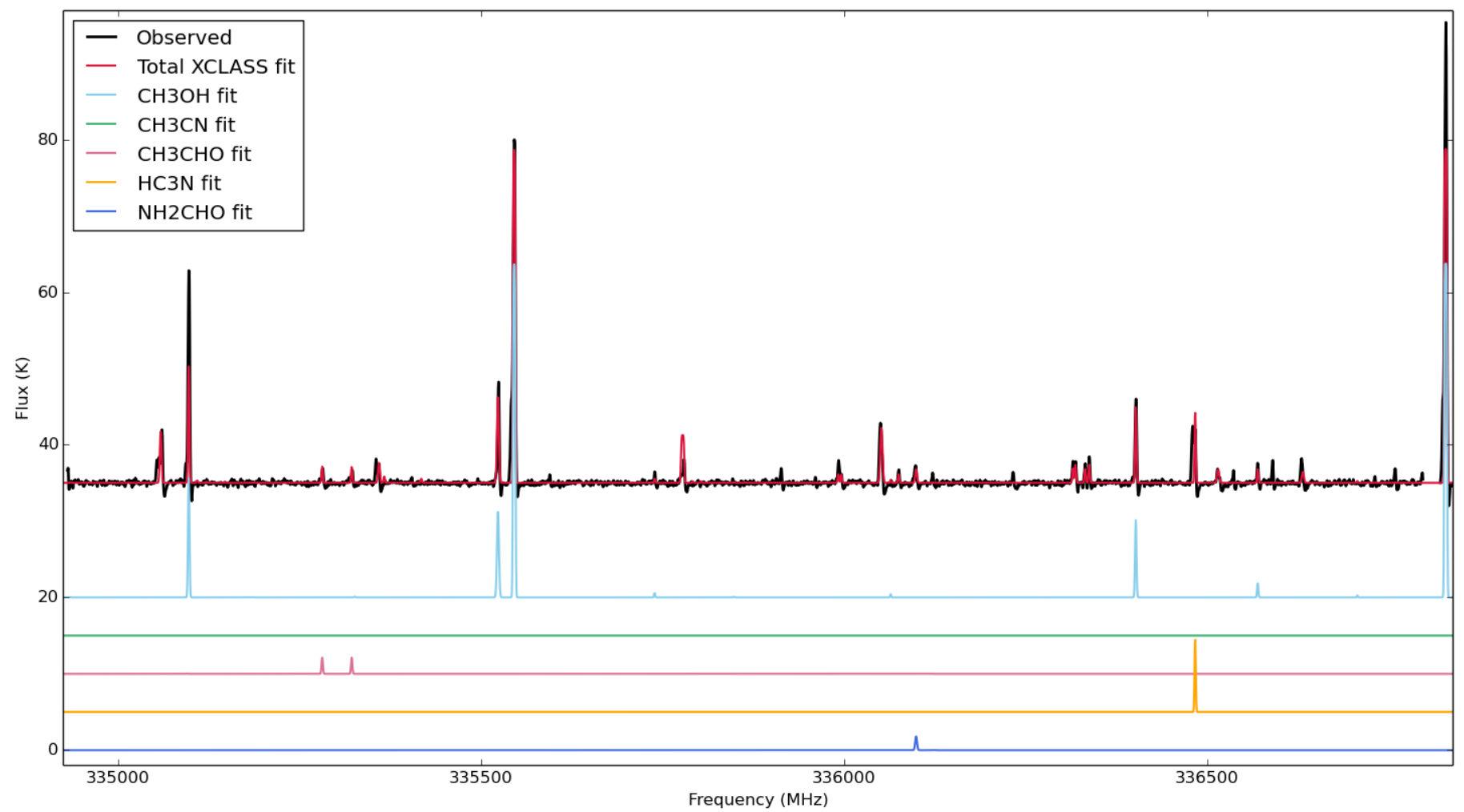

Fig. E.9. G35.20 peak B2 spectral window 1 (334.9-336.8 GHz), XCLASS total fit, plus selected species.

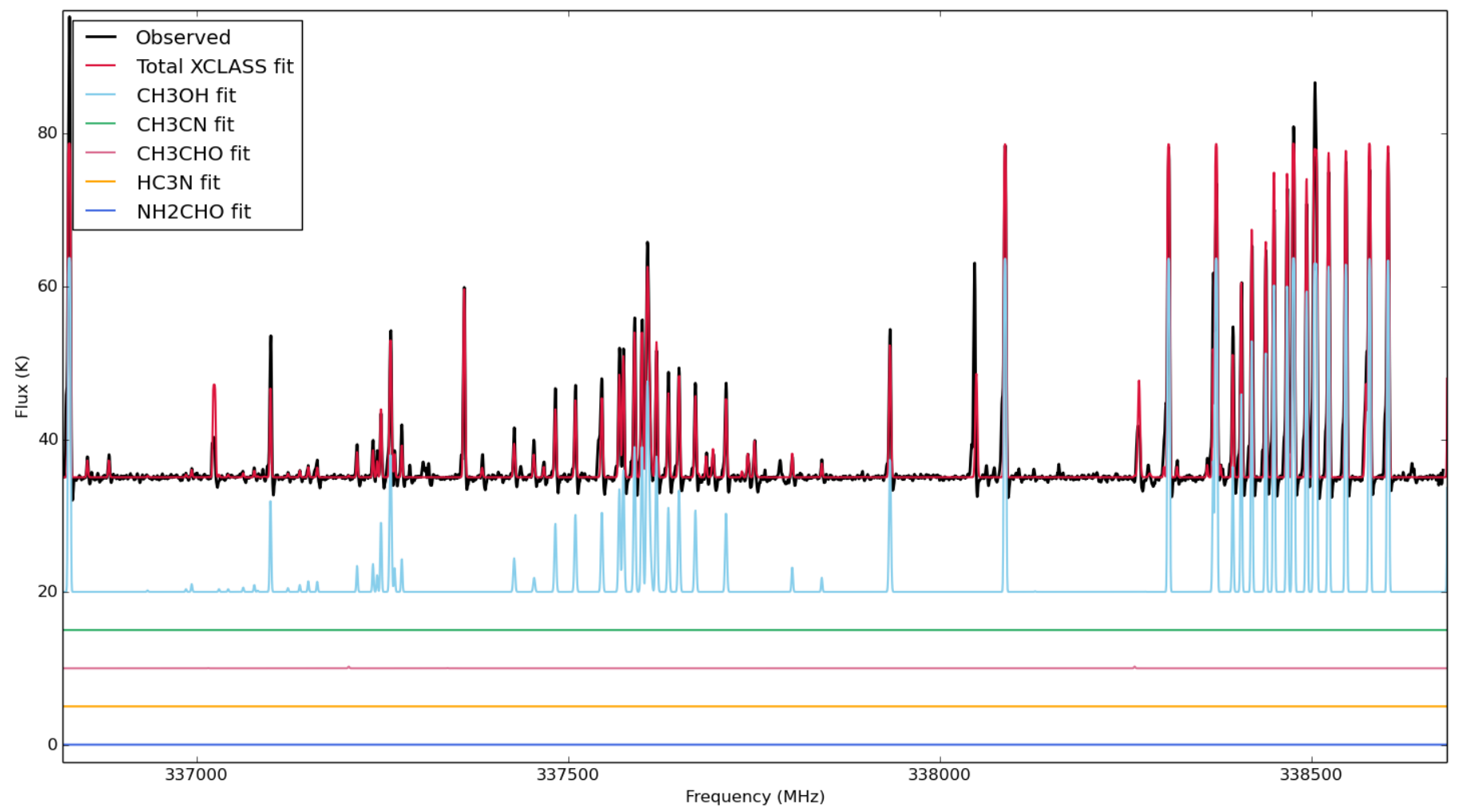

Fig. E.10. G35.20 peak B2 spectral window 0 (336.8-338.7 GHz), XCLASS total fit, plus selected species. 


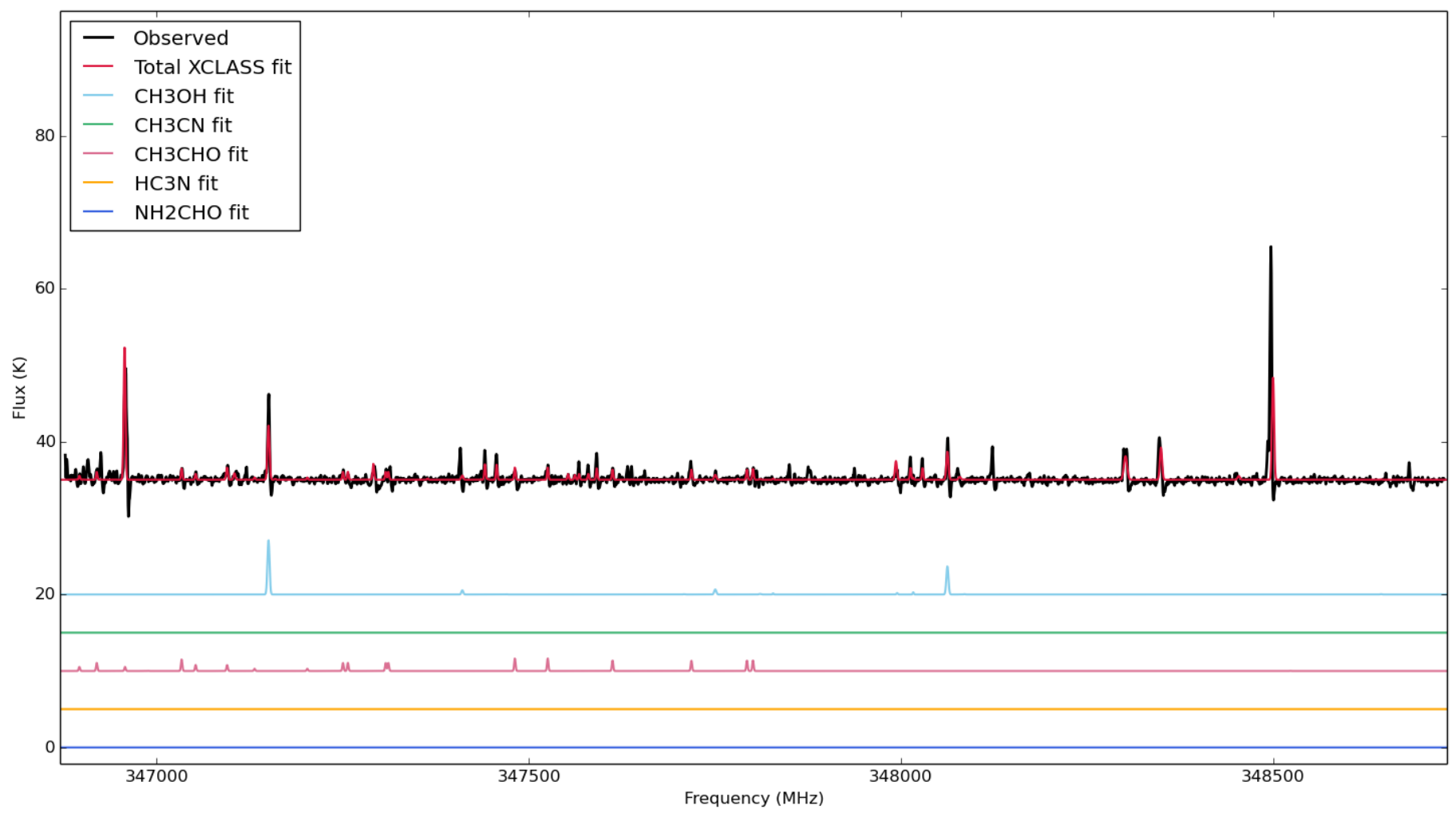

Fig. E.11. G35.20 peak B2 spectral window 3 (346.9-348.7 GHz), XCLASS total fit, plus selected species.

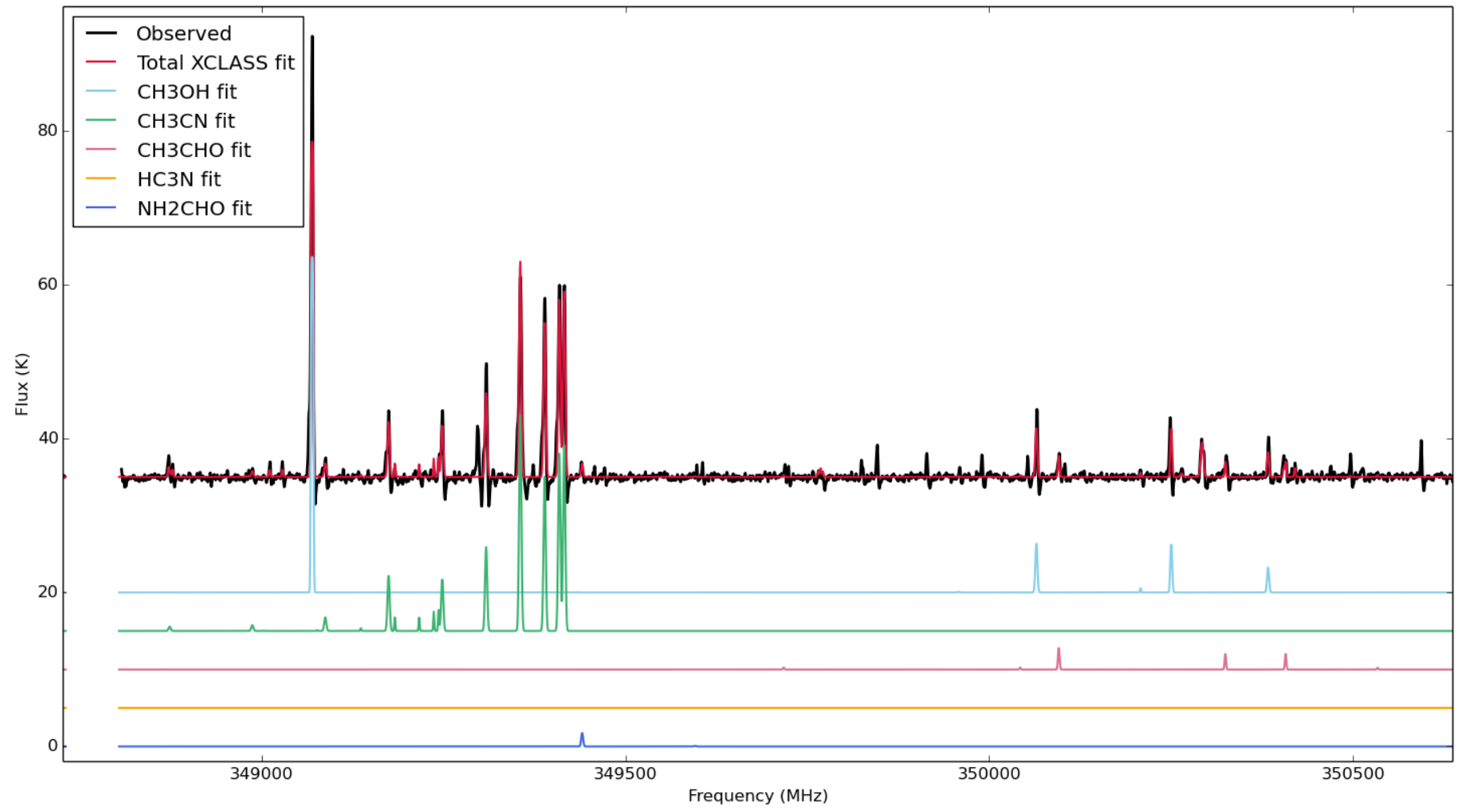

Fig. E.12. G35.20 peak B2 spectral window 2 (348.8-350.7 GHz), XCLASS total fit, plus selected species. 


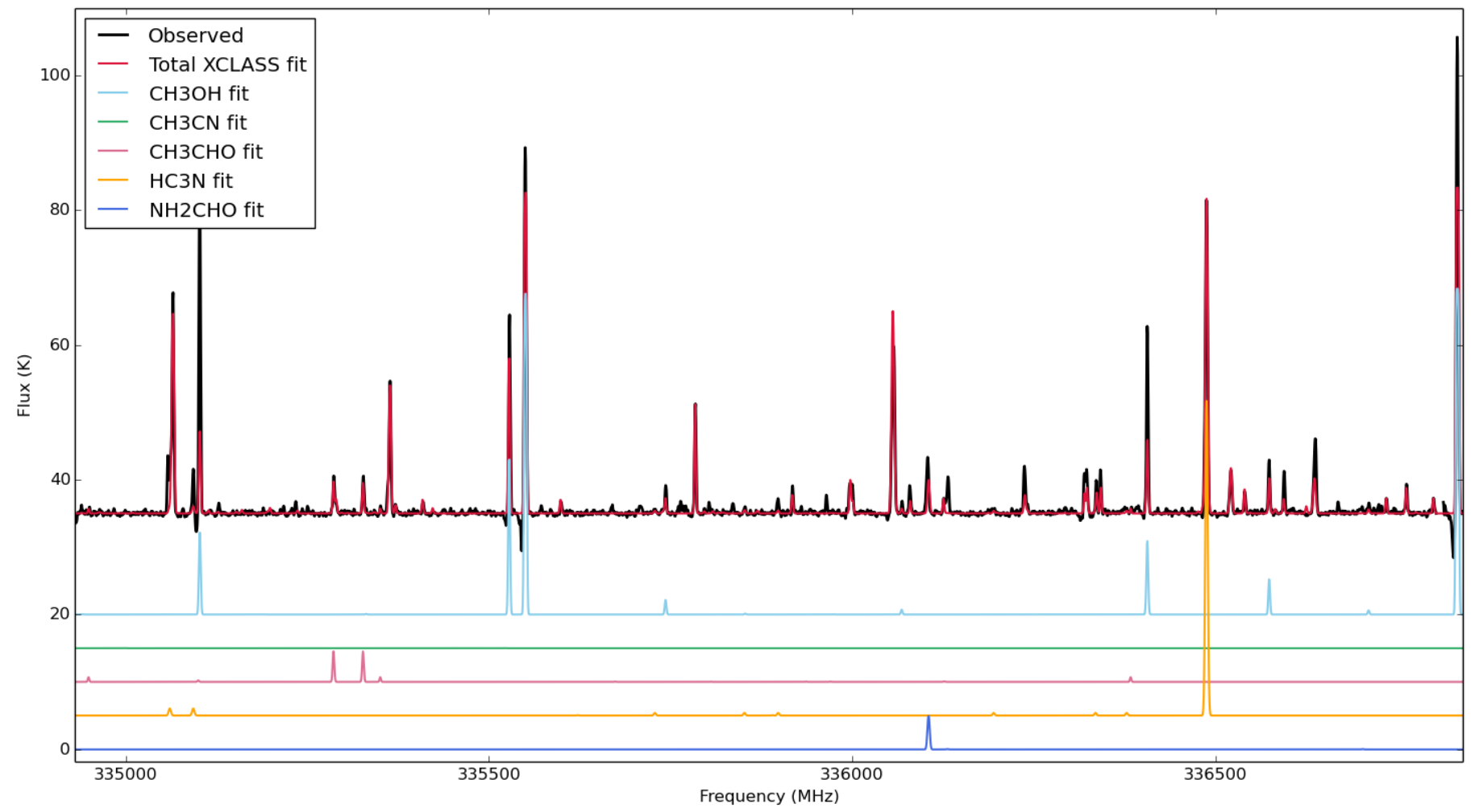

Fig. E.13. G35.20 peak B3 spectral window 1 (334.9-336.8 GHz), XCLASS total fit, plus selected species.

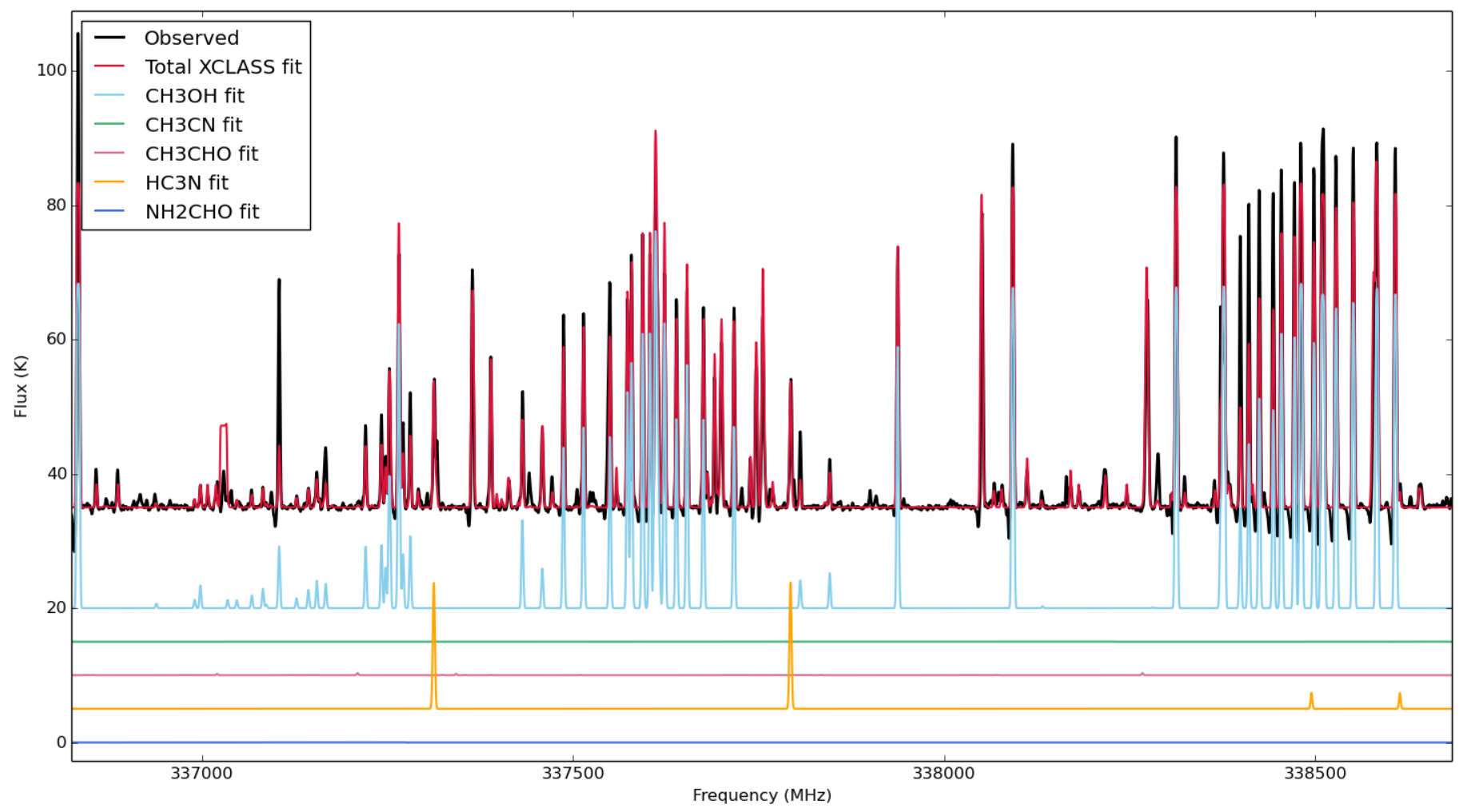

Fig. E.14. G35.20 peak B3 spectral window 0 (336.8-338.7 GHz), XCLASS total fit, plus selected species. 


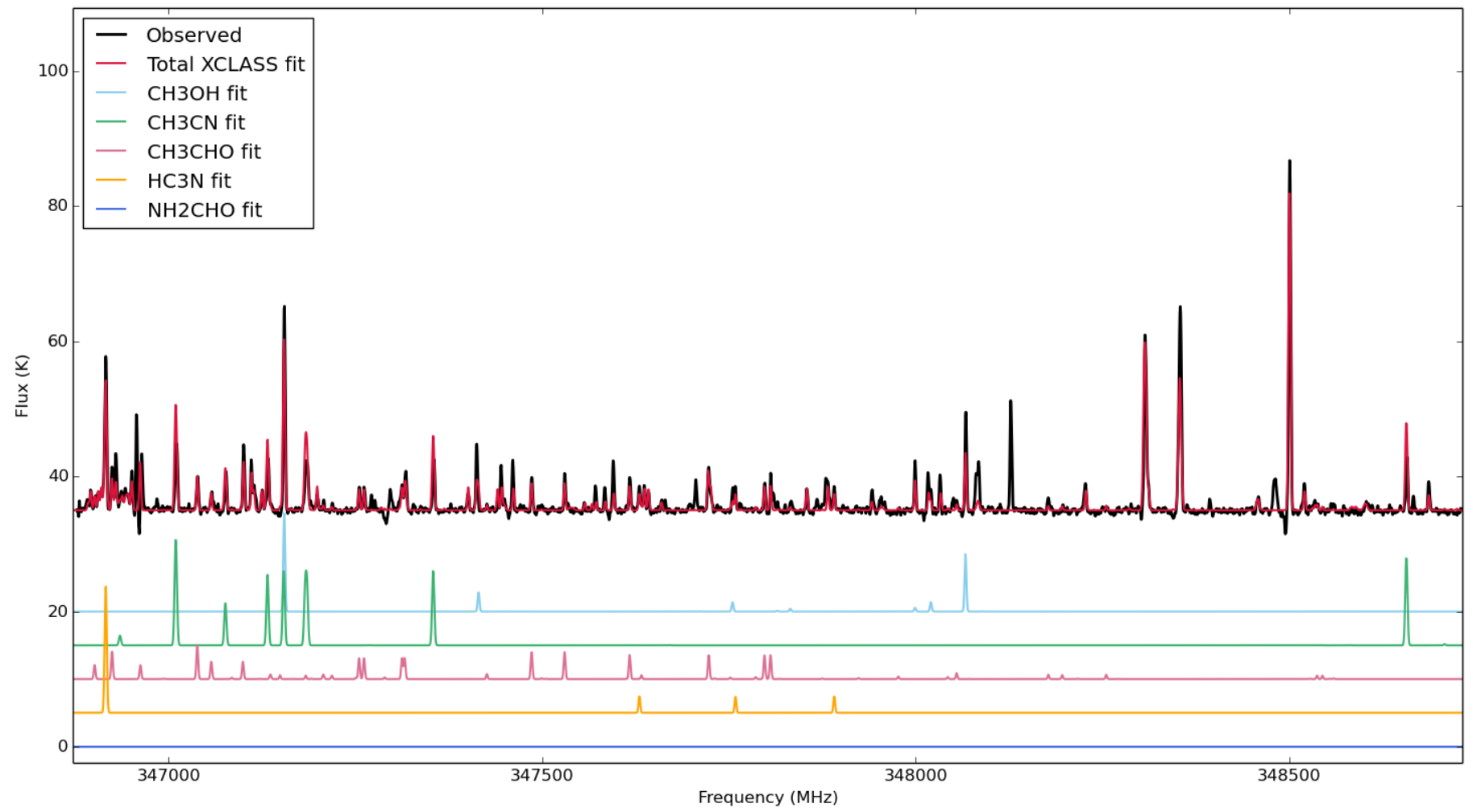

Fig. E.15. G35.20 peak B3 spectral window 3 (346.9-348.7 GHz), XCLASS total fit, plus selected species.

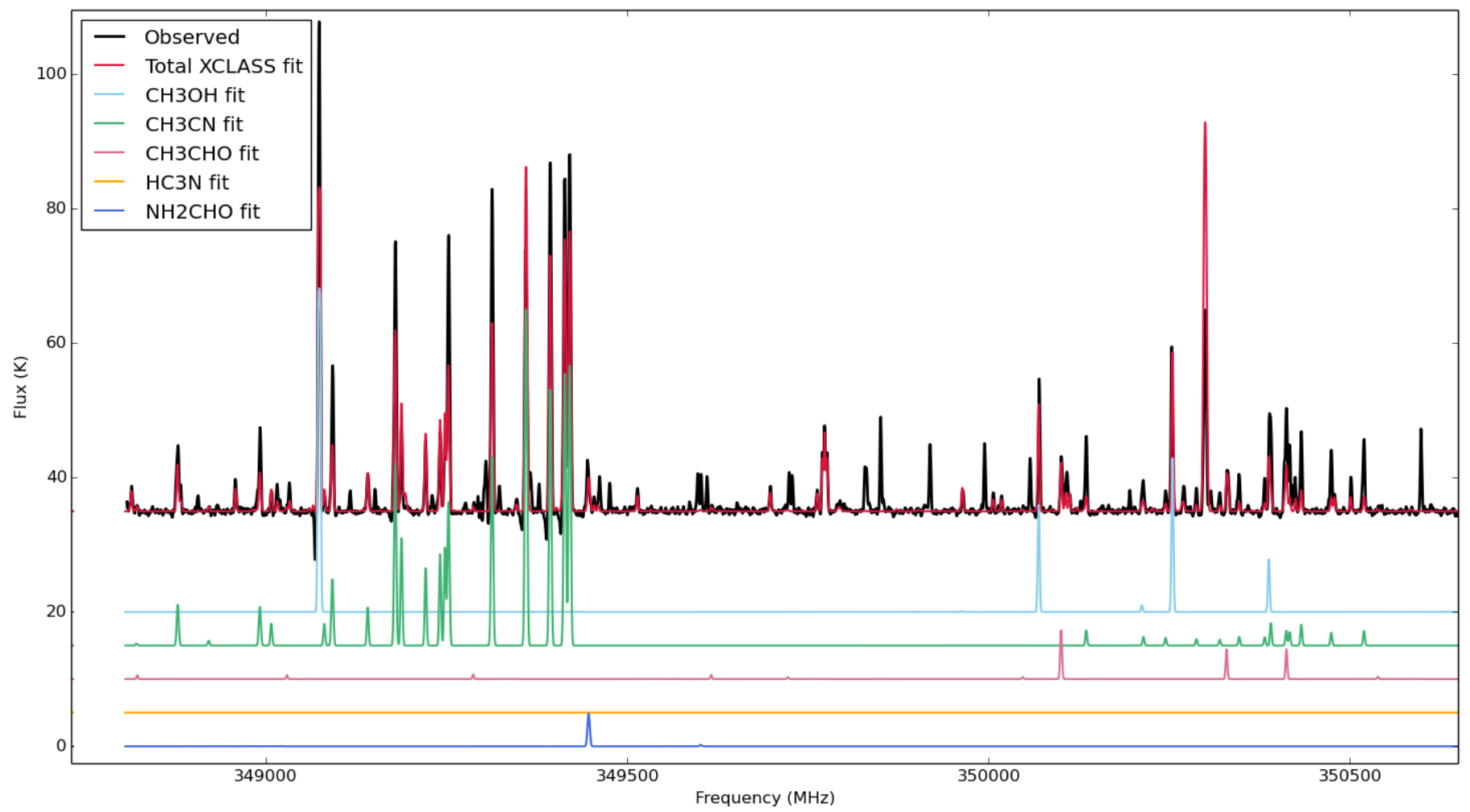

Fig. E.16. G35.20 peak B3 spectral window 2 (348.8-350.7 GHz), XCLASS total fit, plus selected species. 


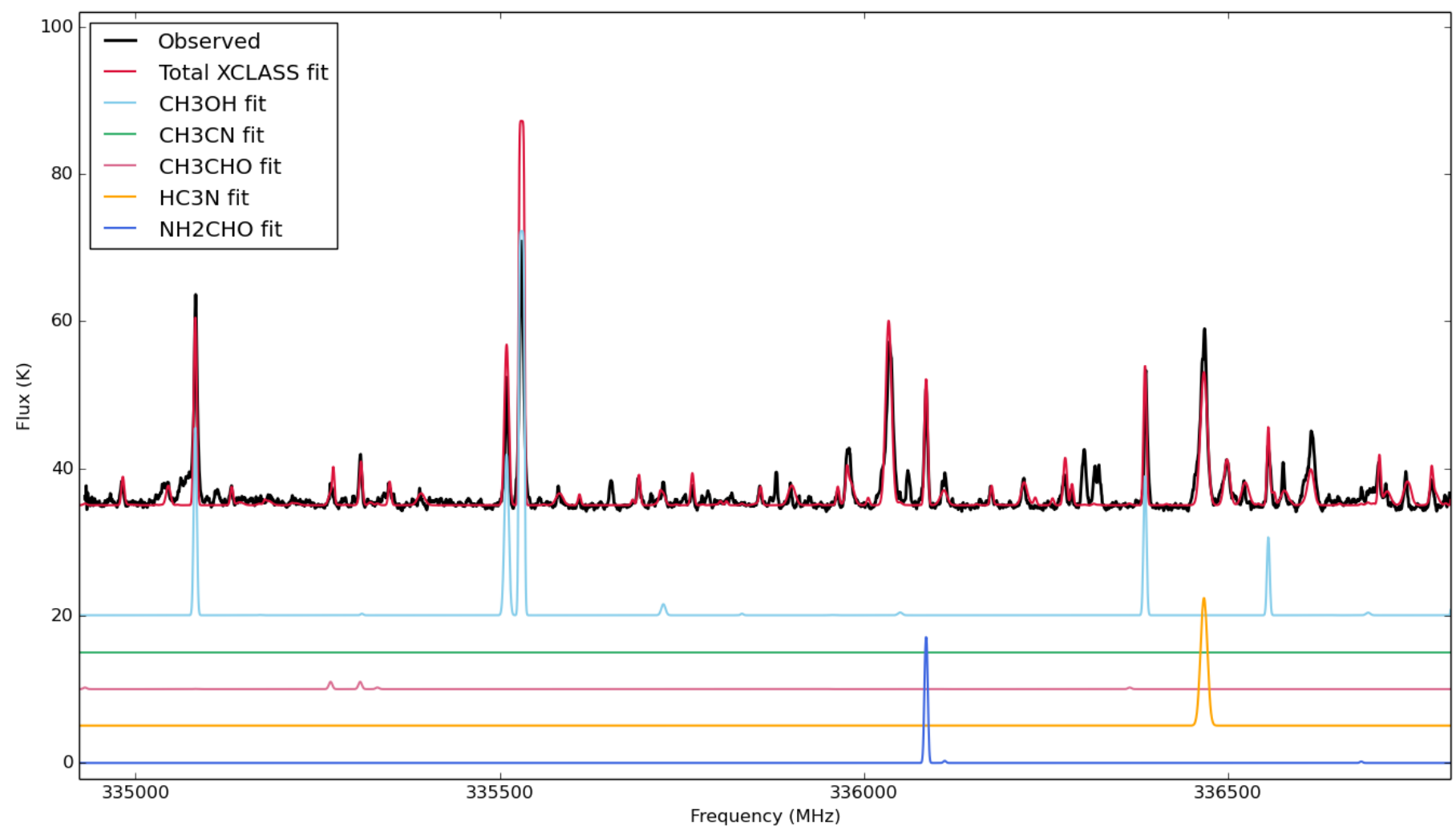

Fig. E.17. G3503 spectral window 1 (334.9-336.8 GHz), XCLASS total fit, plus selected species.

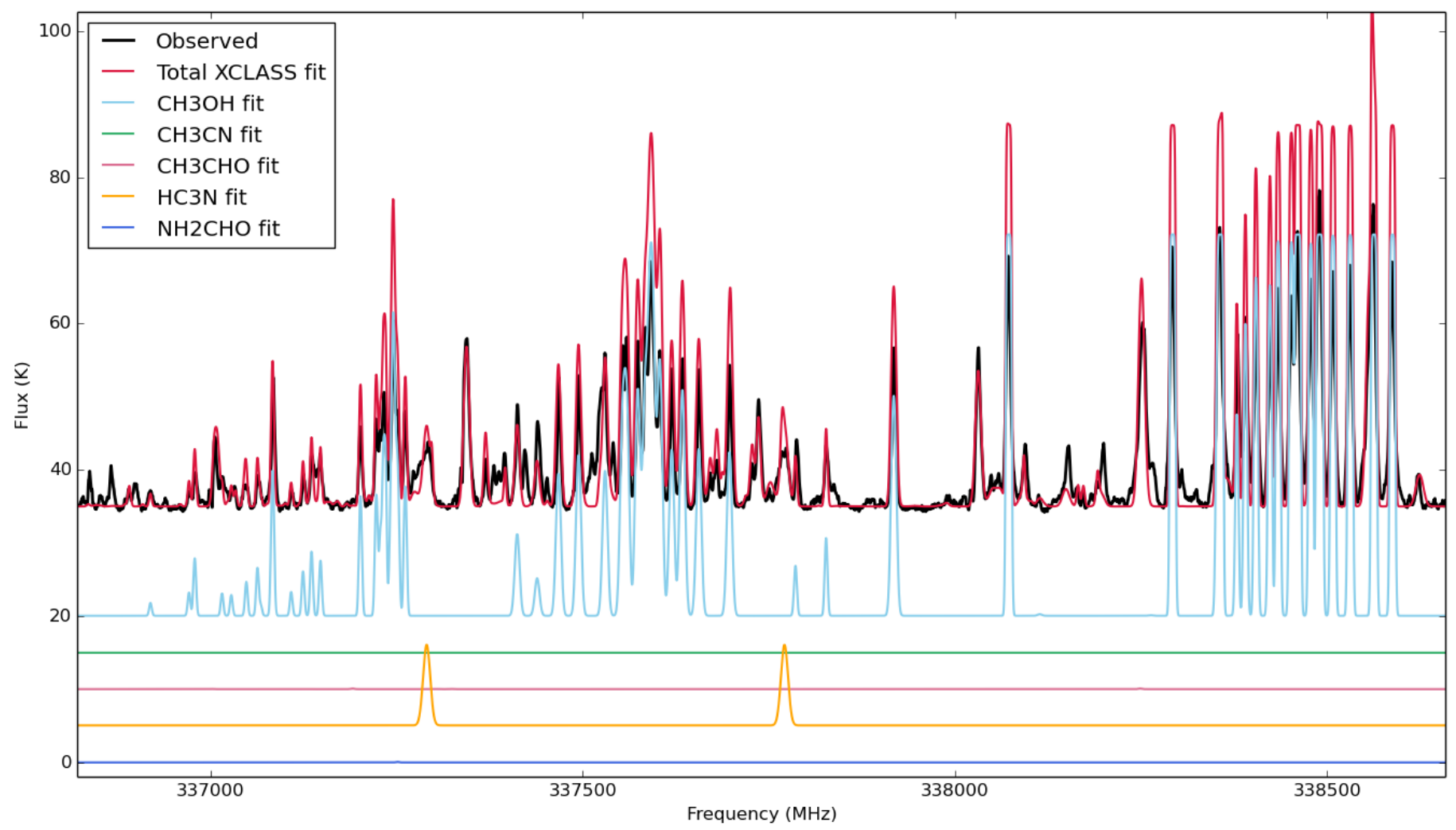

Fig. E.18. G3503 spectral window 0 (336.8-338.7 GHz), XCLASS total fit, plus selected species. 


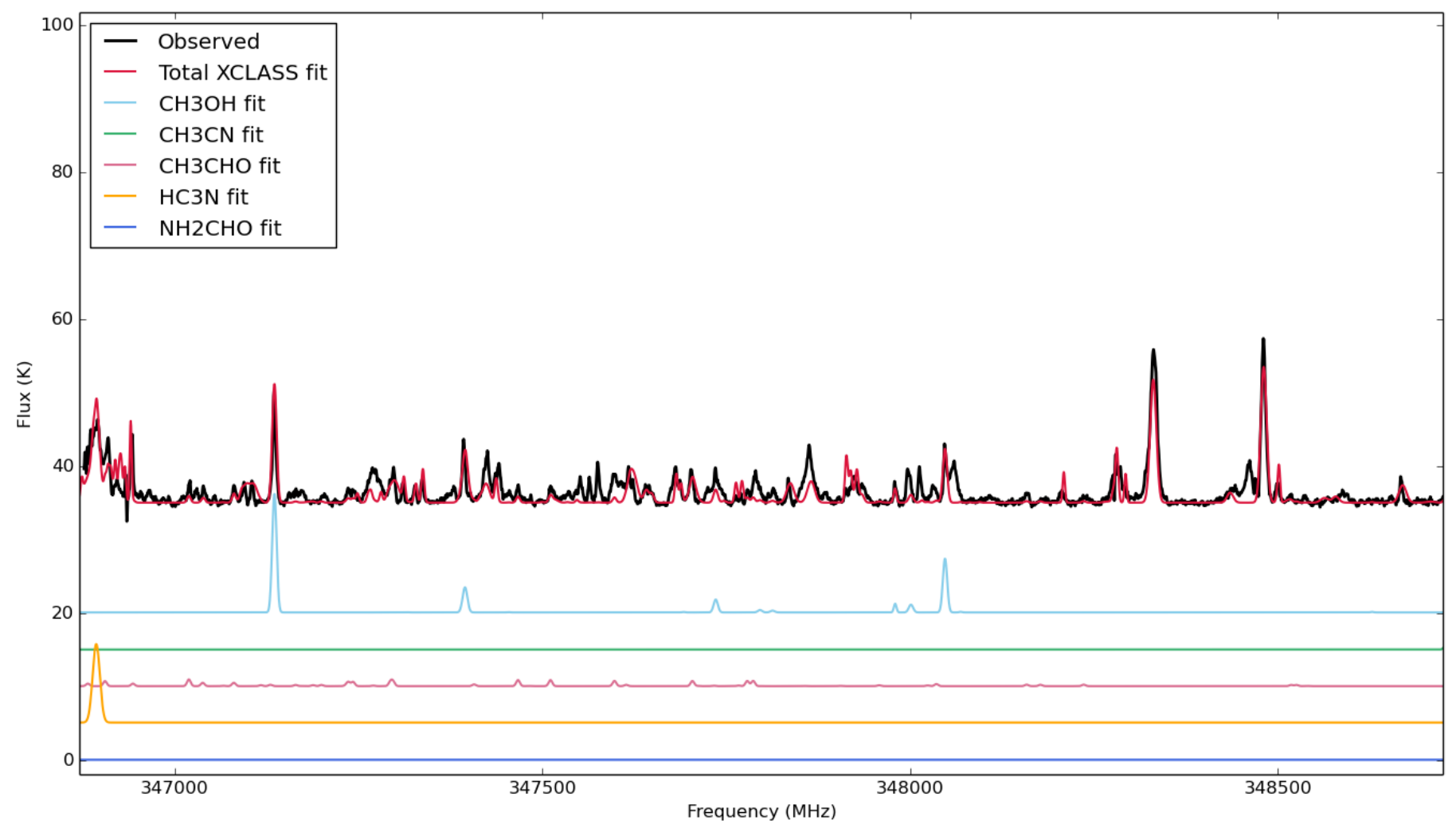

Fig. E.19. G3503 spectral window 0 (336.8-338.7 GHz), XCLASS total fit, plus selected species.

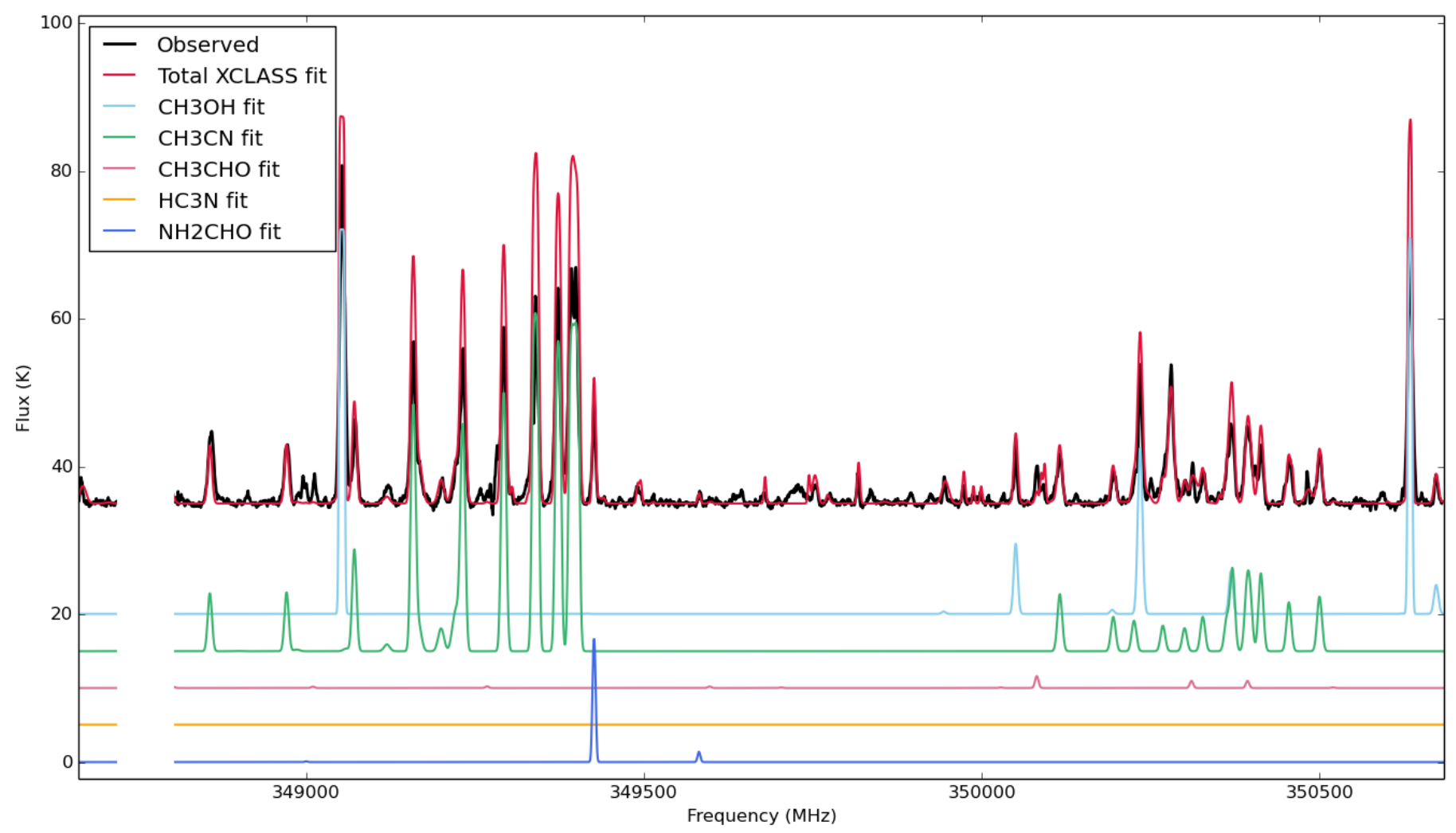

Fig. E.20. G35.03 spectral window 2 (348.8-350.7 GHz), XCLASS total fit, plus selected species. 